\title{
SBAT: A Tool for Estimating Metal Bioaccessibility in Soils
}

\section{April 2004}

S. A. Heuscher, C. C. Brandt, P. M. Jardine

Environmental Sciences Division

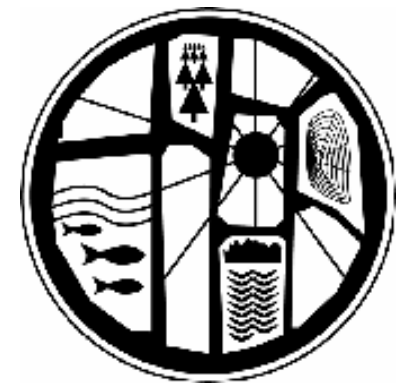




\section{DOCUMENT AVAILABILITY}

Reports produced after January 1, 1996, are generally available free via the U.S. Department of Energy (DOE) Information Bridge.

Web site http://www.osti.gov/bridge

Reports produced before January 1, 1996, may be purchased by members of the public from the following source.

National Technical Information Service

5285 Port Royal Road

Springfield, VA 22161

Telephone 703-605-6000 (1-800-553-6847)

TDD 703-487-4639

Fax 703-605-6900

E-mailinfo@ntis.fedworld.gov

Web site http://www.ntis.gov/support/ordernowabout.htm

Reports are available to DOE employees, DOE contractors, Energy Technology Data Exchange (ETDE) representatives, and International Nuclear Information System (INIS) representatives from the following source.

Office of Scientific and Technical Information

P.O. Box 62

Oak Ridge, TN 37831

Telephone 865-576-8401

Fax 865-576-5728

E-mail reports@adonis.osti.gov

Web site http://www.osti.gov/contact.html

This report was prepared as an account of work sponsored by an agency of the United States Government. Neither the United States Government nor any agency thereof, nor any of their employees, makes any warranty, express or implied, or assumes any legal liability or responsibility for the accuracy, completeness, or usefulness of any information, apparatus, product, or process disclosed, or represents that its use would not infringe privately owned rights. Reference herein to any specific commercial product, process, or service by trade name, trademark, manufacturer, or otherwise, does not necessarily constitute or imply its endorsement, recommendation, or favoring by the United States Government or any agency thereof. The views and opinions of authors expressed herein do not necessarily state or reflect those of the United States Government or any agency thereof. 
Environmental Sciences Division

\title{
SBAT: A TOOL FOR ESTIMATING METAL BIOACCESSIBILITY IN SOILS
}

\author{
S. A. Heuscher, C. C. Brandt, P. M. Jardine \\ Environmental Sciences Division \\ Oak Ridge National Laboratory
}

Date Published: April 2004

\author{
Prepared for \\ U.S. Department of Defense \\ Strategic Environmental Research and Development Program \\ Budget Activity Number 43WQ30801 \\ Prepared by \\ OAK RIDGE NATIONAL LABORATORY \\ Oak Ridge, Tennessee 37831 \\ managed by \\ UT-BATTELLE, LLC \\ for the \\ U.S. DEPARTMENT OF ENERGY \\ under contract DE-AC05-00OR22725
}




\section{CONTENTS}

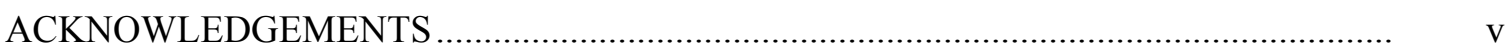

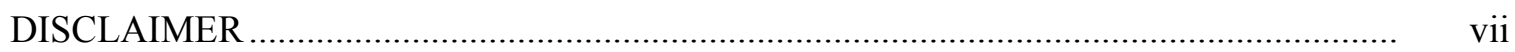

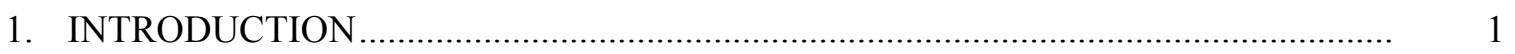

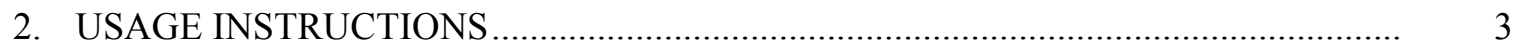

2.1 USING HISTORICAL DATA ……….........................................................

2.2 USING SITE-SPECIFIC DATA (OPTIONAL) ….............................................. 5

2.3 REVIEWING THE BIOACCESSIBILITY ESTIMATES.................................... 5

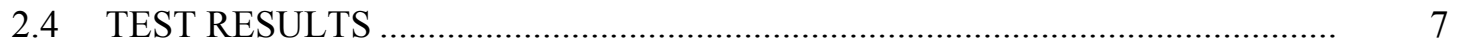

3. PREPARATION OF THE AGGREGATED HISTORICAL DATA................................ 8

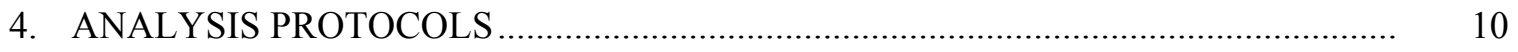

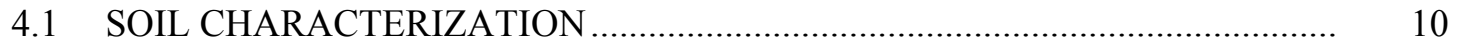

4.2 SAMPLE PREPARATION ............................................................................... $\quad 10$

4.3 DETERMINATION OF TOTAL CHROMIUM AND ARSENIC ON SOIL ....... 10

4.4 IN VITRO BIOACCESSIBILITY ..................................................................... 11

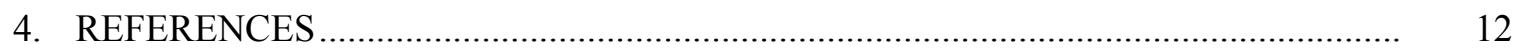

APPENDIX A: SBAT QUICK GUIDE …….......................................................... A-1

APPENDIX B: INFLUENCE OF SOIL GEOCHEMICAL AND PHYSICAL PROPERTIES ON THE SORPTION AND BIOACCESSIBILITY OF CHROMIUM(III) (Stewart et al. 2003a) ........................................................................ B-1

APPENDIX C: ADSORPTION SEQUESTRATION, AND BIOACCESSIBILITY OF AS(V) IN SOILS (Yang et al. 2002) ……......................................................... C-1

APPENDIX D: EFFECTS OF CONTAMINANT CONCENTRATION, AGING, AND SOIL PROPERTIES ON THE BIOACCESSIBILITY OF CR(III) AND CR(IV) IN SOIL (Stewart et al. 2003b)......

APPENDIX E: FACTORS CONTROLLING THE BIOACCESSIBILITY OF ARSENIC(V) AND LEAD(II) IN SOIL (Yang et al. 2003) 


\section{ACKNOWLEDGMENTS}

This research was sponsored by the U.S. Department of Defense's Strategic Environmental Research and Development Program (Dr. Andrea Leeson, Program Manager for Cleanup) as supplemental funding to CU-1166 ("Quantifying the Bioavailability of Toxic Metals in Soils"). We would like to acknowledge Dr. Jack Parker, Oak Ridge National Laboratory, for his suggestions on improving the application design, Dr. Mark Barnett, Auburn University, for providing arsenic bioaccessibility data, and Ms. Melanie Stewart, Oak Ridge National Laboratory for providing details of analytical protocols. 


\section{DISCLAIMER}

Documents available from the web server were prepared as an account of work sponsored by an agency of the U.S. Government. Neither the U.S. Government nor any agency thereof, or any of their employees, makes any warranty, express or implied, or assumes any legal liability or responsibility for the accuracy, completeness, or usefulness of any information, apparatus, product, or process disclosed, or represents that its use would not infringe privately owned rights. Further, Oak Ridge National Laboratory is not responsible for the contents of any off-site pages referenced. 


\section{INTRODUCTION}

Heavy metals such as chromium and arsenic are widespread in the environment due to their usage in many industrial processes. These metals may pose significant health risks to humans, especially children, due to their mutagenic and carcinogenic properties. Typically, the health risks associated with the ingestion of soil-bound metals are estimated by assuming that the metals are completely absorbed through the human intestinal tract (100\% bioavailable). This assumption potentially overestimates the risk since soils are known to strongly sequester metals thereby potentially lowering their bioavailability.

Beginning in 2000, researchers at Oak Ridge National Laboratory, with funding from the Strategic Environmental Research and Development Program (SERDP), studied the effect of soil properties on the bioaccessibility of soil-bound arsenic and chromium. Representative A and upper-B horizons from seven major U.S. soil orders were obtained from the U.S. Department of Agriculture's National Resources Conservation Service and the U.S. Department of Energy's Oak Ridge Reservation. The soils were spiked with known concentrations of arsenic (As(III) and $\mathrm{As}(\mathrm{V})$ ) and chromium ( $\mathrm{Cr}(\mathrm{III})$ and $\mathrm{Cr}(\mathrm{VI})$ ), and the bioaccessibility was measured using a physiologically based extraction test that mimics the gastric activity of children. Linear regression models were then developed to relate the bioaccessibility measurements to the soil properties (Yang et al. 2002; Stewart et al. 2003a). Important results from these publications and other studies include:

- $\mathrm{Cr}(\mathrm{VI})$ and $\mathrm{As}(\mathrm{III})$ are more toxic and bioavailable than $\mathrm{Cr}(\mathrm{III})$ and $\mathrm{As}(\mathrm{V})$ respectively.

- Several favorable processes can occur in soils that promote the oxidation of As(III) to $\mathrm{As}(\mathrm{V})$ and the reduction of $\mathrm{Cr}(\mathrm{VI})$ to $\mathrm{Cr}(\mathrm{III})$, thereby lowering bioaccessibility. Iron and manganese oxides are capable of oxidizing $\mathrm{As}(\mathrm{III})$ to $\mathrm{As}(\mathrm{V})$, whereas organic matter and $\mathrm{Fe}(\mathrm{II})$-bearing minerals are capable of reducing $\mathrm{Cr}(\mathrm{VI})$ to $\mathrm{Cr}(\mathrm{III})$.

- The ubiquitous metal-sequestering properties of soils significantly lower the bioaccessibility of arsenic and chromium upon ingestion relative to the currently used $100 \%$ default values.

- Key soil physical and chemical properties (particle size, $\mathrm{pH}$, mineral oxide, clay, and organic matter contents) govern the extent of toxic metal bioaccessibility thus providing the necessary conceptual understanding for building accurate predictive models.

- The $\mathrm{As}(\mathrm{V})$ regression model was able to predict the in vivo bioavailability in ten contaminated soils within a root mean square error of $<10 \%$.

- Metal bioaccessibility is controlled by molecular-level speciation, where metal sequestration and solid phase stability are enhanced by increased soil-metal contact time.

Using the results obtained from the SERDP-funded research, we have created an Excel ${ }^{\circledR} 2000$ application called SBAT ( $\underline{\text { Soil }} \underline{B} i \underline{\text { Accessibility }}$ Tool) to estimate the bioaccessibility of soil bound arsenic ( $\mathrm{As}(\mathrm{III})$ and $\mathrm{As}(\mathrm{V}))$ and chromium $(\mathrm{Cr}(\mathrm{III})$ and $\mathrm{Cr}(\mathrm{VI}))$ from soil properties. The tool combines the previously developed regression models with an extensive set of summarized historical data on soil properties. When a soil series or great group name is entered, SBAT will retrieve the associated historical data and calculate an estimate of bioaccessibility. Alternatively, a user can enter site-specific soils data that will be used in calculating the estimate, or a combination of historical and site-specific data can be used. Uncertainty estimates are also calculated to provide the user with a confidence measure.

Instructions for using the tool are provided in Chapter 2. For estimation, a user can enter either site-specific soils data or use the extensive set of summarized historical data provided with 
SBAT. Chapter 3 provides background information on the source and methods used to summarize the historical data. Information on sampling and analysis protocols for obtaining site-specific measurements are given in Chapter 4. An abbreviated set of instructions for using the tool is provided in Appendix A, and reprints of relevant publications are included in Appendices B through E (Stewart et al. 2003a; Yang et al. 2002; Stewart et al. 2003b; Yang et al. 2003).

SBAT is designed to help managers identify sites that pose the greatest threat to human health and are thus most deserving of remediation or additional study. Since SBAT provides estimates of bioaccessibility, it is only intended for screening work. Site-specific measurements of bioaccessibility should be made when accurate results are needed for risk assessment. 


\section{USAGE INSTRUCTIONS}

SBAT is a standalone Microsoft Excel ${ }^{\circledR} 2000$ application (SBAT.xls). Prior to use, the application should be copied to your computer. Before opening SBAT, set the macro security level of Excel ${ }^{\circledR}$ to medium. To accomplish this, open Excel ${ }^{\circledR}$, click on the "Tools" pull down menu and then on "Options". Once the Options box appears, click on the "Security" tab, and then click on the "Macro Security" button. Set the security level to medium and click "OK". Next, open SBAT.xls and click on the "Enable Macro" button when asked by Excel ${ }^{\circledR}$ to enable or disable macros.

The SBAT interface screen is shown in Figure 1. The yellow highlighted cells are used for input. SBAT consists of the following six worksheets:

1. Form-Application interface. This worksheet is used to input the soil series or great group name and display the bioaccessibility estimates. The other worksheets in the workbook are linked to this worksheet.

2. Taxonomy - Series names and their great group assignment.

3. Chem - Aggregated historical soil characterization data.

4. Metals - Bioaccessibility regression models.

5. Prediction_Intervals - Data for prediction interval calculation.

6. Measurement-Assists the user in inputting site-specific data on the Form worksheet.

Each worksheet is password protected to prevent users from accidentally editing the formulas or data. Initially, the worksheet tabs are not displayed when the workbook is opened. To display the tabs, click on the "Tools" pull down menu and then on "Options". Once the Options box appears, click on the "View" tab and make sure the "Sheet Tabs" option is selected. Click on "OK" to save.

SBAT can use two different sources of data for estimating bioaccessibility. If available, a user can enter site-specific soil properties (Section 2.2) in the Site-Specific Parameters section of the interface screen. If site-specific data are unavailable, the user can specify the name of a soil series or great group. The tool will use soil properties data stored in the Chem worksheet (Section 2.1) and display the results in the Estimated Parameters portion of the interface screen. In either case, SBAT calculates the bioaccessibility estimate and uncertainty based on the models stored in the Metals worksheet (Section 2.3) and outputs these estimates to the Bioaccessibility Estimates section.

\subsection{USING HISTORICAL DATA}

At the top of the interface screen is an area in which the user can enter the name of the soil series or great group for which bioacccessibility estimates will be calculated. If the name of soil series is known (e.g., Fullerton), the user should type this name into the yellow-highlighted cell adjacent to the words Enter Series and press the Enter key. The series name may be upper or lower case, but it must be spelled correctly. If the user is unsure of the series spelling, she or he can click on the Taxonomy worksheet tab to view an alphabetic list of soil series in column B. If only the great group is known, the user should type this name into the yellow-filled cell adjacent to the words Select Great Group and press the Enter key. Clicking on the button on the right side of the cell will enable the user to select a great group name from a scroll list. If either the soil series or great group is unknown, leave the appropriate yellow-highlighted cell blank. 
Once a soil series name is entered, SBAT retrieves the great group name from the Taxonomy worksheet and displays this information in cell B9. The Estimated Parameters section displays the aggregated historical data for this great group. The cells in the Estimated Parameters section will contain \#N/A (not available) if this great group is not in the aggregated data (Chem worksheet) or if the series entered is not found in the Taxonomy worksheet.

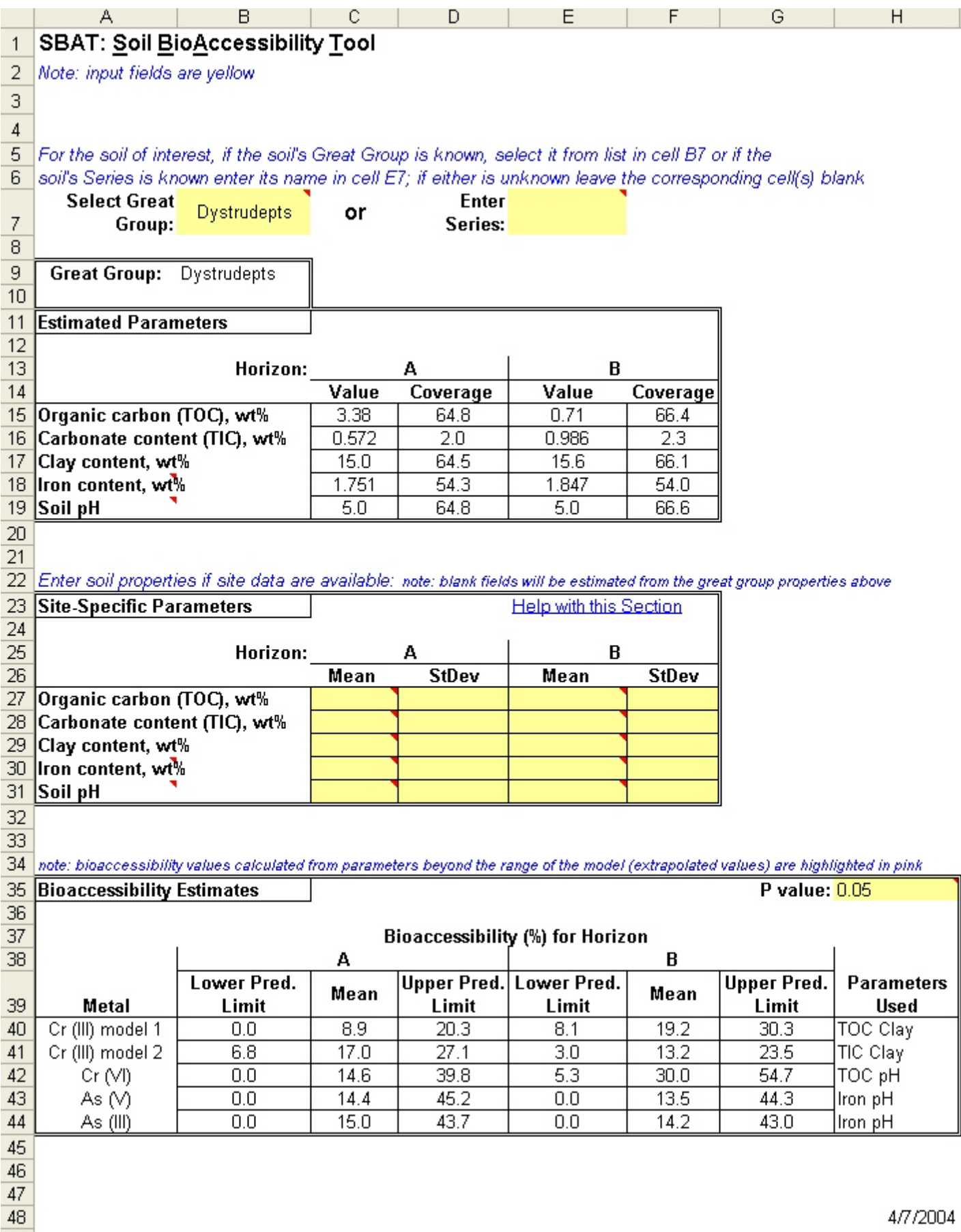

\begin{tabular}{|c|c|c|c|c|c|c|}
\hline \multicolumn{3}{|c|}{ A } & \multicolumn{3}{|c|}{ B } & \multirow[b]{2}{*}{$\begin{array}{c}\text { Parameters } \\
\text { Used }\end{array}$} \\
\hline $\begin{array}{c}\text { Lower Pred. } \\
\text { Limit }\end{array}$ & Mean & $\begin{array}{c}\text { Upper Pred. } \\
\text { Limit }\end{array}$ & $\begin{array}{c}\text { Lower Pred. } \\
\text { Limit }\end{array}$ & Mean & $\begin{array}{c}\text { Upper Pred. } \\
\text { Limit }\end{array}$ & \\
\hline 0.0 & 8.9 & 20.3 & 8.1 & 19.2 & 30.3 & \multirow{5}{*}{$\begin{array}{l}\text { TOC Clay } \\
\text { TIC Clay } \\
\text { TOC pH } \\
\text { Iron } p H \\
\text { Iron } \mathrm{pH} \\
\end{array}$} \\
\hline 6.8 & 17.0 & 27.1 & 3.0 & 13.2 & 23.5 & \\
\hline 0.0 & 14.6 & 39.8 & 5.3 & 30.0 & 54.7 & \\
\hline 0.0 & 14.4 & 45.2 & 0.0 & 13.5 & 44.3 & \\
\hline 0.0 & 15.0 & 43.7 & 0.0 & 14.2 & 43.0 & \\
\hline
\end{tabular}

Fig. 1. SBAT interface. 
When the great group name is retrieved, the average measurements for organic carbon, carbonate carbon, clay content, iron, and $\mathrm{pH}$ are displayed under the Value columns and the coverage of each of these soil properties is displayed under the Coverage columns. See Section 3 for a definition of coverage and how it was calculated.

If a measurement for a soil property is unavailable due to lack of appropriate data, the word missing is displayed. There are two ways in which this can result. First, there may not be any measurements for the great group and soil property in the historical data set. Possible reasons for missing measurements include: (i) the soil property was not measured in the laboratory, (ii) the horizon thickness or bulk density was missing, or (iii) quality control resulted in deletion of measurements. A second cause of missing data is that the area(s) of the aggregated series in a great group are missing from the geographic database used to identify soil series in the U.S.

\subsection{USING SITE-SPECIFIC DATA (OPTIONAL)}

If site-specific soils data are available, they may be entered in the Site-Specific Parameters section. Enter the site-specific measurements for the soil of interest in the appropriate yellowhighlighted cells. If a measurement is unavailable, leave the corresponding cell(s) blank. Soil $\mathrm{pH}$ should be the measured in distilled water at a 1:1 soil to solution ratio. Iron content should be measured with a dithionite citrate extraction procedure. Total organic carbon (TOC) and carbonate carbon (TIC) should be measured by combustion on a total carbon analyzer. Section 4 gives additional information about the proper analytical protocols for generating the site-specific data.

If multiple measurements are available, the user should enter the average of the measurements. For help in calculating the average, click Help with this section. Clicking this link will take the user to the Measurement worksheet. Multiple measurements for soil properties can be entered here, and the average and standard deviation of these measurements will be calculated and displayed in the Results section. To copy these results to the Form worksheet press Ctrl and the "s" key simultaneously.

A combination of site-specific and aggregated data can be used to calculate bioaccessibility. If site-specific soils data are available but measurements are missing for some soil properties, then the aggregated data measurement will automatically be substituted for these soil properties in the bioaccessibility calculation.

\subsection{REVIEWING THE BIOACCESSIBILITY ESTIMATES}

Multiple regression equations were developed from data collected in previous studies (Yang et al. 2002; Stewart et al. 2003a). Reprints of these publications are provided in Appendices B and C. These equations, which form the basis of the estimates generated by SBAT, are displayed in Table 1. 
Table 1. Regression models for estimating arsenic and chromium bioaccessibility (BA) in soils.

\begin{tabular}{|c|c|c|c|}
\hline Metal & Model $^{\dagger}$ & $\mathbf{R}^{2}$ & $\mathbf{P}$ \\
\hline As(V) & $\mathrm{BA}=-22.37-36.22 \log \mathrm{Fe}+9.11 \mathrm{pH}$ & 0.720 & $<0.001$ \\
\hline $\mathrm{As}(\mathrm{III})$ & $\mathrm{BA}=-1.41-30.64 \log \mathrm{Fe}+4.76 \mathrm{pH}$ & 0.574 & $<0.001$ \\
\hline Cr(III) model 1 & $\mathrm{BA}=15.53-3.78 \mathrm{TOC}+0.408$ Clay & 0.674 & $<0.001$ \\
\hline Cr(III) model 2 & $\mathrm{BA}=16.02-9.56 \mathrm{TIC}+0.426$ Clay & 0.722 & $<0.001$ \\
\hline $\mathrm{Cr}(\mathrm{VI})$ & $\mathrm{BA}=57.34-22.55 \log \mathrm{TOC}-6.15 \mathrm{pH}$ & 0.601 & $<0.001$ \\
\hline
\end{tabular}

There are two models for $\mathrm{Cr}$ (III) for reasons described in Stewart et al. (2003a). Briefly, clay, organic carbon (TOC) and carbonate carbon (TIC) are thought to be important predictions of $\mathrm{Cr}$ (III) bioaccessibility. However, when clay, TIC, and TOC were used in the same model, the contribution of TOC was not significant at the $90 \%$ confidence level. This may be an artifact of the limited data from which the models were derived. A more extensive data set is necessary to test this hypothesis (Stewart et al. 2003a). For completeness, SBAT includes models with TOC and TIC.

The Bioaccessibility Estimates section displays the estimates and upper and lower prediction limits of $\mathrm{Cr}(\mathrm{III}), \mathrm{Cr}(\mathrm{VI}), \mathrm{As}(\mathrm{V})$, and $\mathrm{As}(\mathrm{III})$ bioaccessibility for the A and B horizons of the soil of interest. This section also displays the soil properties used to estimate bioaccessibility for the metal of interest under Parameters Used. Bioaccessibility values displayed in this section have been restricted between 0 and 100 (their physical limits). \#VALUE! and \#N/A are errors that may occasionally be displayed in this section. If \#VALUE! is displayed, data were missing for an aggregated soil property necessary for modeling. Look in the Estimated Parameters section to see where the word missing is displayed. \#N/A is displayed if aggregated data are not available and site-specific data for the soil properties necessary for modeling are not available.

The user may enter a probability value for the prediction interval in the upper right corner of this section adjacent to the word $P$ value. For example, if a $p$ value of 0.10 is entered, the $90 \%$ prediction interval is displayed, and the user can say that she or he is $90 \%$ confident that the bioaccessibility for the particular soil of interest lies between the upper and lower prediction limits. It is important to note that prediction intervals are displayed, not confidence intervals. Both types of intervals reflect the uncertainty of a bioaccessibility estimate. Confidence intervals quantify the uncertainty in estimating the mean bioaccessibility of all soils whose physical and chemical properties are equal to numeric values of interest. Prediction intervals are wider than confidence intervals because prediction intervals include the additional uncertainty associated with estimating the bioaccessibility of a particular soil.

Bioaccessibility estimates are highlighted in pink if they are calculated from soil measurements that are outside the range of data used to build the original bioaccessibility regression models. These estimates should be used with caution because they are extrapolations of the model. In this case, the regression model may not properly describe the relationship between bioaccessibility and soil properties.

There are several factors to consider in interpreting the output of SBAT. Foremost, the user should evaluate the data used for predicting bioaccessibility. The parameters (soil properties) necessary for modeling the bioaccessibility are listed under Parameters Used in the Bioaccessibility Estimates section. If site-specific data were not entered for these soil properties, then the corresponding aggregated soil property data in the Estimated Parameters 
section were automatically used to predict bioaccessibility. Site specific measurements for the soil of interest are obviously better than using aggregated historical data to estimate bioaccessibility. However, if data from the Estimated Parameters section were used, the user should evaluate the Coverage values of the parameters used for modeling. If the coverage for a parameter is low, then the aggregated value is based on only a few soil series and should not be trusted to accurately predict bioaccessibility for the great group of interest. If no data were available for the aggregated soil property, then the word missing is displayed and the coverage value is zero.

\subsection{TEST RESULTS}

To test the accuracy of using aggregated soil properties, bioaccessibility estimates for nineteen soil series were calculated using SBAT. These bioaccessibility estimates were compared to laboratory measurements made on the same samples. Table 2 shows the proportion of the variance in bioaccessibility explained $\left(\mathrm{R}^{2}\right)$ by the regression equations using aggregated and measured soil properties.

Table 2. Bioaccessibility predictions using aggregated and measured soil data.

\begin{tabular}{|c|c|c|}
\hline \multirow{2}{*}{ Metal } & \multicolumn{2}{|c|}{ Variance Explained $\left(\mathbf{R}^{2}\right)$} \\
\hline & Aggregated Soil Data & Measured Soil Data \\
\hline $\mathrm{As}(\mathrm{III})$ & 0.55 & 0.57 \\
\hline $\mathrm{As}(\mathrm{V})$ & 0.77 & 0.72 \\
\hline $\mathrm{Cr}(\mathrm{III})$ model 1 & 0.57 & 0.67 \\
\hline $\mathrm{Cr}(\mathrm{III})$ model 2 & 0.05 & 0.72 \\
\hline $\mathrm{Cr}(\mathrm{VI})$ & 0.65 & 0.60 \\
\hline
\end{tabular}

These results indicate that, with the exception of the $\mathrm{Cr}$ (III) model 2, soil data aggregated to the great group level provides almost as good a bioaccessibility estimate as is obtained from measured soil data. Bioaccessibility estimates used in this comparison were not restricted by coverage values. In other words, estimates based on soil properties with low coverage $(<30 \%)$ were not deleted. Coverage values indicate how well the historical data represents a given great group (See Section 3). Many of the aggregated TIC values used in the Cr (III) model 2 were based on low coverage. This is a possible explanation for the low $\mathrm{R}^{2}$ of this model. Another explanation is that there could be a large variance in TIC within great groups. 


\section{PREPARATION OF THE AGGREGATED HISTORICAL DATA}

The aggregated historical data included with the bioaccessibility tool is derived from the Soil Survey Laboratory Soil Characterization database compiled by the U.S. Department of Agriculture's Natural Resources Conservation Service (NRCS). This database contains physical, chemical, engineering, mineralogical, and descriptive data for more than 21,000 pedons collected from all fifty states (Soil Survey Staff 1997). Analytical procedures used to measure the soil physical and chemical properties are described in the Soil Survey Laboratory Investigations Report No. 42 (Soil Survey Staff 1996).

The NRCS data were reviewed and suspicious values were removed. In order to provide more extensive spatial coverage, the NRCS data were aggregated to the great group taxonomic level. The aggregation process consists of several steps which are summarized in Figure 2. First, measurements for multiple subhorizons within a pedon were averaged to the master horizons for the pedon. The sample measurements were weighted by the subhorizon mass which was calculated by multiplying the subhorizon's thickness by its bulk density. The measurements were restricted to the top meter of soil since this represents the maximum volume of soil likely to be ingested. Next, all of the pedons belonging to a series were averaged resulting in aggregated measurements for the series. Finally, this series data was averaged to great group. This last step was weighted by series area. Series areas were obtained from the State Soil Geographic (STATSGO) Database (U.S. Department of Agriculture 1991).

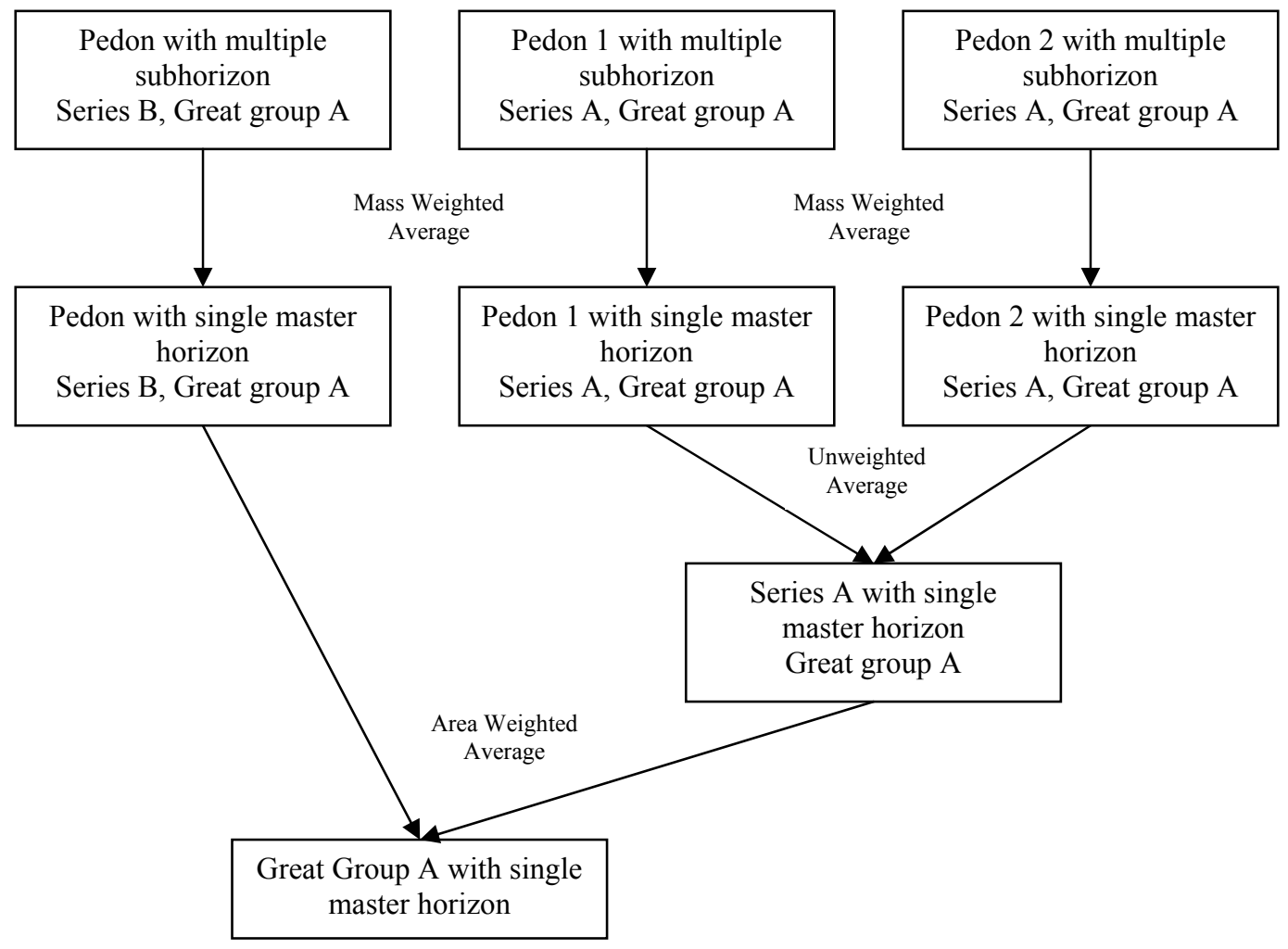

Fig. 2. Data aggregation process. 
The great group level aggregated data were incorporated into SBAT. However, before aggregating to great group level, the series level aggregated data were evaluated. The series aggregated data were unsuitable due to lack of sufficient data. Approximately 55\% of aggregated measurements for carbonate are missing and $45 \%$ of the aggregated data are missing iron measurements. Approximately 51\% of series level aggregated measurements for clay, $\mathrm{pH}$, and organic carbon content were based on only one pedon.

Since approximately $60 \%$ of the NRCS database is missing bulk density measurements, only $40 \%$ of the database would be available for data aggregation. To remedy this problem, multiple regression equations were developed to estimate bulk density from common soil properties present in the database. Using these models to add predicted bulk density values to the database, only $17 \%$ of the database was missing bulk density measurements (Heuscher et al. 2004).

Since both the NRCS and STASGO databases are consistently being updated and revised, the aggregated data is essentially a snapshot in time. In other words, every existing soil series is not mapped and analytical data have not been recorded for every sample. To indicate how well the aggregated soil properties represent a given great group, percent aerial coverage was calculated as follows for each type of measurement or soil property:

$$
\text { Coverage }(\%)=100 \times \frac{\text { total area of aggregated series in the great group }}{\text { total area of all series in the great group }}
$$

If the coverage value for a soil property is low, then the aggregated value is based on only a few soil series in that great group. Thus, it is probable that the aggregated soil property is not representative of the given great group. 


\section{ANALYSIS PROTOCOLS}

Bioaccessibility is a measure of the mobilization of contaminants from soil during digestion. The bioavailability of ingested contaminated soils is defined as the contaminant fraction that reaches systemic circulation (Oomen et al. 2002). Thus, bioaccessibility is a precursor measurement to bioavailability since bioaccessibility is measured in vitro and bioavailability is measured in vivo with test animals. Bioavailability protocols are often not feasible for site-specific risk assessment studies due to this fact.

Several in vitro digestion models based on human physiology have been developed as cheap and reproducible tools to investigate bioaccessibility of soil contaminants (Oomen et al. 2002). A modified version of a physiologically based extraction test (PBET) developed by Ruby et al. (1996) was used to generate the data used for SBAT since it has been cross-correlated with in vivo bioavailability studies involving arsenic, lead, and cadmium (Ruby et al. 1996; Rodriguez et al. 1999; Schroder et al. 2003). Using this method, the reported bioaccessibility is a measure of the amount of ingested contaminant that is soluble due to simulated human gastric functions and has the potential to cross the intestinal wall. Protocols for obtaining bioaccessibility measurements using the modified PBET method are described in the attached publications (Appendices B and C) but are repeated here for convenience.

\subsection{SOIL CHARACTERIZATION}

Soil $\mathrm{pH}$ was determined using double deionized (DDI) water and $5 \mathrm{mM} \mathrm{CaCl}_{2}$ in a 2:1 solution to solid ratio. The $\mathrm{pH}$ of the clear supernatant was measured with a microprocessor ionalyzer/901 (Orion Research, Beverly, MA) using a combination glass and Calomel electrode (Beckman, Fullerton, CA). Extractable iron and manganese oxides were determined with dithionite-citratebicarbonate (DCB) using the methods of Mehra and Jackson (1960). Total organic carbon (TOC) and total inorganic carbon (TIC) were measured by combustion on a Perkin-Elmer 2400 Series II CHNS/O analyzer. Soil TOC was determined on pretreated samples to remove TIC which involved a near-boiling, $3 \mathrm{M} \mathrm{HCl}$ extraction method on agitated samples. Soil TIC was computed from the difference between total soil carbon (no pretreatment) and TOC.

\subsection{SAMPLE PREPARATION}

Soils were disaggregated with gentle grinding using a mortar and pestle and sieved to provide a soil fraction $<250 \mu \mathrm{m}$. It is this smaller size material that is more commonly ingested by children since it adheres more readily to the hand (Sheppard et al. 1995; Rodriguez et al. 1999). Soils were spiked with various mass-loadings of $\mathrm{Cr}(\mathrm{III}), \mathrm{Cr}(\mathrm{VI}), \mathrm{As}(\mathrm{III})$, or $\mathrm{As}(\mathrm{V})$ as described in Stewart et al. (2003a) and Yang et al. (2002).

\subsection{DETERMINATION OF TOTAL CHROMIUM AND ARSENIC ON SOIL}

Total chromium and arsenic on the soil was determined using a modification of EPA method 3052 (http://www.epa.gov/SW-846/pdfs/3052.pdf). The soil was digested in a CEM microwave, model MDS-81D, with hydrofluoric and nitric acid. Boric acid was added before sample analysis in order to facilitate the removal of hydrofluoric acid from solution through the formation of fluoroboric acid. Samples were stored and analyzed for total chromium and arsenic using Inductively Coupled Plasma. Soils from the National Institute of Standards, with known concentrations of solid phase chromium or arsenic, were also analyzed with each block of analysis. 


\subsection{IN VITRO BIOACCESSIBILITY}

Triplicate $0.39 \mathrm{~g}$ moist samples $(0.3 \mathrm{~g}$ dry weight $)$ were placed in $50 \mathrm{ml}$ polyethylene tubes to which $30 \mathrm{ml}$ of PBET solution was added. The PBET solution is $0.4 \mathrm{M}$ glycine at $\mathrm{pH} 1.5$ and $37^{\circ} \mathrm{C}$. It is important to note that the quantity of soil can vary as long as the soil dry weight to PBET solution ratio of 1 to 100 is maintained. The slurries were then quickly placed in a rotating water bath of $37^{\circ} \mathrm{C}$ and agitated at $30 \pm 2 \mathrm{rpm}$ for 1 hour. Supernatant was separated from the solid via centrifugation. The $\mathrm{pH}$ of the supernatant was measured to ensure that the final $\mathrm{pH}$ was within $\pm 0.5 \mathrm{pH}$ units of the initial $\mathrm{pH}$. This scenario held for all cases. The PBET $\mathrm{pH}$ of 1.5 simulates the most aggressive stomach digestive scenario which is a condition indicative of human fasting.

For arsenic, the supernatant was analyzed using graphite furnace atomic adsorption spectrometry. For chromium, the supernatant was first analyzed for $\mathrm{Cr}(\mathrm{VI})$ using a modified $s$-diphenylcarbohydride colormetric method (Bartlett and James 1979) with a Hewlett-Packard model 8453 UV-VIS spectrophotometer at wavelength $540 \mu \mathrm{m}$ (Palo Alto, CA). Analysis of $\mathrm{Cr}(\mathrm{VI})$ was performed immediately on rapidly cooled PBET supernatant solutions to avoid possible reduction of $\mathrm{Cr}(\mathrm{VI})$ to $\mathrm{Cr}(\mathrm{III})$ by glycine (Jardine et al. 1999). Total $\mathrm{Cr}\left(\mathrm{Cr}_{\mathrm{T}}\right)$ in the supernatant was measured on a Perkin Elmer AAnalyst 800 atomic absorption spectrometer (Wellseley, PA). Chromium (III) was calculated as the difference between $\mathrm{Cr}_{\mathrm{T}}$ and $\mathrm{Cr}(\mathrm{VI})$. Bioaccessibility was then calculated as:

$\%$ Bioaccessibility $=\left(\frac{\text { Cr or As in PBET supernatant }(\mu \mathrm{g} / \mathrm{mL}) \times 30.0 \mathrm{~mL}(\text { vol. of PBET solution })}{\text { Cr or As on soil surface }(\mu \mathrm{g} / \mathrm{g}) \times 0.3 \mathrm{~g}(\text { dry soil weight })}\right) \times 100$ 


\section{REFERENCES}

Bartlett, R. and B. James. 1979. Behavior of chromium in soils: III. Oxidation. Journal of Environmental Quality. 8:31-35.

Heuscher, S.A., C.C. Brandt, and P.M. Jardine. 2004. Using soil properties to estimate bulk density. Soil Science Society of America Journal. (submitted).

Jardine, P.M., S.E. Fendorf, M.A. Mayes, S.C. Brooks, and W.B. Bailey. 1999. Fate and transport of hexavalent chromium in undisturbed heterogeneous soil. Environmental Science and Technology. 33:2939-2944.

Mehra, O.P. and M.L. Johnson. 1960. Iron oxide removed from soils and clays by a diothionitecitrate system buffered with sodium bicarbonate. Clays and Clay Minerals. 7:317-327.

Oomen, A.G., A. Hack, M. Minekus, E. Zeijdner, C. Cornelis, G. Schoeters, W. Verstraete, T. Van De Wiele, J. Wragg, C. Rompelberg, A. Sips, and J. Van Wijnen. 2002. Comparison of five in vitro digestion models to study the bioaccessibility of soil contaminants. Environmental Science and Technology. 36:3326-3334.

Rodriguez, R.R., N.T. Basta, S.W. Casteel, and L.W. Pace. 1999. An in vitro gastrointestinal method to estimate bioavailable arsenic in contaminated soils and solid media. Environmental Science and Technology. 33:642-649.

Ruby, M.V., A. Davis, R. Schoof, S. Eberle, and C.M. Sellstone. 1996. Estimation of lead and arsenic bioavailability using a physiologically based extraction test. Environmental Science and Technology. 30:422-430.

Schroder, J.L., N.T. Basta, J. Si, S.W. Casteel, T. Evans, and M. Payton. 2003. In vitro gastrointestinal method to estimate relative bioavailable cadmium in contaminated soil. Environmental Science and Technology. 37:1365-1370.

Sheppard, S.C., W.G. Evenden, and W.J. Schwartz. 1995. Ingested soil: bioavailability of sorbed lead, cadmium, cesium, iodine and mercury. Journal of Environmental Quality. 24:498-505.

Soil Survey Staff. 1996. Soil Survey Laboratory Methods Manual. Soil Survey Laboratory Investigations Report No. 42. U.S. Department of Agriculture. 716 p.

Soil Survey Staff. 1997. National Soil Survey Characterization Data. Soil Survey Laboratory, National Soil Survey Center, Natural Resources Conservation Service, U.S. Department of Agriculture. Lincoln, NE.

Stewart, M.A., P.M. Jardine, M.O. Barnett, T.L. Mehlhorn, L.K. Hyder, and L.D. McKay. 2003a. Influence of soil geochemical and physical properties on the sorption and bioaccessibility of chromium(III). Journal of Environmental Quality. 32:129-137 (reprint in Appendix B).

Stewart, M.A., P.M. Jardine, C.C. Brandt, M.O. Barnett, S.E. Fendorf, L.D. McKay, T.L. Mehlhorn, and K. Paul. 2003b. Effects of contaminant concentration, aging and soil properties on the bioaccessibility of $\mathrm{Cr}(\mathrm{III})$ and $\mathrm{Cr}(\mathrm{VI})$ in soil. Soil and Sediment Contamination. 12:1-21 (reprint in Appendix D). 
U.S. Department of Agriculture, Natural Resources Conservation Service, National Soil Survey Center, 1991. State Soil Geographic (STATSGO) Database.

Yang, J-K., M.O. Barnett, P.M. Jardine, N.T. Basta, and S.W. Casteel. 2002. Adsorption, sequestration, and bioaccessibility of $\mathrm{As}(\mathrm{V})$ in soils. Environmental Science and Technology. 36:4562-4569 (abstract in Appendix C).

Yang, J-K., M.O. Barnett, P.M. Jardine, and S.C. Brooks. 2003. Factors controlling the bioaccessibility of arsenic (V) and lead(II) in soils. Soil and Sediment Contamination. 12:165-179 (reprint in Appendix E). 
APPENDIX A

SBAT QUICK GUIDE 


\section{SBAT QUICK GUIDE}

1. Prior to opening SBAT, set the macro security level on Excel ${ }^{\circledR}$ to medium. To accomplish this, open Excel ${ }^{\circledR}$, click on the "Tools" pull down menu and then on "Options". Once the Options box appears, click on the "Security" tab, and then click on the "Macro Security" button. Set the security level to medium and click "OK". Open the Excel® file SBAT.xls, and, when prompted, click the "Enable Macros" button. The worksheet tabs are not displayed when the workbook is initially opened. If the user would like to display the tabs, click Tools $\rightarrow$ Options, click the "View" tab, click the box adjacent to the words "Sheet tabs", and click OK. Each worksheet is password protected to prevent users from accidentally editing formulas or reference data.

2. The interface worksheet (Form) will appear when the application is initially opened. This worksheet contains three boxed sections (top to bottom): Estimated Parameters, SiteSpecific Parameters, and Bioaccessibility Estimates. The yellow cells are available for user input.

3. Immediately above the Estimated Parameters section, the user can enter the soil series or great group of interest in either of the two yellow cells. If the great group or series is not known, ignore this section and proceed to step (4). If the soil's great group is known, click on the yellow colored cell adjacent to the words Select Great Group. Either type in the great group name or click on the button that appears on the right side of the cell and use the scroll bar to select the great group name from the list. If the soil great group is not known, but the soil series is known, enter the series name by clicking on the yellow colored cell adjacent to the words Enter Series, typing the soil series name and pressing enter. The Estimated Parameters section displays the great group aggregated data. Upon entering a soil series name or picking a great group from the list, the great group name is retrieved and the great group's averages for organic carbon, inorganic carbon, clay content, iron content, and $\mathrm{pH}$ are displayed under the Value columns. If a measurement for one of these soil properties is unavailable due to lack of appropriate data, the word missing is displayed. If the great group of interest is not in the aggregated data or if the series entered is not listed in the most current taxonomy, then the cells in the Estimated Parameters section will fill with \#N/A.

4. If site-specific soils data are available, they may be entered in the Site-Specific Parameters section. In the yellow colored cells, enter site specific measurements for the soil of interest. If a measurement is unavailable, leave the corresponding cell(s) blank.

5. If the site has multiple measurements for soil properties, then enter the average of the measurements. For help in calculating this average click Help with this section. Clicking this link will take you to the Measurement worksheet. Multiple measurements for soil properties can be entered here, and the average and standard deviation of these measurements are calculated and displayed in the Results section. To copy these results to the interface worksheet press Ctrl and the "s" key simultaneously.

6. In the Bioaccessibility Estimates section, look under Bioaccessibility (\%) for Horizon to see an estimate of $\mathrm{As}(\mathrm{V}), \mathrm{As}(\mathrm{III}), \mathrm{Cr}(\mathrm{III})$, and $\mathrm{Cr}(\mathrm{VI})$ bioaccessibility as well as the upper and lower prediction limits for the A and B horizons of the soil of interest. \#VALUE! and \#N/A are errors that may be displayed under Bioaccessibility (\%) for Horizon in Bioaccessibility Estimates section. If \#VALUE! is displayed, data were missing for an aggregated soil property necessary for modeling; look in the Estimated Parameters section to see where the 
word missing is displayed. \#N/A is displayed if aggregated data are not available and sitespecific data for the soil properties necessary for modeling are not available.

7. Enter the $\mathrm{p}$ value of interest for the prediction interval in the upper right corner of this section adjacent to the word $P$ value. For example, if a $\mathrm{p}$ value of 0.10 is entered, the $90 \%$ prediction interval is displayed under Bioaccessibility (\%) for Horizon. Bioaccessibility estimates are highlighted in pink if they are calculated from soil properties that are outside the range of data used to build the bioaccessibility models. These estimates should not be trusted because they are extrapolating the model outside the range of data. Therefore, the model may not properly describe the relationship between bioaccessibility and soil properties. The Bioaccessibility Estimates section also displays the soil properties used to estimate bioaccessibility under Parameters Used.

8. If site specific data were not entered for soil properties listed under Parameters Used, then the corresponding aggregated soil property data in the Estimated Parameters section were automatically used to predict bioaccessibility. If data from the Estimated Parameters section were used, evaluate the coverage column(s) of the parameters used for modeling. If the coverage for a parameter is low, then the aggregated value is based on only a few soil series and should not be trusted to accurately predict bioaccessibility for the great group of interest. 
APPENDIX B

STEWART, M.A., P.M. JARDINE, M.O. BARNETT, T.L. MEHLHORN, L.K. HYDER, AND L.D. MCKAY. 2003a. INFLUENCE OF SOIL GEOCHEMICAL AND PHYSICAL PROPERTIES ON THE SORPTION AND BIOACCESSIBILITY OF CHROMIUM(III). JOURNAL OF ENVIRONMENTAL QUALITY. 32:129-137. 


\title{
Influence of Soil Geochemical and Physical Properties on the Sorption and Bioaccessibility of Chromium(III)
}

\author{
M. A. Stewart, P. M. Jardine,* M. O. Barnett, T. L. Mehlhorn, L. K. Hyder, and L. D. McKay
}

\begin{abstract}
There are numerous Cr(III)-contaminated sites on Department of Defense (DoD) and Department of Energy (DOE) lands that are awaiting possible clean up and closure. Ingestion of contaminated soil by children is the risk driver that generally motivates the likelihood of site remediation. The purpose of this study was to develop a simple statistical model based on common soil properties to estimate the bioaccessibility of $\mathbf{C r}$ (III)-contaminated soil upon ingestion. Thirtyfive uncontaminated soils from seven major soil orders, whose properties were similar to numerous U.S. DoD contaminated sites, were treated with $\mathrm{Cr}$ (III) and aged. Statistical analysis revealed that $\mathrm{Cr}$ (III) sorption (e.g., adsorption and surface precipitation) by the soils was strongly correlated with the clay content, total inorganic $\mathrm{C}, \mathrm{pH}$, and the cation exchange capacity of the soils. Soils with higher quantities of clay, inorganic $\mathrm{C}$ (i.e., carbonates), higher $\mathrm{pH}$, and higher cation exchange capacity generally sequestered more $\mathrm{Cr}$ (III). The amount of $\mathrm{Cr}$ (III) bioaccessible from the treated soils was determined with a physiologically based extraction test (PBET) that was designed to simulate the digestive process of the stomach. The bioaccessibility of $\mathrm{Cr}$ (III) varied widely as a function of soil type with most soils limiting bioaccessibility to $<45$ and $<30 \%$ after 1 and $100 \mathrm{~d}$ soil-Cr aging, respectively. Statistical analysis showed the bioaccessibility of $\mathrm{Cr}$ (III) on soil was again related to the clay and total inorganic carbon (TIC) content of the soil. Bioaccessibility decreased as the soil TIC content increased and as the clay content decreased. The model yielded an equation based on common soil properties that could be used to predict the $\mathrm{Cr}$ (III) bioaccessibility in soils with a reasonable level of confidence.
\end{abstract}

$\mathrm{T}_{\mathrm{s}}$ HE PRESENCE of chromium $(\mathrm{Cr})$ in the environment is widespread due to its usage in many industrial processes. The metallurgic, tanning, and plating industries are just a few examples of very common applications, large and small, which use $\mathrm{Cr}$ on a daily basis (Nriagu and Nieboer, 1988). Chromium itself is thermodynamically stable in two oxidative states: cationic $\mathrm{Cr}$ with a valence of three, $\mathrm{Cr}(\mathrm{III})$, and anionic $\mathrm{Cr}$ with a valence of six, $\mathrm{Cr}(\mathrm{VI})$. Chromium(VI) is often considered to be mobile in the environment while the more environmentally stable $\mathrm{Cr}$ (III) is considered less mobile (Chung et al., 1994; Patterson et al., 1997). There are several factors that contribute to the decreased mobility of $\mathrm{Cr}$ (III) in soil: (i) strong adsorption onto the nega-

M.A. Stewart, P.M. Jardine, T.L. Mehlhorn, and L.K. Hyder, Environ. Sci. Div., Oak Ridge, TN 37831-6038; M.O. Barnett, Dep. of Civil Engineering, 208 Harbert Engineering Center, Auburn Univ., AL 36849-5337; and L.D. McKay, Dep. of Geological Sciences, Univ. of Tennessee, Knoxville, TN 37996-1410. This research was sponsored by the U.S. Department of Defense (DoD) Strategic Environmental Research and Development Program. Oak Ridge National Lab is managed by the University of Tennessee- Battelle LLC, under contract DE- AC05- 00OR22725 with the U.S. Department of Energy. Received 7 Nov. 2001. *Corresponding author (jardinepm@ornl.gov).

Published in J. Environ. Qual. 32:129-137 (2003). tively charged soil surfaces, (ii) the ability to form complex molecules with organics found in the soil, and (iii) the formation of oxides and hydroxides and other insoluble minerals in soil (Fendorf and Zasoski, 1992; Losi et al., 1994; Dragun, 1998).

When assessing the risks posed by $\mathrm{Cr}(\mathrm{VI})$ and $\mathrm{Cr}(\mathrm{III})$, the exposure pathway of most concern is ingestion by children (Paustenbach, 1989; Davis et al., 1990; Sheehan et al., 1991; Skowronski et al., 2001). Chromium(VI) is considered the most harmful of the oxidative states since it is both a mutagen and a carcinogen at low sub-ppm levels (Levis and Bianchi, 1982). Although Cr(III) is generally considered less harmful to human health than its oxidized counterpart, it may be of concern due to its potential to oxidize to $\mathrm{Cr}(\mathrm{VI})$ and its ability to accumulate to very high solid phase concentrations in some soils (Fendorf et al., 1992). The bioaccessibility of organic contaminants in soils has been relatively well studied (Linz and Nakles, 1997); however, the bioaccessibility of soil-bound metals such as $\mathrm{Cr}$ has received less attention (Ruby et al., 1996; Rodriguez et al., 1999; Skowronski et al., 2001; Stewart et al., 2003), where the bioaccessibility is defined as that amount of contaminant that is soluble due to simulated in vitro gastric functions and has the potential to cross the intestinal wall (Hamel et al., 1998). Typically, calculated health risks are inappropriately based on a reference dose derived from studies that use soluble aqueous metal species. The ubiquitous metal-sequestering properties of soil may significantly lower the bioaccessibility of $\mathrm{Cr}$ upon digestion, which, in turn may influence the decision for remediation at contaminated sites. Thus, action levels set by state regulators concerning the bioaccessibility of $\mathrm{Cr}$ in soil may need to consider specific soil properties instead of using generic guidelines (Proctor et al., 1997).

The intent of this paper is to show that $\mathrm{Cr}$ (III) can be strongly sequestered by soil, which in turn influences its bioaccessibility. We developed a simple statistical model based on measured soil properties to estimate the bioaccessibility of $\mathrm{Cr}$ (III)-contaminated soils upon ingestion. We show that common soil properties, which are easily obtainable from the National Resource Conservation Service (NRCS) database, can be used to assess $\mathrm{Cr}(\mathrm{III})$ bioaccessibility at contaminated sites.

\footnotetext{
Abbreviations: DoD, Department of Defense; DOE, Department of Energy; PBET, physiologically based extraction test; NRCS, National Resource Conservation Service; CEC, cation exchange capacity; DDI, double deionized; TOC, total organic carbon; TIC, total inorganic carbon; VIF, Variance Inflation Factor; XAS, x-ray adsorption spectroscopy.
} 


\section{METHODS}

\section{Soil Type and Characterization}

A database of metal-contaminated Department of Defense (DoD) sites was obtained from the U.S. Army Environmental Center, Aberdeen Proving Ground, Maryland. Twenty (20) DoD Army facilities throughout the USA were chosen for consideration based on the high concentration of $\mathrm{Cr}$ in their soils and the possible need for remediation (Table 1). Because of the difficulty in obtaining actual contaminated soils from these sites, uncontaminated soils whose properties were similar to the contaminated soils were acquired and treated with $\mathrm{Cr}(\mathrm{III})$. The soil series present at the DoD sites of interest were identified using Soil Conservation Survey documents. The USDA-NRCS database was then utilized to locate pedon numbers associated with each soil series. The NRCS was contacted and in most cases $200 \mathrm{~g}$ of the A-horizon and the upper B-horizon soil were obtained for each soil series (Table 1). Two additional soils were obtained from the Oak Ridge Reservation in eastern Tennessee, which also had properties similar to DoD sites in the southeast USA. Thirty-five soils were acquired and these encompassed seven major soil orders (Table 1).

Soils were disaggregated with gentle grinding using a mortar and pestle and sieved to provide a soil fraction $<250 \mu \mathrm{m}$. It is this smaller size material that is more commonly ingested by children since it adheres more readily to the hand (Sheppard et al., 1995; Rodriguez et al., 1999). Soil properties were obtained from (i) the NRCS database and (ii) repeated or additional measurements in our laboratory. Soil properties included $\mathrm{pH}$, cation exchange capacity (CEC), Fe- and Mn-oxide content, particle size distribution, and total organic and inorganic $\mathrm{C}$ (Table 2). Repetitive or additional measurements of soil $\mathrm{pH}$, $\mathrm{Fe}-$ and Mn-oxide content, and total organic and inorganic $\mathrm{C}$ on all soils were performed to verify the quality of, and provide

Table 1. U.S. Department of Defense Army bases with their associated soil series designations.

\begin{tabular}{|c|c|c|}
\hline Army bases by soil order & $\begin{array}{c}\text { Facility location } \\
\text { by state }\end{array}$ & Soil series \\
\hline $\begin{array}{l}\text { Ultisol } \\
\text { Holston AAP } \\
\text { Fort Gillem } \\
\text { ORNL } \dagger\end{array}$ & $\begin{array}{l}\text { Tennessee } \\
\text { Georgia } \\
\text { Tennessee }\end{array}$ & $\begin{array}{l}\text { Allen } \\
\text { Cecil } \\
\text { Minvale }\end{array}$ \\
\hline $\begin{array}{l}\text { Alfisol } \\
\text { Seneca AD } \\
\text { Indiana AAP } \\
\text { Bluegrass Facility } \\
\text { Ft. Knox } \\
\text { Lexington Facility—LBAD }\end{array}$ & $\begin{array}{l}\text { New York } \\
\text { Indiana } \\
\text { Kentucky } \\
\text { Kentucky } \\
\text { Kentucky }\end{array}$ & $\begin{array}{l}\text { Angola } \\
\text { Crider } \\
\text { Lawrence } \\
\text { Lenberg } \\
\text { Lenberg }\end{array}$ \\
\hline $\begin{array}{l}\text { Inceptisol } \\
\text { Letterkenny AD } \\
\text { ARDEC (Picatinny Arsenal) } \\
\text { Letterkenny } \\
\text { ORNL } \dagger\end{array}$ & $\begin{array}{l}\text { Pennsylvania } \\
\text { New Jersey } \\
\text { Pennsylvania } \\
\text { Tennessee }\end{array}$ & $\begin{array}{l}\text { Berks } \\
\text { Rockaway } \\
\text { Weikert } \\
\text { Montevell }\end{array}$ \\
\hline $\begin{array}{l}\text { Spodosol } \\
\text { Stratford Army Engine Plant }\end{array}$ & Connecticut & Charlton \\
\hline $\begin{array}{l}\text { Mollisol } \\
\text { Kansas AAP } \\
\text { Lake City AAP }\end{array}$ & $\begin{array}{l}\text { Kansas } \\
\text { Missouri }\end{array}$ & $\begin{array}{l}\text { Dennis } \\
\text { Sibley }\end{array}$ \\
\hline $\begin{array}{l}\text { Aridisol } \\
\text { Ft. Wingate } \\
\text { Tolle Army Depot } \\
\text { Desert Chem. Depot } \\
\text { Dugway } \\
\text { Hawthorne } \\
\text { Pueblo Chem. Depot }\end{array}$ & $\begin{array}{l}\text { New Mexico } \\
\text { Utah } \\
\text { Utah } \\
\text { Utah } \\
\text { Nevada } \\
\text { Colorado }\end{array}$ & $\begin{array}{l}\text { Doakum } \\
\text { Kzin } \\
\text { Kzin } \\
\text { Kzin } \\
\text { Oricto } \\
\text { Stoneham }\end{array}$ \\
\hline $\begin{array}{l}\text { Entisol } \\
\text { Savanna Depot Activity }\end{array}$ & Illinois & Wakeland \\
\hline
\end{tabular}

$\dagger$ Department of Energy sites at the Oak Ridge National Laboratory. missing information to the NRCS database. In general, data generated in our laboratory was in excellent agreement with the NRCS database. Soil $\mathrm{pH}$ was determined using double deionized (DDI) water and $5 \mathrm{mM} \mathrm{CaCl}$ in a 2:1 solution/solid ratio. The $\mathrm{pH}$ of the clear supernatant was measured with a microprocessor ionalyzer/901 (Orion Research, Beverly, MA) using a combination glass and Calomel electrode (Beckman, Fullerton, CA). Extractable iron and manganese oxides were determined with dithionite-citrate-bicarbonate (DCB) using the methods of Mehra and Jackson (1960). Total organic carbon (TOC) and total inorganic carbon (TIC) were measured by combustion on a Perkin-Elmer 2400 Series II CHNS/O analyzer. Soil TOC was determined on pretreated samples to remove TIC, which involved a near-boiling, $3 \mathrm{M} \mathrm{HCl}$ extraction method on agitated samples. Soil TIC was computed from the difference between total soil $\mathrm{C}$ (no pretreatment) and TOC.

\section{Contaminant Addition to Soil}

Ten grams of soil was placed in a $200-\mathrm{mL}$ glass centrifuge vessel along with $100 \mathrm{~mL}$ of $500 \mathrm{ppm} \mathrm{Cr}(\mathrm{III})$ as $\mathrm{CrCl}_{3}, \mathrm{pH}$ 4.0. The slurry was agitated on a reciprocal shaker for $2 \mathrm{~d}$, centrifuged, and the supernatant decanted for analysis. This was repeated three more times. After the forth addition of $\mathrm{Cr}$, the soils were washed three times with DDI water and allowed to air dry. Once the soils were dry, they were gently crushed, homogenized, and then wetted with DDI water to achieve a $30 \%$ moisture content. The soils were kept in a container out of direct light and maintained at 30\% water content in a moisture saturated environment. Soils were incubated in this manner for the duration of the study (i.e., at least $100 \mathrm{~d})$.

\section{Determination of Chromium on Soil}

Total $\mathrm{Cr}$ on the soil was determined using a modification of EPA method 3052. The soil was digested in a CEM microwave, model MDS-81D, with hydrofluoric and nitric acid. Boric acid was added before sample analysis to facilitate the removal of hydrofluoric acid from solution through the formation of fluoroboric acid. Soils from the National Institute of Standards, with known concentrations of solid phase $\mathrm{Cr}$, were also analyzed with each block of analysis. Samples were stored and analyzed for total $\mathrm{Cr}$ using inductively coupled plasma.

\section{In Vitro Bioaccessibility}

A physiologically based extraction test (PBET) was adapted from Ruby et al. (1996, 1999; Ruby, personal communication, 2000) to assess the in vitro bioaccessibility of $\mathrm{Cr}$ (III) from contaminated soils in humans. The method is designed to simulate the stomach digestive system in humans. The PBET method has been shown to agree with in vivo studies involving $\mathrm{Pb}$-contaminated soils (Ruby et al., 1996) as well as As-contaminated soils (Rodriguez et al., 1999); however, limited data is currently available in the literature that evaluates Cr bioavailability in contaminated soils using in vivo methods (Witmer et al., 1989, 1991; Gargas et al., 1994), and this data does not appear useful for cross-correlating with the results of the current study. Nevertheless, the PBET method can serve as a useful approximation of $\mathrm{Cr}$ bioavailability until in vivo studies become available to validate the methods credibility with regard to $\mathrm{Cr}$.

In the current study, triplicate $0.39 \mathrm{~g}$ moist samples $(0.3 \mathrm{~g}$ dry wt) were placed in $50 \mathrm{~mL}$ polyethylene tubes to which $30 \mathrm{~mL} 0.4 \mathrm{M}$ glycine at $\mathrm{pH} 1.5$ and $37^{\circ} \mathrm{C}$ was added. The slurries were quickly placed in a rotating water bath of $37^{\circ} \mathrm{C}$ 
Table 2. Select soil chemical and physical properties. $\dagger$

\begin{tabular}{|c|c|c|c|c|c|c|c|c|c|}
\hline & TOC & TIC & Clay & Silt & $\mathbf{F e}$ & Mn & CEC & pH & pH \\
\hline & $\longrightarrow$ & 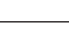 & 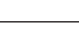 & 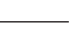 & $\longrightarrow$ & - & $\mathrm{cmol}_{\mathrm{d}} / \mathrm{kg}$ & $5 \mathrm{~m} M \mathrm{CaCl}_{2}$ & DDI \\
\hline \multicolumn{10}{|l|}{ Ultisol } \\
\hline Allen A & 1.55 & 0.56 & 8.7 & 29.5 & 6.95 & 0.31 & 7.7 & 4.59 & 5.05 \\
\hline Allen Ba & 0.19 & 0.09 & 14.9 & 28.4 & 18.96 & 0.10 & 1.3 & 4.30 & 4.74 \\
\hline Cecil Ap & 1.64 & 0.39 & 10.2 & 23.0 & 6.01 & 0.06 & 5.8 & 4.04 & 4.47 \\
\hline Cecil Bt1 & 0.29 & 0.21 & 44.8 & 15.5 & 32.56 & 0.11 & 1.6 & 4.44 & 4.48 \\
\hline Minvale Ap & 1.89 & 0.99 & 6.1 & 59.0 & 7.71 & 1.51 & 6.0 & 6.01 & 6.61 \\
\hline Minvale Bt1 & 0.10 & 0.07 & 23.6 & 44.2 & 19.55 & 0.16 & 4.0 & 4.30 & 5.17 \\
\hline \multicolumn{10}{|l|}{ Alfisol } \\
\hline Lawrence Apl & 0.91 & 0.59 & 19.5 & 48.5 & 11.17 & 1.35 & 5.8 & 4.97 & 5.27 \\
\hline Lawrence Btl & 0.11 & 0.10 & 25.8 & 38.3 & 17.53 & 0.29 & 3.7 & 4.28 & 4.91 \\
\hline Angola Ap & 3.72 & 0.96 & 32.1 & 56.1 & 23.28 & 1.23 & 6.7 & 5.29 & 5.48 \\
\hline Crider Ap & 0.55 & 0.39 & 22.5 & 75.8 & 13.34 & 0.72 & 5.6 & 6.57 & 6.84 \\
\hline Crider B2lt & 0.21 & 0.13 & 30.9 & 67.2 & 13.38 & 0.30 & 5.4 & 5.27 & 5.63 \\
\hline Lenberg A & 3.41 & 1.01 & 49.1 & 44.5 & 12.94 & 1.37 & 7.9 & 5.92 & 6.06 \\
\hline Lenberg Btl & 0.36 & 0.25 & 64.7 & 29.5 & 15.69 & 0.12 & 5.5 & 4.35 & 4.77 \\
\hline \multicolumn{10}{|l|}{ Inceptisol } \\
\hline Berks A & 2.72 & 1.01 & 15.7 & 46.6 & 13.18 & 0.15 & 9.1 & 3.65 & 3.91 \\
\hline Rockaway A1 & 3.54 & 1.49 & 12.4 & 34.8 & 14.03 & 0.52 & 10.6 & 3.86 & 3.98 \\
\hline Rockaway B2t & 0.21 & 0.18 & 12.6 & 32.1 & 17.34 & 0.16 & 3.7 & 4.10 & 4.41 \\
\hline Weikert Ap & 3.97 & 2.37 & 24.4 & 56.2 & 21.41 & 6.47 & 13.3 & 4.44 & 4.70 \\
\hline Weikert Be & 2.01 & 1.15 & 23.9 & 54.3 & 28.98 & 5.42 & 8.0 & 4.28 & 4.65 \\
\hline Montevello A & 3.55 & 0.62 & 6.0 & 69.0 & 10.68 & 1.42 & 8.0 & 6.91 & 7.18 \\
\hline Montevello B & 0.42 & 0.26 & 19.0 & 42.2 & 22.07 & 0.17 & 14.0 & 4.23 & 4.87 \\
\hline \multicolumn{10}{|l|}{ Spodosol } \\
\hline Charlton A2 & 2.30 & 0.40 & 2.9 & 28.7 & 1.33 & 0.00 & 11.7 & 3.15 & 3.57 \\
\hline \multicolumn{10}{|l|}{ Mollisol } \\
\hline Dennis Ap & 1.32 & 0.89 & 15.9 & 66.1 & 15.11 & 0.60 & 8.7 & 5.82 & 6.08 \\
\hline Dennis Ba & 0.38 & 0.41 & 29.7 & 57.5 & 24.29 & 0.59 & 4.4 & 4.77 & 5.28 \\
\hline Sibley A & 1.06 & 0.49 & 23.5 & 69.7 & 8.23 & 0.67 & 7.1 & 6.36 & 6.66 \\
\hline Sibley B1 & 0.72 & 0.52 & 26.9 & 68.0 & 9.11 & 0.59 & 6.8 & 6.36 & 6.76 \\
\hline \multicolumn{10}{|l|}{ Aridisol } \\
\hline Doakum Ab & 0.28 & 0.08 & 10.8 & 24.8 & 4.74 & 0.19 & 6.9 & 6.94 & 7.42 \\
\hline Doakum Bt & 0.39 & 0.18 & 29.3 & 15.0 & 6.86 & 0.16 & 7.0 & 6.87 & 7.39 \\
\hline Kzin A2 & 3.27 & 1.35 & 22.2 & 44.2 & 4.07 & 0.29 & 13.3 & 7.74 & 7.87 \\
\hline Kzin Bk & 3.40 & 1.88 & 27.0 & 38.5 & 3.26 & 0.18 & 10.0 & 7.80 & 7.88 \\
\hline Oricto A2 & 0.09 & 0.94 & 10.2 & 34.7 & 2.92 & 0.34 & 13.7 & 8.72 & 9.60 \\
\hline Oricto Bt & 0.16 & 1.10 & 23.2 & 27.5 & 3.16 & 0.29 & 8.6 & 9.01 & 9.60 \\
\hline Stoneham A & 1.45 & 0.71 & 16.2 & 41.4 & 3.40 & 0.26 & 10.1 & 6.43 & 6.83 \\
\hline Stoneham Bt1 & 0.66 & 0.32 & 21.4 & 23.2 & 2.20 & 0.20 & 7.8 & 6.80 & 7.15 \\
\hline \multicolumn{10}{|l|}{ Entisol } \\
\hline Wakeland Ap & 0.92 & 0.00 & 23.8 & 64.7 & 8.82 & 0.71 & 6.1 & 5.86 & 6.09 \\
\hline Wakeland Cg1 & 0.56 & 0.25 & 21.1 & 66.4 & 9.18 & 0.80 & 5.7 & 5.77 & 6.07 \\
\hline
\end{tabular}

$\dagger$ TOC, total organic carbon; TIC, total inorganic carbon; CEC, cation exchange capacity; DDI, double deionized.

and agitated at $30 \pm 2 \mathrm{rpm}$ for $1 \mathrm{~h}$. Supernatant was separated from the solid via centrifugation. The $\mathrm{pH}$ of the supernatant was measured to ensure that the final $\mathrm{pH}$ was within $\pm 0.5 \mathrm{pH}$ units of the initial $\mathrm{pH}$. This scenario held for all cases. Thus, bioaccessibility was calculated as:

$$
\begin{aligned}
& \% \text { Bioaccessibility }= \\
& \left(\begin{array}{c}
\mathrm{Cr} \text { in PBET supernatant }(\mu \mathrm{g} / \mathrm{mL}) \times \\
30.0 \mathrm{~mL} \div 0.3 \mathrm{~g} \text { dry soil } \\
\text { Cr on soil surface }(\mathrm{mg} / \mathrm{kg})
\end{array}\right) \times 100
\end{aligned}
$$

The PBET $\mathrm{pH}$ of 1.5 simulates the most aggressive stomach digestive scenario, which is a condition indicative of human fasting. Conditions of higher $\mathrm{pH}$, as a result of food intake, would most likely decrease Cr bioaccessability even more profoundly than the results presented in the current study, thus offering a potential avenue for future research. Both Ruby et al. (1996) and Yang et al. (2002) found that soil Pb bioaccessibility was strongly $\mathrm{pH}$ dependent with soluble $\mathrm{Pb}$ decreasing profoundly over a $\mathrm{pH}$ range of 1.5 to 4.0.

\section{Chromium Analysis}

The PBET supernatant, soil spiking solution, and equilibrium solution were measured for $\mathrm{Cr}(\mathrm{VI})$ and total $\mathrm{Cr}\left(\mathrm{Cr}_{\mathrm{T}}\right)$.
Chromium(VI) was measured using a modified $s$-diphenylcarbohydrazide colormetric method (Bartlett and James, 1979) using a UV-VIS spectrophotometer at wavelength 540 $\mu \mathrm{m}$ (HP model 8453, Palo Alto, CA). Analysis of $\mathrm{Cr}(\mathrm{VI})$ was performed immediately on rapidly cooled PBET solutions to avoid possible reduction of $\mathrm{Cr}(\mathrm{VI})$ to $\mathrm{Cr}$ (III) by glycine (Jardine et al., 1999). Independent studies revealed that $\mathrm{Cr}(\mathrm{VI})$ reduction by glycine at $37^{\circ} \mathrm{C}$ and $1 \mathrm{~h}$ was insignificant. Total $\mathrm{Cr}$ was measured on a Perkin Elmer AAnalyst 800 atomic absorption spectrophotometer (Wellseley, PA). Standards were made using an atomic absorption Cr standard (EM Industries, Hawthorne, NY). Chromium(III) was calculated as the difference between $\mathrm{Cr}_{\mathrm{T}}$ and $\mathrm{Cr}(\mathrm{VI})$.

\section{Modeling}

A multiple regression technique in the statistical software package SigmaStat 2.0 (Jandel Scientific) was used to derive an expression that related $\mathrm{Cr}$ (III) sorption and bioaccessibility to common soil properties. The model was run using forward stepwise regression to determine the most salient soil properties for calculating sorption or bioaccessibility. Multiple linear regression was then employed to determine the linear equation to use when computing the $\mathrm{Cr}$ (III) sorption or bioaccessibility based on the important soil properties previously ascertained. 


\section{RESULTS AND DISCUSSION \\ Influence of Soil Properties on Chromium Sorption}

Chromium sorption (i.e., adsorption and surface precipitation) by the 35 soils varied markedly with values ranging from $736 \mathrm{mg} / \mathrm{kg}$ to $17460 \mathrm{mg} / \mathrm{kg}$ (Table 3). Sorption of $\mathrm{Cr}(\mathrm{III})$ was independent of horizon type where no distinct trend between A- and B-horizons was evident. The majority of the soils adsorbed between approximately $3000 \mathrm{mg} / \mathrm{kg}$ to approximately $6000 \mathrm{mg} /$ $\mathrm{kg}$ with four soils as high as approximately $18000 \mathrm{mg} /$ $\mathrm{kg}$. These four soils were all Aridisols and are noted for their high soil $\mathrm{pH}$ and for their high TIC content. Observed Cr(III) loading levels on many of these different soil types were similar to those measured on actual contaminated soils from the DoD sites. For example, actual contaminated Kzin soil (Xeric Torriorthents) from the Desert Chemical Depot contained $27000 \mathrm{mg}$ $\mathrm{Cr} / \mathrm{kg}$ soil. Artificially contaminated Kzin soils in this study contained approximately $18000 \mathrm{mg} \mathrm{Cr} / \mathrm{kg}$ soil.

The large contrast in $\mathrm{Cr}(\mathrm{III})$ sorption by the various

Table 3. Chromium(III) solid phase concentrations on the various soils and their corresponding bioaccessibility after 1 and $100 \mathrm{~d}$ aging.

\begin{tabular}{|c|c|c|c|}
\hline & $C_{\mathrm{T}}$ on soil & $\begin{array}{c}1 \text { day \% } \\
\text { Cr(III) bioaccessible }\end{array}$ & $\begin{array}{c}100 \text { day \% } \\
\text { Cr(III) bioaccessible }\end{array}$ \\
\hline Ultisol & mg/kg & & \\
\hline Allen A & 940.32 & 16.37 & 8.13 \\
\hline Allen Ba & 736.15 & 31.11 & 17.98 \\
\hline Cecil Ap & 1342.49 & 18.84 & 9.90 \\
\hline Cecil Bt1 & 2333.76 & 41.77 & 28.34 \\
\hline Minvale Ap & 2261.67 & 15.88 & 8.55 \\
\hline Minvale Bt1 & 1294.09 & 54.65 & 35.52 \\
\hline \multicolumn{4}{|l|}{ Alfisol } \\
\hline Lawrence Ap1 & 2586.96 & 26.03 & 11.62 \\
\hline Lawrence Bt1 & 2359.18 & 41.48 & 28.10 \\
\hline Angola Ap & 9408.00 & 32.40 & 16.58 \\
\hline Crider Ap & 3719.38 & 33.90 & 22.88 \\
\hline Crider B21t & 4247.30 & $\mathbf{5 0 . 3 0}$ & 32.35 \\
\hline Lenberg A & 8169.92 & 30.27 & 20.28 \\
\hline Lenberg Bt1 & 7254.84 & $\mathbf{5 0 . 8 9}$ & 41.63 \\
\hline \multicolumn{4}{|l|}{ Inceptisol } \\
\hline Berks A & 2275.20 & 18.77 & 7.67 \\
\hline Rockaway A1 & 2482.08 & 11.62 & 6.46 \\
\hline Rockaway B2t & 1525.58 & 32.96 & 22.36 \\
\hline Weikert Ap & 5561.77 & 12.21 & 5.62 \\
\hline Weikert Be & 3229.97 & 19.73 & 10.35 \\
\hline Montevello A & 5925.66 & 19.03 & $\mathbf{7 . 0 3}$ \\
\hline Montevello B & 2751.57 & 47.71 & 26.23 \\
\hline \multicolumn{4}{|l|}{ Spodosol } \\
\hline Charlton A2 & 1721.95 & 27.65 & 21.26 \\
\hline \multicolumn{4}{|l|}{ Mollisol } \\
\hline Dennis Ap & 3577.05 & 19.43 & 13.67 \\
\hline Dennis Ba & 3521.90 & 33.61 & 26.68 \\
\hline Sibley A & 4436.16 & 29.78 & 20.50 \\
\hline Sibley B1 & 4689.17 & 36.36 & 25.37 \\
\hline \multicolumn{4}{|l|}{ Aridisol } \\
\hline Doakum Ab & 2507.82 & 31.19 & 16.60 \\
\hline Doakum Bt & 5964.29 & 39.40 & 32.77 \\
\hline Kzin A2 & 16306.33 & 17.22 & 14.00 \\
\hline Kzin Bk & 12452.82 & 24.03 & 19.81 \\
\hline Oricto A2 & 17460.00 & 13.66 & 10.26 \\
\hline Oricto Bt & 15964.28 & 18.45 & 16.44 \\
\hline Stoneham A & 4377.44 & 29.27 & 18.97 \\
\hline Stoneham Bt1 & 4599.44 & 33.70 & 24.82 \\
\hline \multicolumn{4}{|l|}{ Entisol } \\
\hline Wakeland Ap & 4262.61 & 32.33 & 21.08 \\
\hline Wakeland Cg1 & 3802.32 & 37.68 & 24.79 \\
\hline
\end{tabular}

soils can be explained by the differences in soil properties. Multiple linear regression showed that four soil properties were important in determining the amount of Cr adsorbed by the soils: $\mathrm{pH}$, total inorganic carbon (TIC) content, clay content, and cation exchange capacity (CEC). The relationship describing $\mathrm{Cr}$ adsorption was:

$$
\begin{gathered}
\mathrm{Cr}(\mathrm{III})(\mathrm{mg} / \mathrm{kg} \text { on soil })=-12666.3+ \\
(113.8 \times \% \text { clay })+(364.6 \times \mathrm{CEC})+ \\
(1743.2 \times \% \mathrm{TIC})+(1916.7 \times \text { soil } \mathrm{pH})
\end{gathered}
$$

Chromium(III) sorption by the soils was strongly correlated with these soil properties $\left(r^{2}=0.794\right)$ suggesting that nearly $80 \%$ of the variability in $\mathrm{Cr}$ (III) sorption could be described by $\mathrm{pH}$, TIC, clay, and CEC (Table 4). Incorporating the other measured soil properties from Table 2 (e.g., Fe-oxide content, TOC, etc.) did not improve the model fit. In fact, TIC could have been removed from the model if necessary, since the other three independent soil variables could describe approximately $77 \%$ of the variability in $\mathrm{Cr}$ (III) sorption. The fourparameter model above was statistically rigorous at the $95 \%$ confidence level since $\mathrm{P}$ values for the independent variables were all $<0.05$ (Table 4 ). Thus, it can be concluded that the independent variables, the soil properties, significantly contribute to predicting the dependent variable, $\mathrm{Cr}$ sorption. The Variance inflation factor (VIF) also suggested that collinearity between independent variables was not significant (Table 4). Values for VIF that are 1.0 or slightly larger suggest that the variables do not show multicollinearity and that the parameter estimates are reliable. Collinearity becomes an issue when values of VIF exceed 4.0. This model also passed the Normality Test (indicating that the data was normally distributed) and the Constant Variance Test (suggesting that the variance of the dependent variables was constant). One of the most important criteria of a successful model, however, is the true physical significance of the model parameters. Our model suggests that $\mathrm{Cr}(\mathrm{III})$ sorption is enhanced by higher soil $\mathrm{pH}$, more TIC (i.e., carbonates), more clay, and higher CEC. For a sparingly soluble cation, such as $\mathrm{Cr}$ (III), these soil conditions should enhance sequestration as the model suggests.

The $\mathrm{pH}$ of the soil affects the solubility and form of $\mathrm{Cr}$ and therefore affects sorption. As the soil $\mathrm{pH}$ increases, the amount of $\mathrm{Cr}$ on the soil increases. At low $\mathrm{pH}, \mathrm{Cr}(\mathrm{III})$ is adsorbed or complexed on soil negative charges; at higher soil $\mathrm{pH}$ values, $>5.5, \mathrm{Cr}$ precipitates

Table 4. Parameter estimates, standard errors, and statistics obtained from a multiple linear regression analysis that related soil properties to $\mathbf{C r}$ (III) sorption. $\dagger$

\begin{tabular}{lcrrr}
\hline Parameter & Value & \multicolumn{1}{c}{ SE } & \multicolumn{1}{c}{$\boldsymbol{P}$} & VIF \\
\hline Intercept & -12666.3 & 1794.5 & $<0.001$ & - \\
\% Clay & 113.8 & 30.4 & $<\mathbf{0 . 0 0 1}$ & $\mathbf{1 . 1 1 9}$ \\
pH in DDI & 1916.7 & $\mathbf{2 5 0 . 7}$ & $<\mathbf{0 . 0 0 1}$ & $\mathbf{1 . 0 7 9}$ \\
CEC, cmol $/ \mathrm{kg}$ & $\mathbf{3 6 4 . 6}$ & $\mathbf{1 5 5 . 7}$ & $\mathbf{0 . 0 2 6}$ & $\mathbf{1 . 9 0 2}$ \\
\% TIC & $\mathbf{1 7 4 3 . 2}$ & $\mathbf{8 5 0 . 1}$ & $\mathbf{0 . 0 4 9}$ & $\mathbf{1 . 6 7 0}$ \\
$\boldsymbol{r}^{2}$ & $\mathbf{0 . 7 9 4}$ & & $<\mathbf{0 . 0 0 1}$ & \\
\hline
\end{tabular}

$\dagger$ DDI, double deionized; CEC, cation exchange capacity; TIC, total inorganic carbon; VIF, Variance Inflation Factor. 
as hydroxides covering the surface of the soil (Bartlett and Kimble, 1976). It was presumed by Bartlett and Kimble (1976) and James and Bartlett (1983) that the $\mathrm{Cr}(\mathrm{III})$ precipitit consisted of macromolecules with $\mathrm{Cr}$ ions in six coordination with water and hydroxy groups. Studies by Fendorf et al. (1994) and Fendorf and Sparks (1994), using x-ray adsorption spectroscopy (XAS), showed that with a low $\mathrm{Cr}$ (III) surface coverage the principle mechanism was adsorption with an inner-sphere monodentate complex on the silica. With increased surface coverage $(>20 \%)$, precipitation likely occurred and became the dominant sorption mechanism.

As with $\mathrm{pH}$, TIC or carbonate content in soils enhanced $\mathrm{Cr}$ (III) sorption. The mechanism of increased sequestration is most likely a localized $\mathrm{pH}$ effect at the carbonate surface, which promotes the formation of $\mathrm{Cr}(\mathrm{OH})_{3}$ species. The localized $\mathrm{pH}$ effect is the most plausible scenario since there was no correlation between soil $\mathrm{pH}$ and soil TIC, thus explaining why collinearity was not a problem for these parameters when the model was fit to the $\mathrm{Cr}$ (III) sorption data. Several acidic Inceptisols derived from interbedded limey shales and limestone have relatively large residual carbonate contents (Table 2), due to the slow dissolution of local scale dolomite, and this may serve to enhance $\mathrm{Cr}$ (III) sequestration in these systems, even though the overall bulk soil $\mathrm{pH}$ is acidic.

The model also shows a positive correlation between the amount of $\mathrm{Cr}$ adsorbed and the soil clay content and CEC. This was expected since clay minerals tend to be dominated by negatively charged sites on the surface due to isomorphic substitution (Klein and Hurlbut, 1993). These negatively charged sites attract the cation $\mathrm{Cr}^{3+}$ and a weak, electrostatic bond is formed. The more negatively charged sites that are available (i.e., larger CEC), the greater propensity for Cr(III) sorption. Further, clay minerals typically have a large surface area that is capable of accommodating large quantities of $\mathrm{Cr}^{3+}$ and $\mathrm{Cr}(\mathrm{OH})_{3}$ precipitated phases. The more surface area a soil has, the more reactive sites the soil has, and consequently the more $\mathrm{Cr}$ that will adsorb to the soil.

\section{Influences of Soil Properties on Chromium Bioaccessibility}

The bioaccessibility of $\mathrm{Cr}$ (III), as measured by the PBET method, varied widely as a function of soil type with most soils limiting bioaccessibility to $<45 \%$ and $<30 \%$ after 1 and $100 \mathrm{~d}$ soil-Cr aging, respectively (Table 3, Fig. 1a-e). Bioaccessibility values were consistently higher for $1 \mathrm{~d}$ aging vs. $100 \mathrm{~d}$ aging. For all soils the percent bioaccessibility ranged from 3.0 to $54.7 \%$ at Day 1 and 1.5 to $35.5 \%$ at 100 d (Table 3, Fig. 1a-e). The aging effect is related to the enhanced stability of $\mathrm{Cr}$ on the soil surface with time. Structural reorientation of $\mathrm{Cr}$ surface bonds or slow precipitation reactions can account for the stronger sorption of $\mathrm{Cr}$ at longer times (Karthein et al., 1991). Previous studies by Stewart et al. (2003) have shown that aging effects are insignificant after $100 \mathrm{~d}$ and that the $100 \mathrm{~d}$ data are most relevant to actual DoD-contaminated soils. In general, the A-horizon soils had the lowest percent bioaccessible values, even when they adsorb more $\mathrm{Cr}$ (III) on the soil vs. the B horizons (Table 3). Bioaccessibility did not appear to be a function of soil order, suggesting that detailed soil series data, as is used in the current study, was necessary for predictive purposes (Table 3, Fig. 1a-e). Chromium(VI) was also measured in the PBET extractant to monitor for oxidation of $\mathrm{Cr}(\mathrm{III})$ to $\mathrm{Cr}(\mathrm{VI})$. The proportion of bioaccessible $\mathrm{Cr}$ that was $\mathrm{Cr}(\mathrm{VI})$ was always $<1 \%$, suggesting that oxidation reactions were minimal or that any oxidation products of $\mathrm{Cr}(\mathrm{VI})$ were tightly held by the soil. These results are consistent with the data presented by Stewart et al. (2003), which showed limited bioaccessibility of $\mathrm{Cr}(\mathrm{VI})$ in several soils.

As demonstrated by Stewart et al. (2003), bioaccessibility values leveled off and reached near equilibrium after the first 50 to $100 \mathrm{~d}$. Thus, the $100 \mathrm{~d}$ bioaccessibility data is most appropriate for use in the modeling endeavor. Stepwise multiple regression indicated two combinations of variables considered instrumental in predicting the bioaccessibility of $\mathrm{Cr}$ (III) in soils: (i) \% clay and \% TIC and (ii) \% clay and \% TOC. Using the independent variables from Table 2 , the most significant model revealed that the bioaccessibility of $\mathrm{Cr}$ (III) on the soils was correlated with clay and TIC of the soil (Table 5). The relationship describing $\mathrm{Cr}$ (III) bioaccessibility was:

$$
\begin{aligned}
& \text { \% Cr(III) bioaccessible }= \\
& 16.02+(0.426 \times \% \text { clay })-(9.56 \times \% \text { TIC })
\end{aligned}
$$

with an $r^{2}$ value of 0.722 , which indicated that as much as $72 \%$ of the variability in Cr bioaccessibility was explained by the model (Fig. 2). The model was statistically rigorous at the $99 \%$ confidence level since $\mathrm{P}$ values for the independent variables were well below 0.01 , indicating that they all contributed to predicting the \% bioaccessible $\mathrm{Cr}$ (III) (Table 5). Values for VIF were all nearly 1.000 , indicating that there was no redundant information in the other independent variables, i.e., soil properties, and that collinearity between independent variables was not of concern. This indicated that parameter estimates in the model were reliable, which is in agreement with the low standard errors on the estimated values (Table 5). The model also passed the Normality Test and the Constant Variance Test, suggesting that the data was normally distributed around the regression line and that the variance present in the dependent variable is constant. Most important, however, is the true physical significance of the model parameters. The model suggests that $\mathrm{Cr}$ (III) bioaccessibility decreases as the TIC content increases and as the clay content decreases. As shown with the Cr sorption data, $\mathrm{Cr}$ (III) sequestration is enhanced by soils with high levels of TIC. The presence of TIC promotes the formation of solid phase $\mathrm{Cr}(\mathrm{III})$ - hydroxides that are sparingly soluble, even under acidic conditions. These hydroxides [i.e., $\mathrm{Cr}(\mathrm{OH})_{3}$ ] precipitate and cover the surface of the soil and are not easily bioaccessible even in the presence of the low $\mathrm{pH}$ in the simulated stomach fluid of the PBET. Conse- 

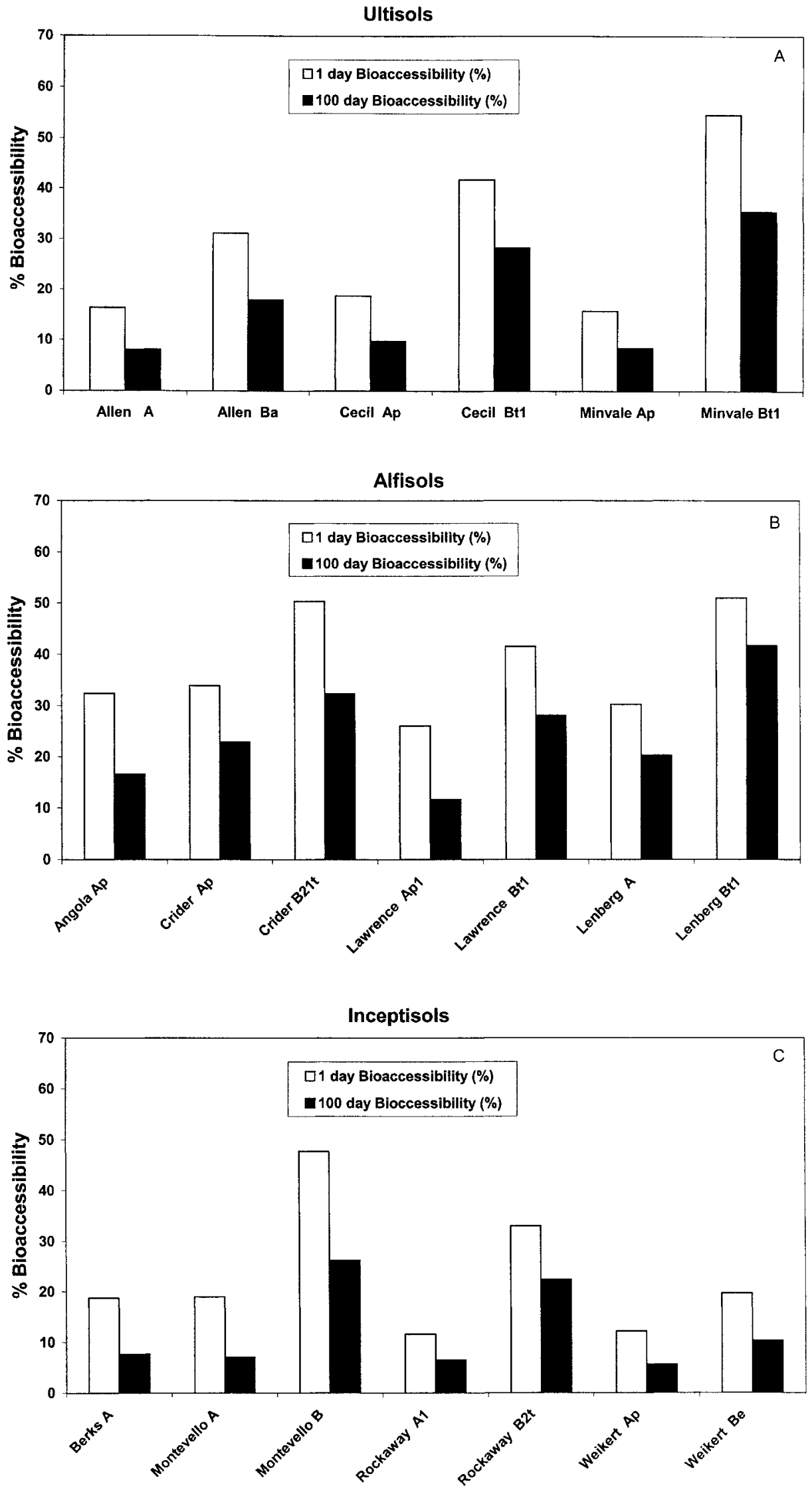

Fig. 1. Percentage Cr(III) bioaccessibility after 1 and 100 d Cr-soil aging for (a) Ulitisols; (b) Alfisols; (c) Inceptisols; (d) Spodosols, Mollisols, Entisols; and (e) Aridisols. 

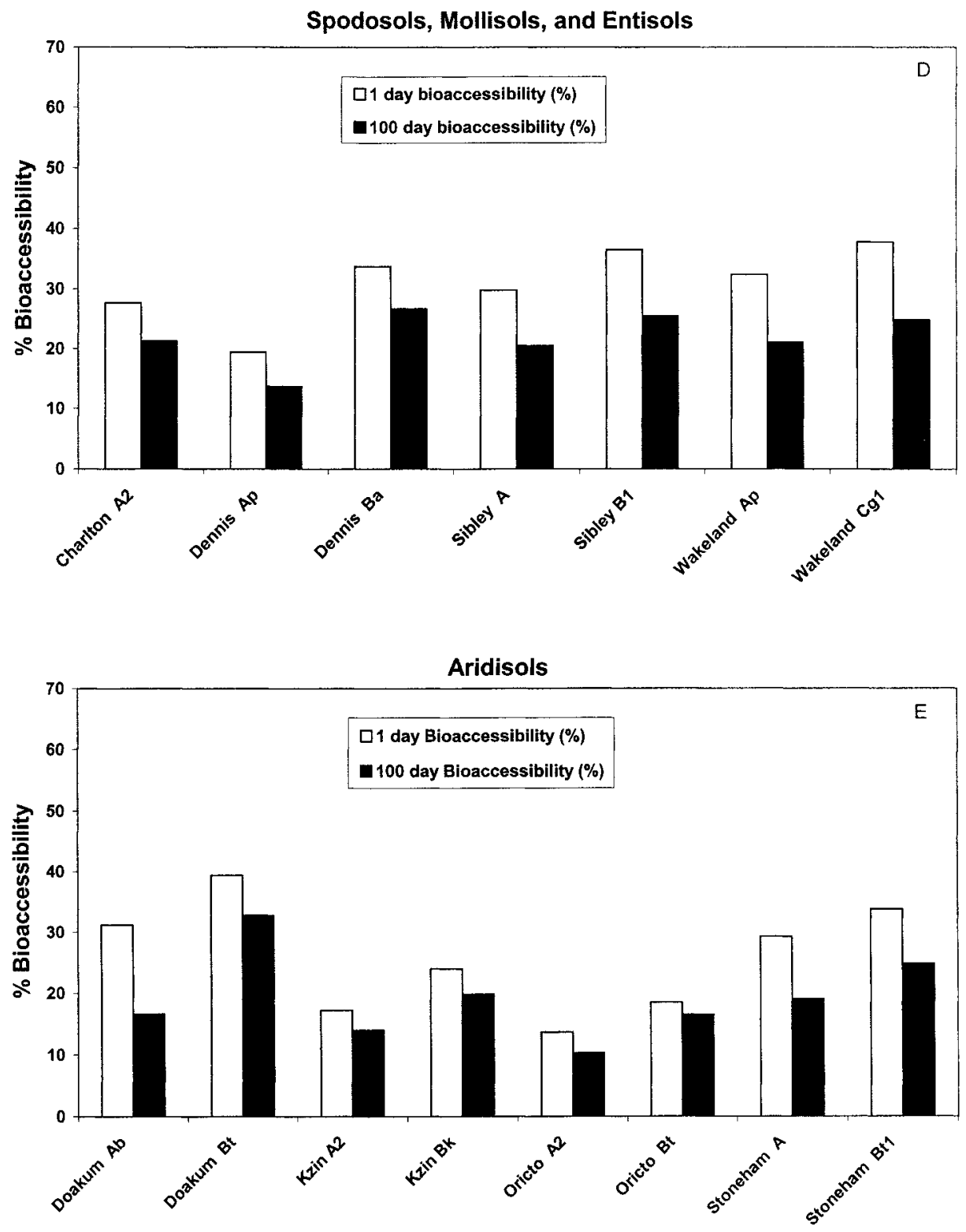

Fig. 1. Continued.

quently as the TIC content increases the bioaccessibility of $\mathrm{Cr}$ (III) in soil decreases. As shown with the Cr sorption data the clay content on the soil was also correlated with the amount of $\mathrm{Cr}$ sequestration and thus should be important in determining bioaccessibility. The bioaccessibility model suggested that, as the clay content of the soils increased, the percent of $\mathrm{Cr}$ on the soil that is bioaccessible also increased. Since the mechanism of $\mathrm{Cr}$ retardation on clay minerals is primarily weak electrostatic bonds, these bonds are easily broken under the conditions of the PBET, allowing $\mathrm{Cr}$ to desorb from the soil and be released into solution during the simulated digestion.

Stepwise multiple regression analysis also indicated that $\mathrm{Cr}$ (III) bioaccessibility was significantly correlated with clay and TOC content of the soil (Table 6). The relationship describing $\mathrm{Cr}(\mathrm{III})$ bioaccessibility was:
$\% \mathrm{Cr}(\mathrm{III})$ bioaccessible $=$

$$
15.54+(0.408 \times \% \text { clay })-(3.78 \times \% \text { TOC })
$$

with an $r^{2}$ value of 0.674 . This relationship was similar to the clay/TIC model where higher quantities of TIC and TOC resulted in decreased $\mathrm{Cr}$ (III) bioaccessibility. When clay, TIC, and TOC were used in the same model, the contribution of TOC was not significant at the $90 \%$

Table 5. Parameter estimates, standard errors, and statistics obtained from a multiple linear regression analysis that related soil properties (clay and TIC) to percent $\mathrm{Cr}$ (III) bioaccessibility. $\dagger$

\begin{tabular}{lcllc}
\hline Parameter & Value & \multicolumn{1}{c}{ SE } & \multicolumn{1}{c}{$\boldsymbol{P}$} & VIF \\
\hline Intercept & $\mathbf{1 6 . 0 2}$ & $\mathbf{1 . 9 9}$ & $<\mathbf{0 . 0 0 1}$ & - \\
\% Clay & $\mathbf{0 . 4 2 6}$ & $\mathbf{0 . 0 6 7 1}$ & $<\mathbf{0 . 0 0 1}$ & $\mathbf{1 . 0 0 2}$ \\
\% TIC & $-\mathbf{9 . 5 6}$ & $\mathbf{1 . 5 4}$ & $<0.001$ & $\mathbf{1 . 0 0 2}$ \\
$\boldsymbol{r}^{2}$ & $\mathbf{0 . 7 2 2}$ & & $<\mathbf{0 . 0 0 1}$ & \\
\hline
\end{tabular}

$\dagger$ TIC, total inorganic carbon; VIF, Variance Inflation Factor. 


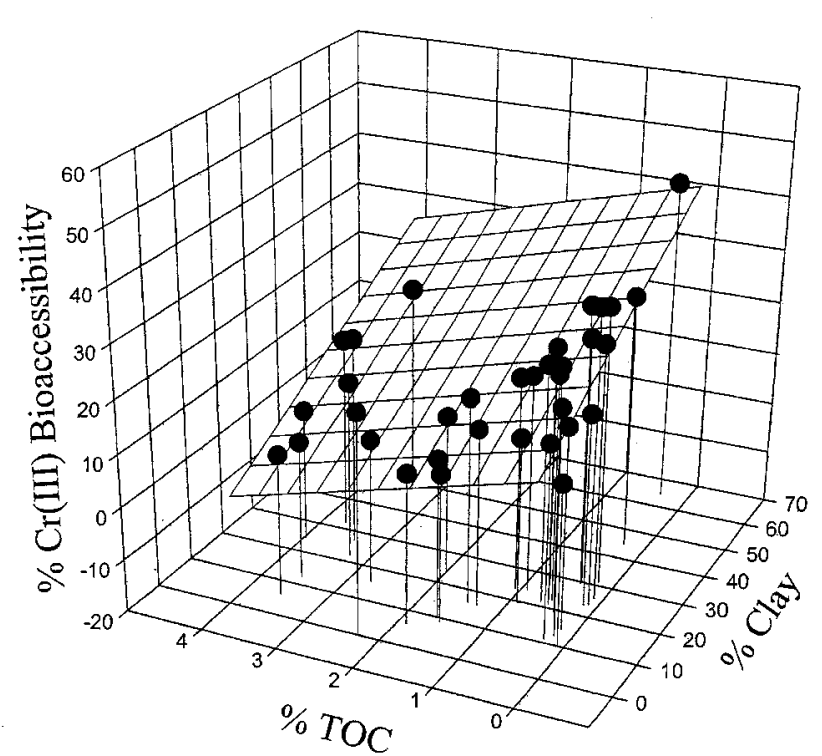

Fig. 2. The observed (data points) and model fitted (grid surface) relationship between the two most significant independent variables (\% clay and TIC) and \% $\mathrm{Cr}$ (III) bioaccessibility using the model: \% $\mathrm{Cr}$ (III) bioaccessible $=16.02+(0.426 \times \%$ clay $)-$ $\left(9.56 \times \%\right.$ TIC) an $r^{2}$ value of 0.722 .

confidence level $(P=0.115)$. This scenario may be an artifact of our limited data set, where the most appropriate model, in fact, includes both TIC and TOC along with clay content. A more extensive data set will be necessary to test this hypothesis. Nevertheless, the model using clay and TOC was statistically rigorous at the $99 \%$ confidence level since $\mathrm{P}$ values for the estimated parameters were $<0.01$ and the VIF values are approximately 1.000 , indicating that the variables all contribute significantly to the equation and that no multicollinearity was present among the independent variables. This model passed the Normality Test and the Constant Variance Test. The model suggested that as the clay content decreased and the TOC content increased, the \% Cr(III) bioaccessible decreased (Fig. 3). The trend regarding clay content is consistent with the previous model and the limited bioaccessibility of $\mathrm{Cr}$ in the presence of higher system organic $\mathrm{C}$ is conceptually correct. Organic matter found in soil is a major contributor to the overall negative charge in soils and thus is an important sorbent for heavy metal cations (Sparks, 1995). Organic matter has the ability to form strong bonds with the $\mathrm{Cr}$ (III) with the metal not readily released during the PBET process. As $\mathrm{Cr}$ (III) is considered a Lewis hard acid, it forms stable complexes with the carboxyl group of the organic matter (Sparks, 1995). These bonds are stable

Table 6. Parameter estimates, standard errors, and statistics obtained from a multiple linear regression analysis that related soil properties (clay and TOC) to percent $\mathrm{Cr}$ (III) bioaccessibility. $\dagger$

\begin{tabular}{lcccc}
\hline Parameter & Value & SE & $\boldsymbol{P}$ & VIF \\
\hline Intercept & $\mathbf{1 5 . 5 4}$ & $\mathbf{2 . 1 6}$ & $<0.001$ & - \\
\% Clay & $\mathbf{0 . 4 0 8}$ & $\mathbf{0 . 0 7 3}$ & $<\mathbf{0 . 0 0 1}$ & $\mathbf{1 . 0 1 0}$ \\
\% TOC & $-\mathbf{3 . 7 8}$ & $\mathbf{0 . 7 1 1}$ & $<\mathbf{0 . 0 0 1}$ & $\mathbf{1 . 0 1 0}$ \\
$\boldsymbol{r}^{2}$ & $\mathbf{0 . 6 7 4}$ & & $<\mathbf{0 . 0 0 1}$ & \\
\hline
\end{tabular}

$\dagger$ TOC, total organic carbon; VIF, Variance Inflation Factor.

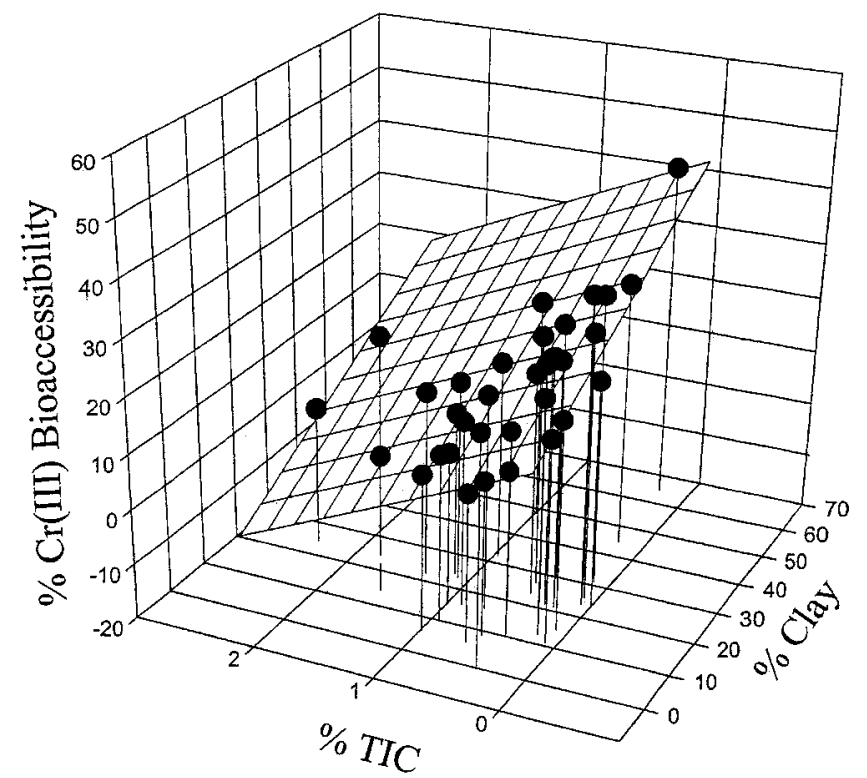

Fig. 3. The observed (data points) and model fitted (grid surface) relationship between the two independent variables ( $\%$ clay and TOC) and \% $\mathrm{Cr}$ (III) bioaccessibility using the model: \% $\mathrm{Cr}$ (III) bioaccessible $=15.54+(0.408 \times \%$ clay $)-(3.78 \times \%$ TOC $)$ with an $r^{2}$ value of 0.674 .

and not easily broken. The current model again explains more than $67 \%$ of the variability in Cr(III) bioaccessibility and should be useful for soils low in carbonate (TIC).

\section{ENVIRONMENTAL SIGNIFICANCE}

This study has shown that site assessments of soil metal bioaccessibility based solely on total soil metal concentrations may not accurately reflect the risk posed by the soils. The sequestering properties of soil significantly lower the percent of $\mathrm{Cr}$ bioaccessible upon ingestion of the otherwise labile Cr. Chromium(III) can be immobilized as strongly bound species on clay and organic matter, and $\mathrm{Cr}-$ hydroxide precipitates on soil mineral surfaces. It has been shown that common soil properties are strongly correlated with $\mathrm{Cr}$ (III) bioaccessibility. The availability of these soil properties is commonplace (e.g., NRCS database), which allows the percent bioaccessibility of $\mathrm{Cr}$ (III) to be estimated for a variety of contaminated sites whose remediation is pending. The ability to rapidly assess metal bioaccessibility in soils will facilitate decision making strategies regarding the need for more detailed and expensive sitespecific bioavailability (e.g., animal feeding) studies, which are designed to assess actual clean-up needs at contaminated DoD sites and other sites to a level safe for human use. Such in vivo studies are lacking with regard to $\mathrm{Cr}$, but research in this area is currently underway (M.V. Ruby, personal communication, 2002).

\section{ACKNOWLEDGMENTS}

We appreciate the efforts of Ms. Cathy Vogel and Dr. Andrea Leeson, the contract officers for the U.S. DoD who supported this work and the efforts of Mr. Warren Lynn of the National Resource Conservation Service (NRCS) who provided us with most of the soils for this study. 


\section{REFERENCES}

Bartlett, R., and B. James. 1979. Behavior of chromium in soils: III. Oxidation. J. Environ. Qual. 8:31-35.

Bartlett, R.J., and J.M. Kimble. 1976. Behavior of chromium in soils: I. Trivalent forms. J. Environ. Qual. 5:379-383.

Chung, J., R.J. Zasoski, and S. Lim. 1994. Kinetics of chromium(III) oxidation by various manganese oxides. Korean J. Agric. Chem. Biotechnol. 37:414-420.

Davis, S., P. Waller, R. Buschbom, J. Ballow, and P. White. 1990. Quantitative estimates of soil ingestion in normal children between the ages of 2 and 7 years. Population-based estimates using aluminum, silicon, and titanium as soil tracer elements. Arch. Environ. Health 45:112-122.

Dragun, J. 1998. The soil chemistry of hazardous materials. Amherst Scientific Publ., Amherst, MA.

Fendorf, S.E., M. Fendorf, D.L. Sparks, and R. Gronsky. 1992. Inhibitory mechanisms of $\mathrm{Cr}(\mathrm{III})$ oxidation by $\delta-\mathrm{MnO}_{2}$. J. Colloid Interface Sci. 153:37-54

Fendorf, S.E., G.M. Lamble, M.G. Stapleton, M.J. Kelly, and D.L. Sparks. 1994. Mechanisms of chromium (III) sorption on silica: I $\mathrm{Cr}$ (III) surface structure derived by extended x-ray adsorption fine structure spectroscopy. Environ. Sci. Technol. 28:284-289.

Fendorf, S.E., and D.L. Sparks. 1994. Mechanisms of chromium (III) sorption on silica: II. Effects of reaction conditions. Environ. Sci. Technol. 28:290-297.

Fendorf, S.E., and R.J. Zasoski. 1992. Chromium(III) oxidation by $\delta-\mathrm{MnO}_{2}$ : I. Characterization. Environ. Sci. Technol. 26:79-85.

Gargas, M.L., R.L. Norton, M.A. Harris, D.J. Paustenbach, and B.L. Finley. 1994. Urinary excretion of chromium following ingestion of chromite-ore processing residues in humans: Implications for biomonitoring. Risk Anal. 14:1019-1024.

Hamel, S.C., B. Buckley, and P.J. Lioy. 1998. Bioaccessibility of metals in soils for different liquid to solid ratios in synthetic gastric fluid. Environ. Sci. Technol. 32:358-362.

James, B.J., and R.J. Bartlett. 1983. Behavior of chromium in soils: VII. Adsorption and reduction of hexavalent forms. J. Environ. Qual. 12:177-181

Jardine, P.M., S.E. Fendorf, M.A. Mayes, S.C. Brooks, and W.B Bailey. 1999. Fate and transport of hexavalent chromium in undisturbed heterogeneous soil. Environ. Sci. Technol. 33:2939-2944.

Karthein, R., M. Motschi, A. Schweiger, S. Ibric, B. Sulzberger, and W. Stumm. 1991. Interactions of chromium(III) complexes with hydrous delta- $\mathrm{Al}_{2} \mathrm{O}_{3}$ rearrangements in the coordination sphere studied by electron-spin-resonance and electron spin-echo spectroscopies. Inorg. Chem. 30:1606-1611.

Klein, C., and C. Hurlbut, Jr. 1993. Manual of mineralogy. 21st ed. Wiley, New York.

Levis, A.G., and V. Bianchi. 1982. Mutagenic and cytogenic effects of chromium compounds. p. 171-208. In S. Langjard (ed.) Biological and environmental aspects of chromium. Elsevier Biomedical Press, New York.

Linz, D.G., and D.V. Nakles (ed.) 1997. Environmentally acceptable endpoints in soil. Am. Academy of Environ. Eng., New York.

Losi, M.E., C. Amrhein, and W.T. Frankenberger, Jr. 1994. Bioremedi- ation of chromate-contaminated groundwater by reduction and precipitation in surface soils. J. Environ. Qual. 23:1141-1150.

Mehra, O.P., and M.L. Jackson. 1960. Iron oxide removed from soils and clays by a diothionite-citrate system buffered with sodium bicarbonate. Clays Clay Miner. 7:317-327.

Nriagu, J.O., and E. Nieboer. 1988. Chromium in the natural and human environments. John Wiley \& Sons, New York.

Patterson, R.R., S. Fendorf, and M. Fendorf. 1997. Reduction of hexavalent chromium by amorphous iron sulfide. Environ. Sci. Technol. 31:2039-2044.

Paustenbach, D.J. (ed.) 1989. The risk assessment of environmental and human health hazards: A textbook of case studies. John Wiley \& Sons, New York.

Proctor, D.M., E.C. Shay, and P.K. Scott. 1997. Health-based soil action levels for trivalent and hexavalent chromium: A comparison with state and federal standards. J. Soil Contam. 6:595-648.

Rodriguez, R.R., N.T. Basta, S.W. Casteel, and L.W. Pace. 1999. An in vitro gastrointestinal method to estimate bioavailable arsenic in contaminated soils and solid media. Environ. Sci. Technol. 33:642649.

Ruby, M.V., A. Davis, R. Schoof, S. Eberle, and C.M. Sellstone. 1996 Estimation of lead and arsenic bioavailability using a physiologically based extraction test. Environ. Sci. Technol. 30:422-430.

Ruby, M.V., R. Schoof, W. Brattin, M. Goldade, G. Post, M. Harnois, D.E. Mosby, S.W. Casteel, W. Berti, M. Carpenter, D. Edwards, D. Cragin, and W. Chappell. 1999. Advances in evaluating the oral bioavailability of inorganics in soil for use in human health risk assessment. Environ. Sci. Technol. 33:3697-3705.

Sheehan, P.J., D.M. Meyer, M.M. Sauer, and D.J. Paustenbach. 1991. Assessment of the human health risks posed by exposure to chromium contaminated soils. J. Toxicol. Environ. Health 32:161-201.

Sheppard, S.C., W.G. Evanden, and W.J. Achwartz. 1995. Ingested soil: Bioavailability of sorbed lead, cadmium, iodine, and mercury. J. Environ. Qual. 24:498-505.

Skowronski, G.A., M. Seide, and M.S. Abdel-Rahman. 2001. Oral bioaccessibility of trivalent and hexavalent chromium in soil by simulated gastric fluid. J. Toxicol. Environ. Health Part A 63:351-362.

Sparks, D.L. 1995. Environmental soil chemistry. Academic Press, New York.

Stewart, M.A., P.M. Jardine, M.O. Barnett, L.D. McKay, T.L. Mehlhorn, S.E. Fendorf, and K. Paul. 2003. Effects of contaminant concentration, aging, and soil properties on the bioaccessibility of $\mathrm{Cr}(\mathrm{III})$ and $\mathrm{Cr}(\mathrm{VI})$ contaminated soil. Soil Sediment Contam. (in press).

U.S. Environmental Protection Agency. 1996. USEPA Method 3052. Microwave assisted acid digestion of siliceous and organically based matrices. [Online.] [20 p.] http://www.epa.gov/epaoswer/hazwaste/ test/pdfs/3052.pdf. USEPA, Washington, DC.

Witmer, C.M., R. Harris, and S.I. Shupack. 1991. Oral bioavailability of chromium from a specific site. Environ. Health Perspect. 92: $105-110$

Witmer, C.M., H.S. Park, and S.I. Shupack. 1989. Mutagenicity and disposition of chromium. Sci. Total Environ. 86:131-138.

Yang, J.K., M.O. Barnett, P.M. Jardine, and S.C. Brooks. 2002. Factors controlling the bioaccessibility of arsenic(V) and lead(II) in soil. Soil Sediment Contam. (In press). 


\section{APPENDIX C}

YANG, J-K., M.O. BARNETT, P.M. JARDINE, N.T. BASTA, AND S.W. CASTEEL. 2002. ADSORPTION, SEQUESTRATION, AND BIOACCESSIBILITY OF AS(V) IN SOILS. ENVIRONMENTAL SCIENCE AND TECHNOLOGY. 36:4562-4569. 


\title{
Adsorption, Sequestration, and Bioaccessibility of As(V) in Soils
}

\author{
Jae-Kyu Yang, $†$ Mark O. Barnett, *† Philip M. Jardine, $₫$ Nicholas T. Basta,, and \\ Stan W. Casteel $\perp$ \\ Department of Civil Engineering, 238 Harbert Engineering Center, Auburn University, \\ Auburn, Alabama 36849, Environmental Sciences Division, Oak Ridge National \\ Laboratory, P.O. Box 2008, Oak Ridge, Tennessee 37831, Department of Plant and Soil \\ Sciences, Oklahoma State University, Stillwater, Oklahoma 74078, and Veterinary \\ Medical Diagnostic Laboratory, University of Missouri-Columbia, Columbia, Missouri \\ 65211
}

Received for review December 30, 2001

Revised manuscript received August 12, 2002

Accepted August 21, 2002

\begin{abstract}
:
The influence of various soil physical and chemical properties (Fe and $\mathrm{Mn}$ oxides, $\mathrm{pH}$, cation exchange capacity, total inorganic and organic carbon, and particle size) on As(V) adsorption, sequestration, and relative bioaccessibility (as a surrogate for oral bioavailability) was investigated in a wide range of well-characterized soils over a 6month period. Arsenic(V) bioaccessibility was measured using a streamlined version of a physiologically based extraction test (PBET), designed to replicate the solubility-limiting conditions in a child's digestive tract. The soil's dithionite-citrate-bicarbonate (DCB) extractable Fe oxide content was the most important (and only statistically significant) soil property controlling the initial degree of adsorption. Sequestration, as measured by the reduction in bioaccessibility over time, occurred to a significant extent in 17 of 36 $(47.2 \%)$ soils over the first 3 months. In contrast, only 4 of $36(11.1 \%)$ soils exhibited a significant reduction in bioaccessibility from 3 to 6 months. Soil $\mathrm{pH}$ was the most important (and only statistically significant) soil property affecting the decrease in bioaccessibility upon aging for 6 months. Soils with $\mathrm{pH}<6$ generally sequestered As(V) more strongly over time, whereas those with $\mathrm{pH}>6$ generally did not. The Fe oxide content and $\mathrm{pH}$ were the most important soil properties governing the steady-state bioaccessibility of As( $\mathrm{V})$ in soil. Two multivariable linear regression models of steadystate $\mathrm{As}(\mathrm{V})$ bioaccessibility were developed using soil properties as independent variables. Generally, soils having higher Fe oxide content and lower soil $\mathrm{pH}$ exhibited lower bioaccessibility. These models were able to account for $\sim 75-80 \%$ of the variability in steady-state bioaccessibility and independently predict bioaccessibility in five soils within a root-mean-square error (RMSE) of 8.2-10.9\%. One of these models was also able to predict within an RMSE of $9.5 \%$ the in vivo bioavailability of As in nine contaminated soils previously used in swine dosing trials. These results indicate the
\end{abstract}


bioaccessibility, and thus, potentially the bioavailability of otherwise soluble As(V) added to soils (i.e., the worst-case bioavailability scenario) is significantly reduced in some soils over time, particularly those with lower $\mathrm{pH}$ and higher Fe oxide content. These results also provide a means of estimating $\mathrm{As}(\mathrm{V})$ bioaccessibility and bioavailability on the basis of soil properties.

DOI: $\underline{10.1021 / \mathrm{es} 011507 \mathrm{~s}}$

Reprints are available from:

http://pubs3.acs.org/acs/journals/doilookup?in_doi=10.1021/es011507s

or contact Philip Jardine at jardinepm@ornl.gov 


\section{APPENDIX D}

STEWART, M.A., P.M. JARDINE, C.C. BRANDT, M.O. BARNETT, S.E. FENDORF, L.D. MCKAY, T.L. MEHLHORN AND K. PAUL. 2003b. EFFECTS OF CONTAMINANT CONCENTRATION, AGING, AND SOIL PROPERTIES ON THE BIOACCESSIBILITY OF CR(III) AND CR(IV) IN SOIL. SOIL AND SEDIMENT CONTAMINATION. 12:1-21. 


\section{Effects of Contaminant Concentration, Aging, and Soil Properties on the Bioaccessibility of $\mathrm{Cr}(\mathrm{III})$ and $\mathrm{Cr}(\mathrm{VI})$ in Soil ${ }^{*}$}

M. A. Stewart, ${ }^{1}$ P. M. Jardine, ${ }^{1 *} C$. C. Brandt, ${ }^{1}$ M. O. Barnett, ${ }^{2}$ S. E. Fendorf, ${ }^{3}$ L. D. McKay, ${ }^{4}$ T. L. Mehlhorn, ${ }^{1}$ and K. Paul ${ }^{1}$

${ }^{1}$ Environ. Sci. Div., Oak Ridge National Lab., P.O. Box 2008, Oak Ridge, TN 37831-6038; ${ }^{2}$ Dept. of Civil Engineering, 208 Harbert Engineering Center, Auburn Univ., AL 368495337; '3Stanford Univ., Dept. Geol. and Environ. Sci., Stanford, CA 94305; ${ }^{4}$ Dept. of Geological Sciences, Univ. of Tennessee, Knoxville, TN 37996-1410

Contaminated soils at numerous U.S. Department of Defense, Department of Energy, and other industrial facilities often contain huge inventories of toxic metals such as chromium. Ingestion of soil by children is often the primary risk factor that drives the need for remediation. Site assessments are typically based solely on total soil-metal concentrations and do not consider the potential for decreased bioaccessibility due to metal sequestration by soil. The objectives of this research are to investigate the effect of soil properties on the bioaccessibility of $\mathrm{Cr}(\mathrm{III})$ and $\mathrm{Cr}(\mathrm{VI})$ as a function of contaminant concentration and aging. The $A$ and upper $B$ horizons of two well-characterized soils, representative of Cr-contaminated soils in the southeastern United States, were treated with varying concentration of $\mathrm{Cr}(\mathrm{III})$ and $\mathrm{Cr}(\mathrm{VI})$ and allowed to age. The bioaccessibility of the contaminated soils was measured over a 200-d time period using a physiologically based extraction test (PBET) that was de- signed to simulate the digestive process of the stomach. The sorption of $\mathrm{Cr}$ (III) and $\mathrm{Cr}(\mathrm{VI})$ varied significantly as a function of soil type and horizon, and the oxidation state of the contaminant. Solid phase concentrations with $\mathrm{Cr}(\mathrm{III})$ were significantly greater than $\mathrm{Cr}(\mathrm{VI})$ for any given initial $\mathrm{Cr}$ concentration. This is consistent with the mechanisms of $\mathrm{Cr}(\mathrm{III})$ vs. Cr(VI) sequestration by the soils, where the formation of Cr(III)-hydroxides can result in the accumulation of large mass fractions of contaminant on mineral surfaces. Overall, $\mathrm{Cr}$ bioaccessibility decreased with duration of exposure for all soils and at all solid phase concentrations, with aging effects being more pronounced for $\mathrm{Cr}$ (III). The decrease in $\mathrm{Cr}$ bioaccessibility was rapid for the first $50 \mathrm{~d}$ and then slowed dramatically between 50 and $200 \mathrm{~d}$. In general, the effects of Cr solid phase concentration on bioaccessibility was small, with $\mathrm{Cr}(\mathrm{III})$ showing the most pronounced effect; higher solid phase concentrations resulted in a decrease in bioaccessibility. Chemical extraction methods and X-ray Adsorption Spectroscopy analyses suggested that the bioaccessibility of $\mathrm{Cr}(\mathrm{VI})$ was significantly influenced by reduction processes catalyzed by soil organic carbon. Soils with sufficient organic carbon had lower $\mathrm{Cr}$ bioaccessibility values ( 10 to $20 \%$ ) due to an enhanced reduction of $\mathrm{Cr}(\mathrm{VI})$ to $\mathrm{Cr}(\mathrm{III})$. In soils where organic carbon was limited and reduction processes were minimal, the bioaccessibility of $\mathrm{Cr}(\mathrm{VI})$ dramatically increased $(\sim 60$ to $70 \%)$.

\footnotetext{
* This research was sponsored by the U.S. Department of Defense (DoD) Strategic Environmental Research and Development Program. Oak Ridge National Lab is managed by the University of Tennessee - Battelle LLC, under contract DE - AC05 - 00OR22725 with the U.S. Department of Energy.

** Corresponding author (jardinepm@ornl.gov).
}

$1532-0383 / 03 / \$ .50$

(C) 2003 by AEHS 
Key Words: metal bioavailability, metal sequestration by soil, redox transformations, $X$-ray absorption spectroscopy.

\section{INTRODUCTION}

$C_{1}$ hromium is used in many industrial processes, including electroplating, leather tanning, pulp production, and wood preservation, and, consequently, can be found throughout the environment (Nriagu and Nieboer, 1988). There are two main oxidation states of chromium found in the environment, anionic $\mathrm{Cr}(\mathrm{VI})$ and cationic $\mathrm{Cr}(\mathrm{III})$. The two forms of chromium have distinct behaviors in subsurface environments. The anionic $\mathrm{Cr}(\mathrm{VI})$ is considered to be highly mobile in soils, while the $\mathrm{Cr}$ (III) cation is believed to be significantly less mobile (Chung et al., 1994; Fendorf et al., 1997; Jardine et al., 1999). In regards to human health, the two forms of $\mathrm{Cr}$ also have major differences, with $\mathrm{Cr}(\mathrm{VI})$ considered carcinogenic and mutagenic even at low concentrations, while $\mathrm{Cr}$ (III) is considered potentially harmful only at high concentrations (Levis and Bianchi, 1982).

Human health is the usual risk driver that motivates the likelihood of remediation at Cr-contaminated sites. The exposure pathway of concern is usually the ingestion of contaminated soil, especially by children who traditionally have greater handto-mouth contact (Paustenbach, 1989; Davis et al., 1990; Sheehan et al., 1991; Skowronski et al., 2001). U.S. EPA soil action levels for $\mathrm{Cr}(\mathrm{III})$ and $\mathrm{Cr}(\mathrm{VI})$ are 78,000 and $390 \mathrm{mg} / \mathrm{kg}$, respectively, which are protective of soil-ingestion exposures for children in residential sites. However, certain states within the U.S. have designated action levels as low as 310 and $0.2 \mathrm{mg} / \mathrm{kg}$ for $\mathrm{Cr}(\mathrm{III})$ and $\mathrm{Cr}(\mathrm{VI})$, respectively (Proctor et al., 1997). When regulators establish clean-up criteria for chromium-contaminated soils, the ubiquitous metal-sequestering properties of the soils are typically not taken into account (Proctor et al., 1997). Instead, the standards are generally universal for all soils and are usually based on that of a soluble salt of the metal and the assumption that $100 \%$ of metal present will be absorbed into the body (Ruby et al., 1999). In order to accurately access the health risk posed by metal-contaminated sites, an improved understanding of the influence of soil sequestration on the bioaccessibility of $\mathrm{Cr}$ is needed, where bioaccessibility is defined as that amount of contaminant, which is soluble due to gastric function and has the potential to cross the intestinal wall (Hamel et al., 1998).

Chromium adsorption in soil occurs under different conditions based on the oxidative state of the $\mathrm{Cr}$ ion. $\mathrm{The} \mathrm{Cr}$ anion, $\mathrm{Cr}(\mathrm{VI})$, generally adsorbs to positively charged mineral surfaces via electrostatic attraction. Thus, conditions of decreasing $\mathrm{pH}$ result in enhanced adsorption of $\mathrm{Cr}(\mathrm{VI})$ (Zachara et al., 1989). Surfaces with proton specific sites, particularly iron oxides, are mostly responsible for Cr(VI) adsorption (Davis and Leckie, 1980; Zachara et al., 1987, 1988). Factors 
interfering with $\mathrm{Cr}(\mathrm{VI})$ adsorption include the presence of $\mathrm{SO}_{4}{ }^{2-}$, the presence of dissolved inorganic carbon (DIC), and $\mathrm{Al}$ substitution for $\mathrm{Fe}$ in oxides. With a limited number of positive surface sites in soil, there is often competition from $\mathrm{SO}_{4}{ }^{2-}$ and DIC for those sites (Leckie et al., 1980; James and Bartlett, 1983; Zachara et al., 1987, 1988, 1989). Ainsworth et al. (1989) concluded that Al substitution in oxides reduces the amount of chromate adsorbed due to the difference in the charge characteristics of the surface sites.

Another important mechanism of $\mathrm{Cr}(\mathrm{VI})$ sequestration by soils is the reduction of $\mathrm{Cr}(\mathrm{VI})$ to sparingly soluble $\mathrm{Cr}(\mathrm{III})$. Electron donors such as organic matter and $\mathrm{Fe}(\mathrm{II})$ are capable of reducing $\mathrm{Cr}(\mathrm{VI})$. Organic matter and surface bound organics are extremely effective at reducing $\mathrm{Cr}(\mathrm{VI})$ to $\mathrm{Cr}(\mathrm{III})$ under acidic conditions (Bartlett and Kimble, 1976b; Jardine et al., 1999) Likewise, Fe(II) bearing minerals are known to rapidly reduce $\mathrm{Cr}$ in soils (Anderson et al., 1994; Peterson et al., 1997). Low soil $\mathrm{pH}$ facilitates the reduction reaction through the release of $\mathrm{Fe}(\mathrm{II})$ from soils (Eary and Rai, 1991). Iron sulfides also have the ability to rapidly reduce $\mathrm{Cr}(\mathrm{VI})$ to $\mathrm{Cr}$ (III), suggesting that complete dissolution of $\mathrm{Fe}(\mathrm{II})$ does not have to occur before the Cr can be reduced (Patterson et al., 1997). These results imply that the reduction is taking place at the solid-solution interface making, FeS an effective reductant of $\mathrm{Cr}(\mathrm{VI})$.

Cationic $\mathrm{Cr}$ (III) also sorbs to soil through a variety of mechanisms. The $\mathrm{pH}$ of the soil has a strong influence on $\mathrm{Cr}$ (III) adsorption because changes in $\mathrm{pH}$ affect the variable charge on minerals and organic matter. Conditions of higher $\mathrm{pH}$ creates more negative surface sites on soil mineral surface and organic matter to which $\mathrm{Cr}$ (III) can sorb (Sparks, 1995). Further, at pH conditions above 5.5, $\mathrm{Cr}$ (III) rapidly precipitates from solution and forms hydroxides on the soil surface (Bartlett and Kimble, 1976a). These hydroxides have low solubility and therefore are not likely to dissolve and reenter the soil solution (Losi et al., 1994).

With all the highly variable factors influencing chromium's ability to sorb to the soil surface, blanket clean-up regulations that ignore the importance of individual soil properties may not be accurate with regard to human health risk. The objective of this research was to investigate the effect of soil properties on the bioaccessibility of $\mathrm{Cr}(\mathrm{III})$ and $\mathrm{Cr}(\mathrm{VI})$ as a function of contaminant concentration and aging. We show that soils can strongly sequester both anionic and cationic forms of $\mathrm{Cr}$, which, under certain circumstances, dramatically decreases toxic metal bioaccessibility.

\section{METHODS}

\section{Soil Type and Characterization}

The A and upper B horizons of two soils were obtained from the Melton Valley and Walker Branch watersheds on the Oak Ridge Reservation (ORR) in eastern Tennessee. The soils are representative of $\mathrm{Cr}$-contaminated sites common to the 
southeastern U.S. Selected physical and geochemical properties of these soils are listed in Table 1. The Melton Valley soil is an acidic Inceptisol derived from interbedded shales and limestone (Kooner et al., 1995; Jardine et al., 1999; Driese et al., 2001). The soils are extensively weathered and devoid of carbonates. Illites dominate the $<2 \mu \mathrm{m}$ clay fraction, and the clays are heavily coated with amorphous $\mathrm{Fe}-$ oxides and goethite. The $\mathrm{pH}$ and cation exchange capacity (CEC) of these soils range from 4 to 7 and 10 to $20 \mathrm{cmol}_{\mathrm{c}} \mathrm{kg}^{-1}$, respectively (Jardine et al., 1989). Walker Branch soils are an acidic Ultisol that has been weathered from the Knox Group (Arnseth and Turner, 1988), a dolostone sequence with occasional interbeds of limestone and shale. The soils are also extensively weathered and devoid of carbonates. Kaolinite dominates the $<2 \mu \mathrm{m}$ clay fraction, and the clays are heavily coated with hematite and maghemite. The $\mathrm{pH}$ and cation exchange capacity (CEC) of these soils range from 4 to 6 and 4 to $6 \mathrm{cmol}_{\mathrm{c}} \mathrm{kg}^{-1}$, respectively (Jardine et al., 1989). All soils were dried in an oven at $40^{\circ} \mathrm{C}$ and gently crushed with a mortar and pestle to pass a $250-\mu \mathrm{m}$ sieve.

\section{Contaminant Addition to Soil}

Ten grams of the soil and $100 \mathrm{ml}$ of chromium solution were placed in a 200-ml glass centrifuge vessel, shaken, and allowed to equilibrate for 2 days. The spiking concentrations (dose rates) for $\mathrm{Cr}(\mathrm{VI})$, as $\mathrm{K}_{2} \mathrm{CrO}_{4}$, were 1000, 250, and $50 \mathrm{ppm}$ at a pH of 6.0 and for $\mathrm{Cr}(\mathrm{III})$, as $\mathrm{CrCl}_{3}$, were 500,200 , and $50 \mathrm{ppm}$ at a $\mathrm{pH}$ of 4.0. After a 2-d equilibration period, the slurries were centrifuged and the supernatant was discarded. The soils were then rinsed with double deionized (DDI) water three times to remove chromium in the pore water and allowed to air dry. Once the soils were dry, they were gently crushed, homogenized, and then rewetted with DDI water to $30 \%$ moisture. The soils were kept in a container out of direct light and maintained at $30 \%$ water content in a moisture-saturated environment.

\section{In Vitro Bioaccessibility}

A physiologically based extraction test (PBET) was adapted from Ruby et al. (1996, 1999; Ruby, 2000, personal communication) to assess the in vitro bioaccessibility of $\mathrm{Cr}(\mathrm{III})$ and $\mathrm{Cr}(\mathrm{VI})$ from contaminated soils in humans. Sampling was conducted on the treated soils that had been allowed to age in the storage container for $1,21,50,100$, and $200 \mathrm{~d}$ after the initial treatment and subsequent wetting of the treated soils. Triplicate moist samples $(\sim 0.3 \mathrm{~g}$ dry weight) were placed in 50-ml polyethylene tubes to which $30 \mathrm{ml}$ of $0.4 \mathrm{M}$ glycine at $\mathrm{pH} 1.5$ and $37^{\circ} \mathrm{C}$ was added. The slurries were quickly placed in a rotating water bath at $37^{\circ} \mathrm{C}$ and agitated at $30 \pm 2 \mathrm{rpm}$ for $1 \mathrm{~h}$. The method was designed to simulate the stomach digestive system in humans and has also been used by Skowronski et al. 
Table 1 Select soil physical and geochemical properties

\begin{tabular}{|c|c|c|c|c|c|c|c|c|}
\hline & \multicolumn{3}{|c|}{ Particle size analysis } & \multirow[b]{2}{*}{$\begin{array}{l}\text { Organic matter } \\
\text { content }(\%)\end{array}$} & \multirow[b]{2}{*}{$\begin{array}{c}\mathrm{pH}(5 \mathrm{mM} \\
\left.\mathrm{CaCl}_{2}\right)\end{array}$} & \multirow[b]{2}{*}{$\mathrm{pH}(\mathrm{DDI})$} & \multirow[b]{2}{*}{$\mathrm{Fe}(\mathrm{g} / \mathrm{kg})$} & \multirow[b]{2}{*}{$\begin{array}{c}\text { Mineralogy of }<2 \mu \mathrm{m} \\
\quad \text { clay fraction * }\end{array}$} \\
\hline & Sand (\%) & Silt (\%) & Clay (\%) & & & & & \\
\hline Melton A & 56.2 & 30.0 & 13.8 & 3.55 & 6.91 & 7.18 & 10.68 & \\
\hline Melton B & 30.8 & 50.4 & 18.8 & 0.42 & 4.23 & 4.87 & $22.07 \mathrm{I}$ & $\mathrm{I}_{45} \mathrm{IS}_{20} \mathrm{~V}_{10} \mathrm{~K}_{9} \mathrm{VC}_{6} \mathrm{M}_{5} \mathrm{Q}_{3} \mathrm{~F}_{1}$ \\
\hline Walker A & 34.9 & 58.9 & 6.2 & 1.89 & 6.01 & 6.61 & 7.71 & \\
\hline Walker B & 32.2 & 44.2 & 23.6 & 0.10 & 4.30 & 5.17 & 19.55 & $\mathrm{~K}_{27} \mathrm{~V}_{27} \mathrm{VC}_{14} \mathrm{Q}_{13} \mathrm{I}_{10} \mathrm{IS}_{5} \mathrm{G}_{3} \mathrm{~F}_{1}$ \\
\hline
\end{tabular}

${ }^{*} \mathrm{~K}=$ kaolinite $\mathrm{V}=$ vermiculite; $\mathrm{VC}=$ chloritized vermiculite; $\mathrm{I}=$ illite (soil mica); IS = interstratified 2:1; $\mathrm{Q}=$ quartz; $\mathrm{G}=$ gibbsite; 
(2001) to assess Cr bioaccessibility in a sandy and a clayey soil. Supernatant was separated from the solid via centrifugation. The $\mathrm{pH}$ of the supernatant was measured to ensure that the final $\mathrm{pH}$ was within $\pm 0.5 \mathrm{pH}$ units of the initial $\mathrm{pH}$. This scenario held for all cases. Bioaccessibility was calculated as:

$\%$ Bioaccessibility $=\left(\frac{\mathrm{Cr} \text { in PBET supernatant }(\mu \mathrm{g} / \mathrm{mL}) \times 30.0 \mathrm{~mL} \div 0.3 \mathrm{~g} \text { dry soil }}{\mathrm{Cr} \text { on soil surface }(\mu \mathrm{g} / \mathrm{g})}\right) \times 100$

Standard deviations on computed \% Cr(III) and $\mathrm{Cr}(\mathrm{VI})$ bioaccessibility values following triplicate PBET analyses ranged from 0.03 to 2.01 with the average standard deviation of all values being 0.52 .

\section{Chromium Analysis}

The PBET supernatant was measured for $\mathrm{Cr}(\mathrm{VI})$ and $\mathrm{Cr}$ total $\left(\mathrm{Cr}_{\mathrm{T}}\right)$. $\mathrm{Cr}(\mathrm{VI})$ was measured using a modified $s$-diphenylcarbohydrazide colorimetric method (Bartlett and James, 1979) with a UV-VIS spectrophotometer at a wavelength of $540 \mu \mathrm{m}$ (HP model 8453, Palo Alto, CA). Analysis of $\mathrm{Cr}(\mathrm{VI})$ was performed immediately on rapidly cooled PBET solutions to avoid possible reduction of $\mathrm{Cr}(\mathrm{VI})$ to $\mathrm{Cr}$ (III) by glycine (Jardine et al., 1999). Independent studies revealed that $\mathrm{Cr}(\mathrm{VI})$ reduction by glycine at $37^{\circ} \mathrm{C}$ and $1 \mathrm{~h}$ was insignificant. Total chromium was measured on a Perkin Elmer AAnalysist 800 atomic absorption spectrophotometer (Wellseley, PA). All standards used were made from an atomic absorption chromium standard (EM Industries, Hawthorne, NY). Cr(III) was calculated as the difference between $\mathrm{Cr}_{\mathrm{T}}$ and $\mathrm{Cr}(\mathrm{VI})$.

\section{Determination of Chromium on Soil}

Total chromium on the soil was determined using a modification of EPA method 3052. The soil was digested in a CEM microwave, model MDS-81D, with hydrofluoric and nitric acid. Boric acid was added before sample analysis in order to facilitate the removal of hydrofluoric acid from solution through the formation of fluoroboric acid. Soils from the National Institute of Standards, with known concentrations of solid phase $\mathrm{Cr}$, were also analyzed with each block of analyses. Samples were stored and analyzed for total chromium using Inductively Coupled Plasma.

\section{Chromium Solid Phase Speciation}

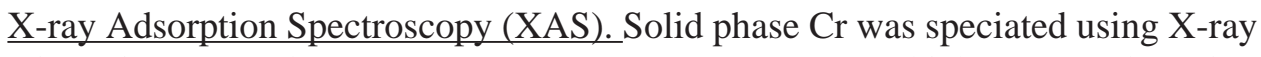
adsorption near-edge structure (XANES) spectroscopy, which was conducted at 
the Stanford Synchrotron Radiation Laboratory (SSRL) under dedicated running conditions. Scans were recorded from -200 to $300 \mathrm{eV}$ around the K-edge of chromium $(5989 \mathrm{eV})$, with $0.2-\mathrm{eV}$ steps across the white-line and main-edge region. Energy selection was accomplished with a $\mathrm{Si}(220)$ double-crystal monochromator, with a 1-mm (h) x 20-mm (w) beam. Adsorption was measured by a proportional fluorescent $\mathrm{X}$-ray production using a 13-element Ge detector (Cramer et al., 1988). Mass fractions of $\mathrm{Cr}(\mathrm{III})$ and $\mathrm{Cr}(\mathrm{VI})$ were determined for each soil using XANES spectroscopy by placing the soil in a $4-\times 4-\times 40-\mathrm{mm}$ slot cut in an acrylic plate that was sealed with Kapton. The proportion of $\mathrm{Cr}(\mathrm{VI})$ relative to total chromium was then determined by the ratio of the white-line amplitude to the total atomic cross section and comparison to standard curves as described by Patterson et al. (1997).

Chemical Extraction. In an effort to indirectly quantify $\mathrm{Cr}(\mathrm{VI})$ reduction processes on the soils, sorption isotherms were constructed and the solid phase extracted with $\mathrm{SO}_{4}{ }^{2-}$. Because $\mathrm{SO}_{4}{ }^{2-}$ competes well for $\mathrm{Cr}(\mathrm{VI})$ sorption sites, but does not compete well for $\mathrm{Cr}$ (III) sorption sites, an indirect measure of the reduction of $\mathrm{Cr}(\mathrm{VI})$ to $\mathrm{Cr}$ (III) should be possible. Approximately $1 \mathrm{~g}$ soil was placed in preweighed centrifuge tubes, and the soils treated with $15 \mathrm{ml}$ of varying concentrations of $\mathrm{Cr}(\mathrm{VI})$ in $5 \mathrm{mM} \mathrm{CaCl}$ that were adjusted to the $\mathrm{pH}$ of the soil. Samples were allowed to equilibrate on the shaker for $48 \mathrm{~h}$. Soils were centrifuged and supernatant was saved for analysis. The $\mathrm{Cr}(\mathrm{VI})$ was extracted from soils with three sequential washings of $0.05 \mathrm{M} \mathrm{Na}_{2} \mathrm{SO}_{4}$. The equilibrium solutions and extraction solutions were analyzed for both $\mathrm{Cr}(\mathrm{VI})$ and $\mathrm{Cr}(\mathrm{III})$. The chromium extract was corrected for pore water $\mathrm{Cr}$ of the equilibration step.

\section{RESUlTS AND DisCUSSION}

\section{Influence of Soil Properties on Cr Sorption}

As expected, soils treated with solutions containing $\mathrm{Cr}$ (III) adsorbed 2 to 10 times more $\mathrm{Cr}$ than those treated with $\mathrm{Cr}(\mathrm{VI})$ (Table 2). This results from a larger cation exchange capacity vs. anion exchange capacity and the propensity for $\mathrm{Cr}$ (III) to precipitate on mineral surfaces at $\mathrm{pH}$ values above 5.5. The adsorption of both $\mathrm{Cr}$ species became more similar on the WB B-horizon soil because acidic conditions and abundant $\mathrm{Fe}$-oxides provided positive surface charges, thereby enhancing $\mathrm{Cr}(\mathrm{VI})$ sorption. Thus, mineral phases, particularly iron oxides, with proton-specific surface sites may effectively adsorb $\mathrm{Cr}(\mathrm{VI})$ at low to medium soil pHs (Zachara et al., 1987, 1988, 1989; Leckie et al., 1980; Davis and Leckie, 1980; Mayer and Schick, 1981). The A-horizon soils had a higher $\mathrm{pH}$ and organic matter content, creating an environment that was not conducive to $\mathrm{Cr}(\mathrm{VI})$ adsorption. 


\section{Table 2 Mass loadings of $\mathrm{Cr}(\mathrm{III})$ and $\mathrm{Cr}(\mathrm{VI})$ on soil $(\mathrm{mg} / \mathrm{kg})$ for various $\mathrm{Cr}$ treatment concentrations ( $\mathrm{ppm})$}

\begin{tabular}{lccc} 
Cr(III) & $500 \mathrm{ppm}$ & $200 \mathrm{ppm}$ & $50 \mathrm{ppm}$ \\
\cline { 2 - 4 } Melton A & 4479.42 & 1823.26 & 426.42 \\
Melton B & 2002.91 & 1430.68 & 452.02 \\
Walker A & 2421.67 & 1779.01 & 451.00 \\
Walker B & 1276.05 & 1070.32 & 445.20 \\
& & & \\
& & & \\
Cr(VI) & $1000 \mathrm{ppm}$ & $250 \mathrm{ppm}$ & $50 \mathrm{ppm}$ \\
Melton A & 386.47 & 199.21 & 91.28 \\
Melton B & 269.14 & 219.86 & 150.00 \\
Walker A & 391.83 & 244.24 & 100.22 \\
Walker B & 423.48 & 330.53 & 218.25
\end{tabular}

In the case of $\mathrm{Cr}(\mathrm{III})$ the patterns of adsorption were reversed, where the A-horizon soils typically adsorbed more $\mathrm{Cr}$ than the B-horizon soils. The Ahorizon soils characteristically had higher $\mathrm{pH}$ creating an environment that favored $\mathrm{Cr}$ (III) adsorption. Deprotonation of oxides and organic matter occurs in soils with higher soil $\mathrm{pH}$ values, which results in more negatively charged sites that attract cations such as $\mathrm{Cr}$ (III). Also, when the soil $\mathrm{pH}$ is above 5.5, as with the two Ahorizon soils used here, the $\mathrm{Cr}$ (III) most likely precipitates from solution as hydroxides creating a surface coating on a variety of soil mineral surfaces (Bartlett and Kimball, 1976a). This suggests that larger solid phase concentrations of $\mathrm{Cr}$ (III) can often be expected in soils with higher $\mathrm{pH}$ and abundant inorganic and organic carbon as shown by Stewart et al. (2003).

\section{Influence of Aging on Cr Bioaccessibility}

Chromium bioaccessibility, as measured by the PBET method, decreased with time for all soils tested and at all solid phase concentrations (with the exception of the $50 \mathrm{ppm} \mathrm{Cr}(\mathrm{VI})$ treated MV-A soil), with aging effects being most pronounced for $\mathrm{Cr}$ (III) (Figures 1 and 2). Standard deviations on computed \% Cr bioaccessibility values were on average 0.52 , which were too small to show error bars on the triplicate-measured values of Figures 1 and 2. Analysis of variance (ANOVA) t-test on day 1 vs. 200 for each of the four soils, two contaminants (Cr(III/VI)), and 

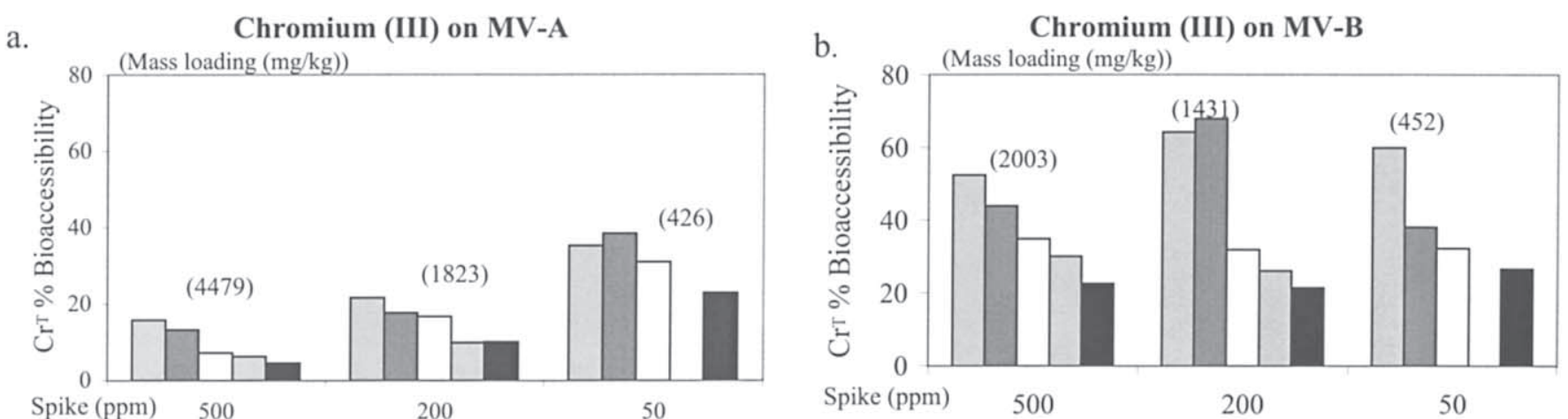

Chromium (III) on WB-A
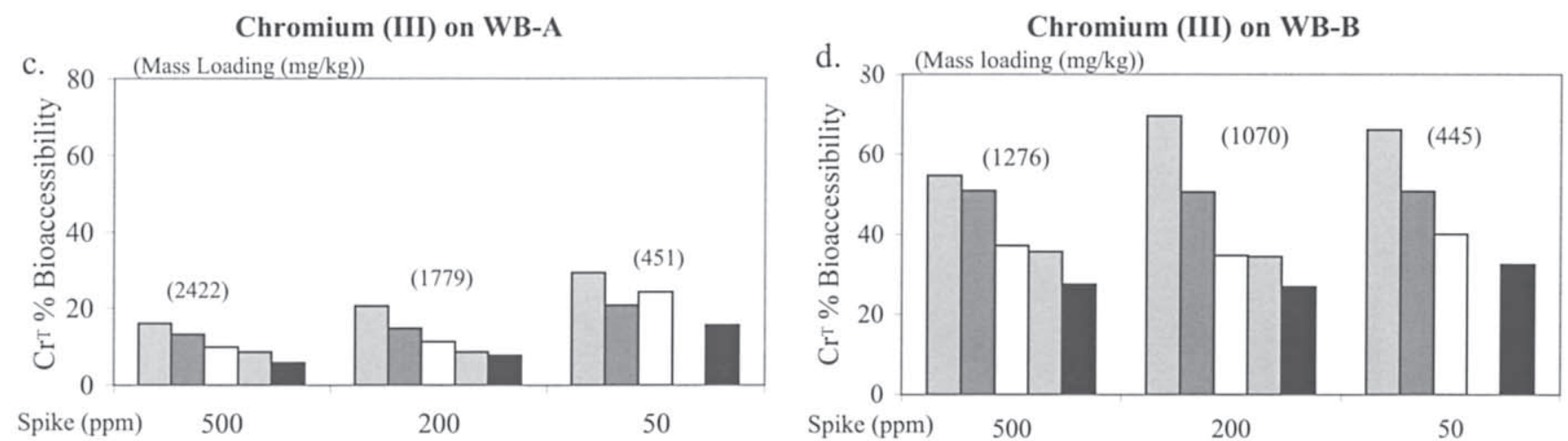

\begin{tabular}{|llll}
\hline & 1 day $\quad \square \quad 21$ day
\end{tabular} 50 day $\quad \square 100$ day $\quad \square \quad 200$ day

FIGURE 1

Aging and solid phase concentration effects on the percent $\mathrm{Cr}$ bioaccessibility for soils treated with varying concentrations of $\mathrm{Cr}(\mathrm{III})(50,200$, and $500 \mathrm{mg} / \mathrm{L})$. (a) Melton Valley A-horizon soil, (b) Melton Valley B-horizon soil, (c) Walker Branch A-horizon soil, and (d) Walker Branch B-horizon soil. 
a.

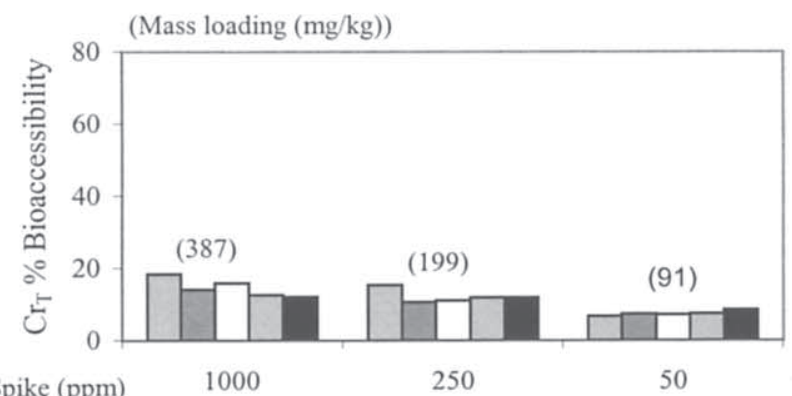

c.

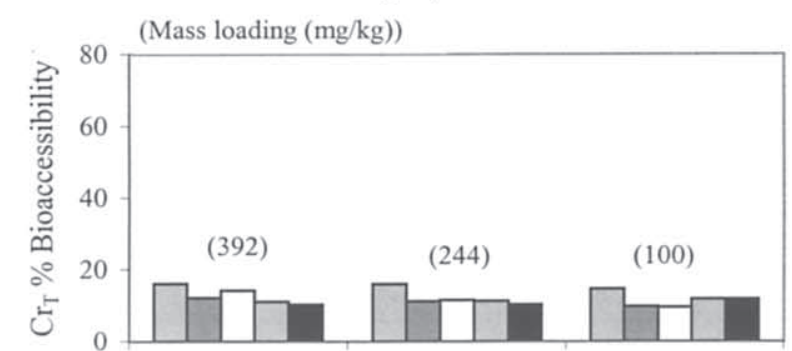

Spike (ppm)

1000

250

50

$\square \quad 21$ day

1 day

d.

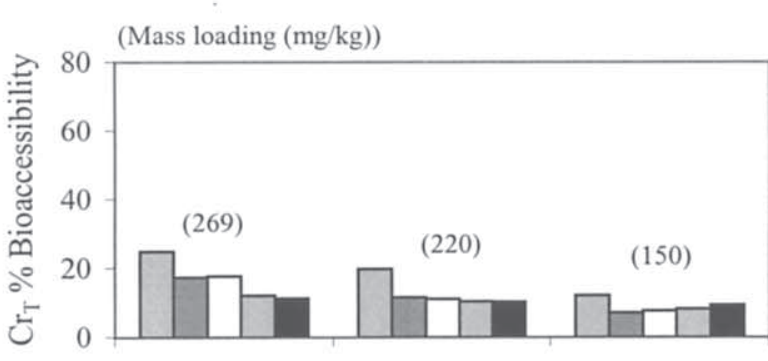

Spike (ppm) 1000

250

50

Chromium (VI) on WB-B

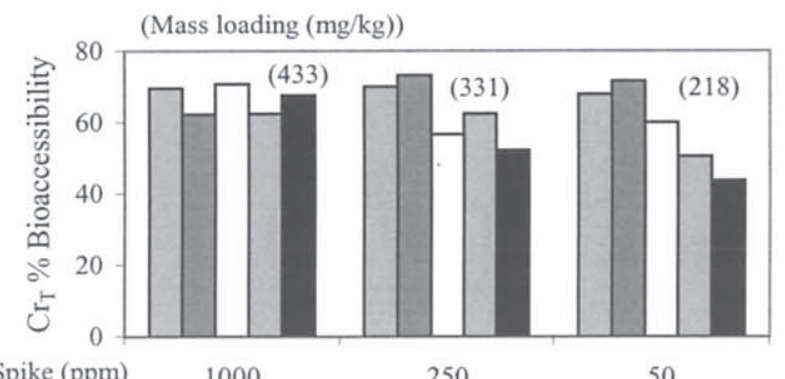

Spike (ppm)

1000

250

50

$\square 100$ day

200 day

\section{FIGURE 2}

Aging and solid phase concentration effects on the percent $\mathrm{Cr}$ bioaccessibility for soils treated with varying concentrations of $\mathrm{Cr}(\mathrm{VI})(50,250$, and $1000 \mathrm{mg} / \mathrm{L})$. (a) Melton Valley A-horizon soil, (b) Melton Valley B-horizon soil, (c) Walker Branch A-horizon soil, and (d) Walker Branch B-horizon soil. 
three treatment concentrations (dose) confirmed that the aging effect was significant at the $95 \%$ level (i.e., most $\mathrm{p}$ values $<0.0001$ ) and was most pronounced on $\mathrm{Cr}$ (III)- treated soils (results not shown). The decrease in bioaccessibility was rapid for the first $50 \mathrm{~d}$ and slowed dramatically as the aging period approached $200 \mathrm{~d}$. As the soils age, they most likely approach a state of equilibrium between the solution phase $\mathrm{Cr}$ and the surface of the soil. The aging effect is related to the enhanced stability of $\mathrm{Cr}$ on the soil surface with time. Structural reorientation of Cr surface bonds or, in the case of $\mathrm{Cr}$ (III), slow precipitation reactions can account for the stronger sorption of $\mathrm{Cr}$ at longer times. The greater aging effect observed for $\mathrm{Cr}$ (III) vs. $\mathrm{Cr}(\mathrm{VI})$ is most likely related to the time-dependent formation of solid phase $\mathrm{Cr}(\mathrm{OH})_{3}$, which is not easily dissolved under the acidic conditions of the PBET.

\section{Influence of Solid Phase Concentration on Cr Bioaccessibility}

In general, the effect of $\mathrm{Cr}$ solid phase concentration (dose effect) on bioaccessibility was small, with $\mathrm{Cr}$ (III) showing the most pronounced effect. A comprehensive ANOVA test, discussed later in the manuscript, confirmed that the dose level exerts only a minor influence on Cr bioaccessibility (see Table 6). No obvious trends were noted for $\mathrm{Cr}(\mathrm{VI})$, whose bioaccessibility remained relatively constant at different solid phase concentrations on any given soil (Figure 2). For the $\mathrm{Cr}$ (III) system, particularly for A-horizon soils, higher bioaccessibility was noted for soils that were treated with $50 \mathrm{ppm} \mathrm{Cr}(\mathrm{III})$ relative to the higher concentration treatments. This is most likely related to the fact that at low surface coverage $(<20 \%)$ adsorption is the dominant process where $\mathrm{Cr}(\mathrm{III})$ forms inner-sphere complexes with the soil, while at higher surface coverages $(>20 \%)$ surface precipitation occurs and becomes the dominant process (Fendorf et al., 1994; Fendorf and Sparks, 1994). The soils that were treated with $50 \mathrm{ppm} \mathrm{Cr(III)} \mathrm{have} \mathrm{significantly}$ lower $\mathrm{Cr}$ on the soil than the other soils treated with higher concentrations. Thus, the mechanism of $\mathrm{Cr}$ sequestration has a higher proportion of inner-sphere bonds related to precipitated phases, which most likely causes a higher percent of $\mathrm{Cr}$ (III) that is bioaccessible at lower solid phase concentrations.

\section{Influence of Soil Properties on Cr Bioaccessibility}

The bioaccessibility of $\mathrm{Cr}(\mathrm{III})$ and $\mathrm{Cr}(\mathrm{VI})$ varied significantly as a function of soil type and horizon, and the oxidation state of the contaminant. Statistical analysis using the ANOVA t-test confirmed that Cr bioaccessibility was significantly influenced by these effects at the $95 \%$ level with p values typically $<0.0001$ (results not shown). In general, A-horizon soils exhibited less $\mathrm{Cr}$ bioaccessibility relative to B-horizon soils. In the $\mathrm{Cr}$ (III) system, the higher organic matter content and 
higher $\mathrm{pH}$ of the A-horizon soils are probably the main factors responsible for this difference. The Walker Branch B-horizon (WB-B) soil is a good example of how soil properties effect the degree of bioaccessibility because it is the most acidic of the soils and has the lowest organic carbon content, and consequently it shows the highest percent of $\mathrm{Cr}(\mathrm{III})$ bioaccessibility (Figure 1d). Both the Melton Valley A-horizon (MV-A) and Walker Branch A-horizon (WB-A) soils have a high $\mathrm{pH}$ and high organic carbon content and an equally low $\mathrm{Cr}$ (III) bioaccessibility. These results are consistent with observations in Stewart et al. (2003) that showed that $\mathrm{Cr}$ (III) bioaccessibility was limited in systems with high levels of inorganic and organic carbon. Skowronski et al. (2001) also noted that Cr(III) bioaccessibility was lower on an organic-rich sandy soil vs. a clay soil that had significantly less organic carbon.

In the $\mathrm{Cr}(\mathrm{VI})$ system, the two A-horizon soils and the Melton Valley B-horizon (MV-B) showed statistically significant lower Cr bioaccessibility than WB-B for all treatment concentrations and aging times. Although the WB-B soil adsorbed the most $\mathrm{Cr}(\mathrm{VI})$, its tendency to release $\mathrm{Cr}$ under the acidic conditions of the PBET is due to the soil's inability to maintain the weak bond between the $\mathrm{Cr}$ and the surface. The $\mathrm{Cr}(\mathrm{VI})$ ion is probably electrostatically bound to mineral oxides through outer sphere complexes, which are unstable during the conditions of the PBET. This leads to the question of why is it that both A-horizon soils and even the Melton Valley Inceptisol B horizon soils (MV-B) have such low Cr(VI) bioaccessibility when soil properties are such as to discourage strong sorption?

To address the above question, both direct and indirect solid phase $\mathrm{Cr}$ speciation methods using X-ray Absorption Spectroscopy (XAS) and a chemical extraction technique, respectively, were employed. Analysis with XAS of the 250 and 1000 ppm $\mathrm{Cr}(\mathrm{VI})$ treated soils after $200 \mathrm{~d}$ aging suggested that all soils, except the WBB soil, had $\mathrm{Cr}$ surface coverages that were $>95 \% \mathrm{Cr}$ (III) (Table 3). The 250 and 1000 ppm Cr(VI) treated WB B-horizon soils contained only 30 and 53\% surface bound $\mathrm{Cr}(\mathrm{III})$, respectively. Thus, the bioaccessibility of $\mathrm{Cr}(\mathrm{VI})$ was significantly influenced by the reduction of $\mathrm{Cr}(\mathrm{VI})$ to $\mathrm{Cr}(\mathrm{III})$. Skowronski et al. (2001) also suggested that $\mathrm{Cr}(\mathrm{VI})$ bioaccessibility in their soils was influenced by oxidationreduction processes. In order for reduction to occur, there needs to be a source of electrons. Both organic matter and the Fe(II)-bearing minerals are able to supply electrons to catalyze the reduction of $\mathrm{Cr}(\mathrm{VI})$ to $\mathrm{Cr}(\mathrm{III})$. Because the soils used in this study were highly oxidized and most likely devoid of Fe(II)-bearing minerals, the reduction of $\mathrm{Cr}(\mathrm{VI})$ to $\mathrm{Cr}(\mathrm{III})$ was most likely catalyzed by soil organic matter or surface-bound organic carbon (Adriano, 1986; Sparks, 1995; Deng and Stone, 1996; Jardine et al., 1999). Thus, extensive reduction processes for the A-horizon soils and the MV B-horizon soils are most likely related to the ample supply of organic carbon in these soils (Table 1). Even the WB B-horizon soil showed Cr(VI) reduction to $\mathrm{Cr}(\mathrm{III})$ with a solid phase carbon mass of $0.1 \%$. Jardine et al. (1999) showed that in acidic soils the availability of even small amounts of surface-bound natural organic carbon $(0.05 \% \mathrm{w} / \mathrm{w}$ on the solid $)$ can result in significant reduction 


\section{Table 3 Percentage of soil solid phase $\mathrm{Cr}(\mathrm{III})$ and $\mathrm{Cr}(\mathrm{VI})$ quantified by X-ray Adsorption Spectroscopy (XAS) *}

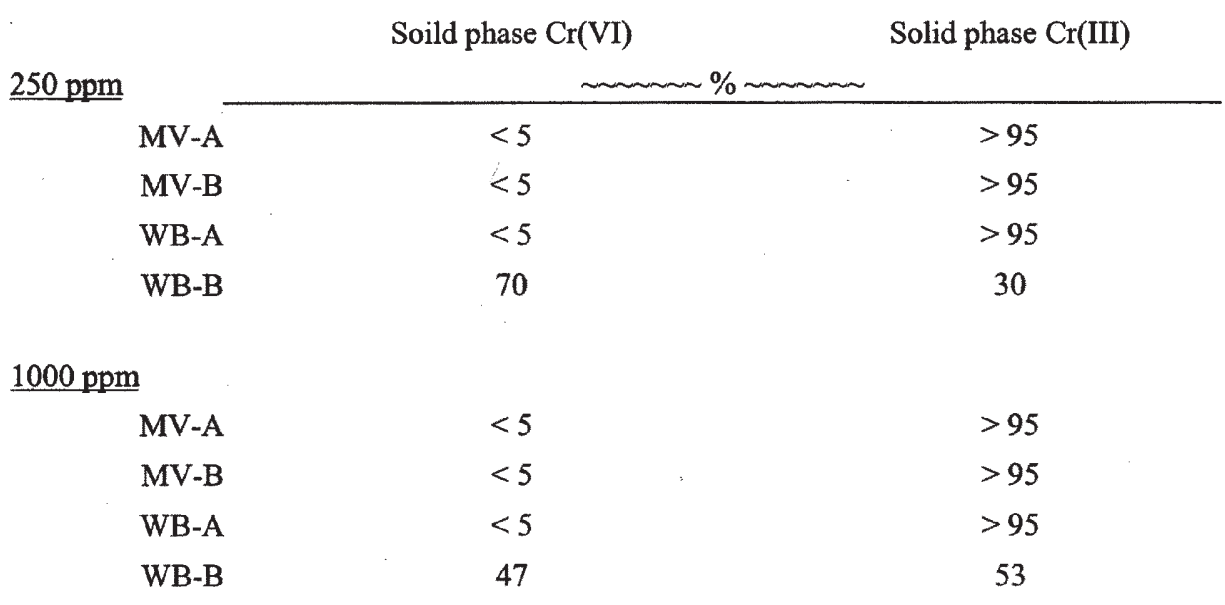

* $200 \mathrm{~d}$ aged samples

of $\mathrm{Cr}(\mathrm{VI})$ to $\mathrm{Cr}(\mathrm{III})$. Therefore, $\mathrm{Cr}(\mathrm{VI})$ reduction decreases $\mathrm{Cr}$ bioaccessibility because the $\mathrm{Cr}(\mathrm{III})$ product is more tightly bound to the solid phase. The $\mathrm{Cr}$ (III) probably adsorbs to the surface through strong covalent bonds or precipitates as hydroxide complexes on mineral surfaces. Thus, the percent of $\mathrm{Cr}$ that is bioaccessible decreases during the PBET.

The XAS data are in agreement with aqueous $\mathrm{Cr}$ speciation measurements on the PBET solutions (Table 4). A significant portion of the total bioaccessible $\mathrm{Cr}$ was found to be $\mathrm{Cr}$ (III), with the WB B-horizon soil having the lowest total amount of extractable $\mathrm{Cr}(\mathrm{III})$ as indicated by the high $\mathrm{Cr}(\mathrm{VI})$ in Table 4. For all soils except WB-B, the trends in the data suggest an increasing percentage of $\mathrm{Cr}(\mathrm{VI})$ in the PBET extraction solution up to $\sim 100 \mathrm{~d}$ followed by an abrupt decrease with continued Cr-soil aging to $200 \mathrm{~d}$. These trends are consistent with the enhanced reduction of $\mathrm{Cr}(\mathrm{VI})$ to $\mathrm{Cr}(\mathrm{III})$ by the A-horizon soils and the MV-B soil relative to the WB-B soil. Using the 200-d aqueous speciation data coupled with the XAS solid speciation results (analyzed on $200 \mathrm{~d}$ aged soils), one can calculate the mass fraction of $\mathrm{Cr}(\mathrm{III})$ and $\mathrm{Cr}(\mathrm{VI})$ that are bioaccessible in each soil (Table 5). In all soils, the bioaccessibility of surface-bound $\mathrm{Cr}(\mathrm{VI})$ was significantly greater than that for $\mathrm{Cr}$ (III). Between 42 and $108 \%$ of the total adsorbed $\mathrm{Cr}(\mathrm{VI})$ was bioaccessible when compared with total adsorbed $\mathrm{Cr}(\mathrm{III})$, which was only 3 and $14 \%$ bioaccessible. Although $\mathrm{Cr}(\mathrm{III})$ may dominate total $\mathrm{Cr}$ in the PBET, surface-bound $\mathrm{Cr}(\mathrm{VI})$ is significantly more bioaccessible. Thus, the reduction of $\mathrm{Cr}(\mathrm{VI})$ to $\mathrm{Cr}$ (III) by soil 


\section{Table 4 Percentage of Cr(VI) in PBET extractant for soils treated with 250 and $1000 \mathrm{ppm} \mathrm{Cr}(\mathrm{VI})$}

\begin{tabular}{|c|c|c|c|c|c|}
\hline & $\underline{1 \text { day }}$ & 21 day & $\underline{50 \text { day }}$ & 100 day & $\underline{200 \text { day }}$ \\
\hline $250 \mathrm{ppm}$ & \multicolumn{5}{|c|}{ 〜 \% } \\
\hline MV-A & 28.73 & 61.90 & 78.02 & 64.91 & 46.26 \\
\hline MV-B & 21.64 & 59.09 & 71.92 & 67.75 & 32.88 \\
\hline WB-A & 16.54 & 22.86 & 57.28 & 28.61 & 26.38 \\
\hline WB-B & 76.92 & 81.16 & 99.10 & 76.07 & 94.27 \\
\hline \multicolumn{6}{|c|}{$1000 \mathrm{ppm}$} \\
\hline MV-A & 3.81 & 15.29 & 6.31 & 44.09 & 21.89 \\
\hline MV-B & 14.59 & 13.26 & 22.09 & 90.46 & 24.07 \\
\hline WB-A & 4.23 & 8.15 & 4.31 & 31.53 & 21.25 \\
\hline WB-B & 60.28 & 84.72 & 63.57 & 73.00 & 78.91 \\
\hline
\end{tabular}

organic matter significantly decreases total $\mathrm{Cr}$ bioaccessibility. These results are important from a human health perspective because $\mathrm{Cr}(\mathrm{VI})$ is believed to be much more toxic than $\mathrm{Cr}$ (III), with even sub-ppm levels considered lethal. Thus, under certain circumstances, soils that contain sufficient organic carbon or Fe(II)-bearing minerals may be capable of decreasing $\mathrm{Cr}$ bioaccessibility through reduction of labile $\mathrm{Cr}(\mathrm{VI})$ to the more sparingly soluble $\mathrm{Cr}(\mathrm{III})$ species.

An indirect chemical extraction method was also used to show that $\mathrm{Cr}(\mathrm{VI})$ was being reduced to $\mathrm{Cr}(\mathrm{III})$. Chromium (VI) was adsorbed onto the soils using different treatment solution concentrations, allowed to equilibrate for $2 \mathrm{~d}$, and then the solid phase was treated with $0.05 \mathrm{M} \mathrm{Na}_{2} \mathrm{SO}_{4}$ to remove the $\mathrm{Cr}(\mathrm{VI})$ (Figure $3 \mathrm{a}-\mathrm{d}$ ). The $\mathrm{SO}_{4}{ }^{2-}$ anion should be a sufficient competitor for surface sites occupied by $\mathrm{HCrO}_{4}^{-}$because the latter is typically sorbed to the solid phase through weak outersphere electrostatic bonds. Thus, if $\mathrm{Cr}$ reduction processes are minimal, the $\mathrm{SO}_{4}{ }^{2-}$ should be able to recover nearly all of the initial adsorbed $\mathrm{Cr}(\mathrm{VI})$. The extractant $\mathrm{Na}_{2} \mathrm{HPO}_{4}$ was also utilized on select soils since the $\mathrm{HPO}_{4}{ }^{2-}$ anion can aggressively compete for $\mathrm{Cr}(\mathrm{VI})$ that is bound to the soil by either inner- or outer-sphere surface complexes. The results compared favorably with the $\mathrm{SO}_{4}{ }^{2-}$ system; however, the $\mathrm{HPO}_{4}{ }^{2-}$ results were somewhat more erratic for reasons unknown to the authors, and thus the $\mathrm{SO}_{4}{ }^{2-}$ system was preferred. In this study, the chemical extraction method can only be qualitatively compared with the XAS results because the latter technique was employed on $200 \mathrm{~d}$ aged samples, whereas the extraction method 
Table 5 Percentage of total surface bound $\mathrm{Cr}(\mathrm{III})$ and $\mathrm{Cr}(\mathrm{VI})$ that was bioaccessible after $200 \mathrm{~d}$ aging

\begin{tabular}{|c|c|c|c|c|c|c|c|c|}
\hline & \multicolumn{2}{|c|}{$\underline{\text { MV-A }}$} & & & \multicolumn{2}{|c|}{ WB-A } & \multicolumn{2}{|c|}{ WB-B } \\
\hline & & & \multicolumn{4}{|c|}{$\mathrm{Cr}(\mathrm{VI})$ treatment conc. (ppm) } & \multirow[b]{2}{*}{250} & \multirow[b]{2}{*}{1000} \\
\hline & 250 & 1000 & 250 & 1000 & 250 & 1000 & & \\
\hline$\% \mathrm{Cr}(\mathrm{III})$ bioaccessible & 6.0 & 9.9 & 7.1 & 8.0 & 7.8 & 8.3 & 3.2 & 14.2 \\
\hline$\%$ Cr(VI) bioaccessible & 101.0 & 51.5 & 65.5 & 48.1 & 52.5 & 42.3 & 71.1 & 107.5 \\
\hline
\end{tabular}



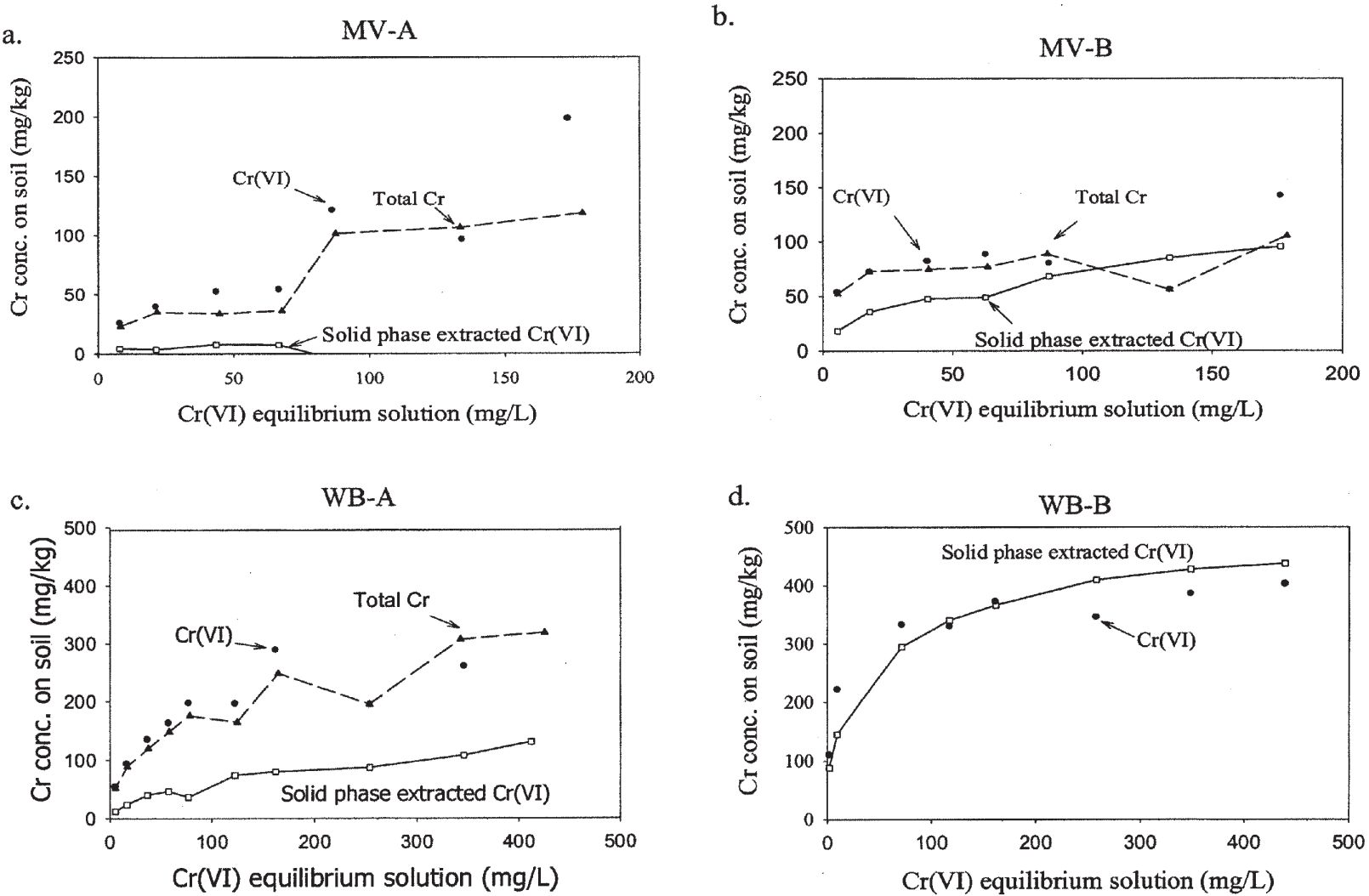

\section{FIGURE 3}

Adsorbed and $\mathrm{SO}_{4}{ }^{2-}$ extractable $\mathrm{Cr}(\mathrm{VI})$ on soil as a function of solution concentration. (a) Melton Valley A-horizon soil, (b) Melton Valley B-horizon soil, (c) Walker Branch A-horizon soil, and (d) Walker Branch B-horizon soil. 
was employed on samples aged for only 2 d. Jardine et al. (1999) previously measured a half-life of $85 \mathrm{~h}$ for $\mathrm{Cr}(\mathrm{VI})$ reduction by organic carbon, so samples analyzed after $200 \mathrm{~d}$ of aging should have more $\mathrm{Cr}(\mathrm{III})$ product than samples analyzed after $2 \mathrm{~d}$ of aging. Nevertheless, the chemical extraction method agreed well with the XAS results and the quantity of organic $\mathrm{C}$ in the soils. With the exception of the WB B-horizon soil, the quantity of $\mathrm{Cr}(\mathrm{VI})$ extracted from the solid phase was significantly lower than the initial $\mathrm{Cr}(\mathrm{VI})$ sorbed, implying that $\mathrm{Cr}$ (III) is being formed and remains sorbed to the soil (Figure $3 \mathrm{a}-\mathrm{d}$ ). A-horizon soils had significantly more $\mathrm{Cr}(\mathrm{III})$ production when compared with B-horizon soils, which is consistent with the larger organic carbon content of the former. The WB B-horizon, which had as little as $0.1 \%$ organic carbon, showed no $\mathrm{Cr}(\mathrm{VI})$ reduction after $2 \mathrm{~d}$ (Figure $3 \mathrm{~b}$ ). The low organic content of this soil does not lend itself to the rapid reduction of $\mathrm{Cr}(\mathrm{VI})$ or is the source of iron, hematite $\left(\mathrm{Fe}_{2} \mathrm{O}_{3}\right)$, and maghemite $\left(\gamma \mathrm{Fe}_{2} \mathrm{O}_{3}\right)$ conducive to $\mathrm{Cr}(\mathrm{VI})$ reduction. The presence of $\mathrm{Fe}(\mathrm{III})$ suggests that the iron is already oxidized and therefore not in the correct state to facilitate the reduction of $\mathrm{Cr}(\mathrm{VI})$. This further explains why the percent of $\mathrm{Cr}$ that is bioaccessible in the WB-B soil remains so high compared with the other three soils examined. These results are consistent with the XAS findings that showed $\mathrm{Cr}(\mathrm{VI})$ reduction was nearly complete on all soils after $200 \mathrm{~d}$, with the exception of the WB-Bhorizon soil.

\section{Factors Influencing Cr Bioaccessibility}

The entire data set was analyzed using an ANOVA model that incorporated three qualitative factors (oxidation state, soil type, and dose level) and one quantitative factor (age). The original dose amounts were converted to low (50 ppm $\mathrm{Cr}(\mathrm{III})$ and $\mathrm{Cr}(\mathrm{VI})$ ), medium (200 ppm $\mathrm{Cr}$ (III) and $250 \mathrm{ppm} \mathrm{Cr}(\mathrm{VI})$ ), or high (500 ppm $\mathrm{Cr}$ (III) and $1000 \mathrm{ppm} \mathrm{Cr}(\mathrm{VI})$ ) categories to simplify the statistical analysis. The complete four-factor ANOVA model explained more than $95 \%$ of the variance in bioaccessibility $\left(\mathrm{r}^{2}=0.952, \mathrm{~F}=127.74, \mathrm{p}<0.0001\right)$ with a summary of the ANOVA results shown in Table 6. The oxidation state, soil type, and dose main effects were all significant as were the two-way and three-way interactions among these effects. Age and its interactions with oxidation state and soil type were also significant. However, age and its interactions with dose were only marginally significant. Thus, it is thought that these marginally significant results indicate that the dose level exerts only a minor influence on the relationship between age and bioavailability. It is also important to realize that some of the significance noted in Table 6 is driven by the high analytical precision of the bioaccessibility results. Thus, in certain cases it may be difficult to tease out statistical significance from geochemical and physical significance. 
Table 6. Summary of analysis of variance results showing the significance of various factors on the bioaccessibility of $\mathrm{Cr}$ in soils.

\begin{tabular}{|c|c|c|c|c|c|}
\hline Factor & SS & df & MS & F & Prob. \\
\hline Oxidation & 1630.7 & 1 & 1630.7 & 73.76 & $<0.0001$ \\
\hline Soil & 87926.5 & 3 & 29308.8 & 1325.70 & $<0.0001$ \\
\hline Oxidation-Soil & 21324.3 & 3 & 7108.1 & 321.51 & $<0.0001$ \\
\hline Dose & 264.4 & 2 & 132.2 & 5.98 & 0.0028 \\
\hline Oxidation-Dose & 3459.0 & 2 & 1729.5 & 78.23 & $<0.0001$ \\
\hline Soil-Dose & 1091.5 & 6 & 181.9 & 8.23 & $<0.0001$ \\
\hline $\begin{array}{c}\text { Oxidation-Soil- } \\
\text { Dose }\end{array}$ & 1317.9 & 6 & 219.6 & 9.94 & $<0.0001$ \\
\hline Age & 9378.9 & 1 & 9378.9 & 424.23 & $<0.0001$ \\
\hline Age-Oxidation & 1753.8 & 1 & 1753.8 & 79.33 & $<0.0001$ \\
\hline Age-Soil & 2956.7 & 3 & 985.6 & 44.58 & $<0.0001$ \\
\hline Age-Oxidation-Soil & 621.8 & 3 & 207.3 & 9.38 & $<0.0001$ \\
\hline Age-Dose & 126.4 & 2 & 63.2 & 2.86 & 0.0589 \\
\hline $\begin{array}{c}\text { Age-Oxidation- } \\
\text { Dose }\end{array}$ & 224.1 & 2 & 112.0 & 5.07 & 0.0068 \\
\hline Age-Soil-Dose & 355.5 & 6 & 59.2 & 2.68 & 0.0151 \\
\hline $\begin{array}{c}\text { Age-Oxidation- } \\
\text { Soil-Dose }\end{array}$ & 297.7 & 6 & 49.6 & 2.24 & 0.0391 \\
\hline Error & 6632.4 & 300 & 22.1 & & \\
\hline
\end{tabular}

$\mathrm{SS}=$ sum of squares, $\mathrm{df}=$ degrees of freedom, $\mathrm{MS}=$ mean squares, $\mathrm{F}=\mathrm{F}$-value statistic, Prob. $=$ probability that one obtains the F-value other than by chance.

\section{ENVIRONMENTAL SigNIFICANCE}

This study has shown that the metal-sequestering properties of soil significantly lower the percent of $\mathrm{Cr}(\mathrm{III})$ and $\mathrm{Cr}(\mathrm{VI})$ bioaccessible after ingestion. The percent of bioaccessible $\mathrm{Cr}$ is largely independent of the initial solid phase concentration of $\mathrm{Cr}$ prior to the PBET simulated digestion. Sorption and bioaccessibility of $\mathrm{Cr}(\mathrm{III})$ and $\mathrm{Cr}(\mathrm{VI})$ vary significantly as a function of soil type and horizon, and the oxidation state of the contaminant. Soils with higher $\mathrm{pH}$ and abundant inorganic and organic carbon can often be expected to have higher solid phase concentrations of $\mathrm{Cr}(\mathrm{III})$, while for $\mathrm{Cr}(\mathrm{VI})$ the patterns are reversed, with $\mathrm{Cr}(\mathrm{VI})$ adsorption favored by lower soil $\mathrm{pH}$ and soil minerals with amphoteric charge. Aging effects show Cr bioaccessibility decreases after the first $50 \mathrm{~d}$, and this is related to the enhanced stability of $\mathrm{Cr}$ on the soil surface followed by stable bioaccessibility to $200 \mathrm{~d}$. Bioaccessibility of $\mathrm{Cr}$ (III) can be significantly reduced by its ability to bind strongly to organic matter and also to $\mathrm{Cr}$ - hydroxide precipitates on the soil surface, even under the conditions present in the PBET. Soil sequestration of $\mathrm{Cr}$ (VI) significantly lowers its bioaccessibility. Organic-rich soils and/or soils with $\mathrm{Fe}$ (II)-bearing minerals present enhance $\mathrm{Cr}$ (VI) reduction to $\mathrm{Cr}(\mathrm{III})$, with the latter being strongly adsorbed and less bioaccessible. This is important from a human health perspective because $\mathrm{Cr}(\mathrm{VI})$ is believed to be much more toxic than $\mathrm{Cr}(\mathrm{III})$. 


\section{ACKNOWLEDGMENTS}

We appreciate the efforts of Ms. Cathy Vogel and Dr. Andrea Leeson, the contract officers for the U.S. DoD SERDP who supported this work.

\section{REFERENCES}

Adriano, D.C. 1986. Trace Elements in the Terrestrial Environment. New York, Springer-Verlag. Ainsworth, C.C., Girvin, D.C., Zachara, J.M., and Smith, S.C. 1989. Chromate adsorption on goethite: effects of aluminum substitution. Soil Sci. Soc. Am. J. 53, 411-418.

Anderson, L.D., Kent, D.B., and Davis, J.A. 1994. Batch experiments characterizing the reduction of $\mathrm{Cr}(\mathrm{VI})$ using suboxic material from a mildly reducing sand and gravel aquifer. Environ. Sci. Technol. 28, 178-185.

Arnseth, R.W. and Turner, R.S. 1988. Sequential extraction of iron, manganese, aluminum, and silicon in soils from two contrasting watersheds. Soil Sci. Soc. Am. J. 52, 1801-1807.

Bartlett, R.J. and Kimble, J.M. 1976a. Behavior of chromium in soils. I. Trivalent forms. J. Environ. Qual. 5, 379-383.

Bartlett, R.J. and Kimble, J.M. 1976b. Behavior of chromium in soils. II. Hexavalent forms. J. Environ. Qual. 5, 383-386.

Bartlett, R.J. and Kimble, J.M. 1979. Behavior of chromium in soils. III. Oxidation. J. Environ. Qual. 8, 31-35.

Chung J., Zasoski, R.J., and Lim, S. 1994. Kinetics of chromium(III) oxidation by various manganese oxides. Korean J Agric Chem Biotechnol. 37, 414-420.

Cramer, S.P., Tench, O., Yocum, M., and George, G.N. 1988. A 13-element GE detector for fluorescence EXAFS. Nucl. Instrum. Meth. A266, 586-591.

Davis, J.A. and Leckie, J.O. 1980. Surface ionization and complexation at the oxide/water interface 3. Adsorption on anions. J. Colloid Interface Sci. 74, 32-43.

Davis, S., Waller, P., Buschbom, R., Ballow, J., and White, P. 1990. Quantitative estimates of soil ingestion in normal children between the ages of 2 and 7 years. Population-based estimates using aluminum, silicon, and titanium as soil tracer elements. Arch. Environ. Health. 45, 112122.

Deng, B. and Stone, A.T. 1996. Surface catalyzed chromium(VI) reduction: reactivity comparisons of different organic reductants and different oxide surfaces. Environ. Sci. Technol. 30, 2484 2494.

Driese, S.G., McKay, L.D., and Penfield, C.P. 2001 Lithologic and pedogenic influences on porosity distribution and groundwater flow fractured sedimentary saprolite: a new application of environmental sedimentology. J. Sedimentary Res. 71, 843-857.

Eary, L.E. and Rai, D. 1991. Chromate reduction by subsurface soils under acidic conditions. Soil Sci. Soc. Am. J. 55, 676-683.

EPA Method 3052. http://www.epa.gov/epaoswer/hazwaste/test/pdfs/3052.pdf.

Fendorf, S.E., Lamble, G.M., Stapleton, M.G., Kelly, M.J., and Sparks, D.L. 1994. Mechanisms of chromium (III) sorption on silica. 1. Cr(III) surface structure derived by extended x-ray adsorption fine structure spectroscopy. Environ. Sci. Technol. 28, 284-289.

Fendorf, S.E. and Sparks, D.L. 1994. Mechanisms of chromium (III) sorption on silica: 2. Effects of reaction conditions. Environ. Sci. Technol. 28, 290-297.

Fendorf, S., Eick, M.J., Grossl, P., and Sparks, D.L. 1997. Arsenate and chromate retention mechanisms on goethite. 1. Surface structure. Environ. Sci. Technol. 31, 315-320.

Hamel, S.C., Buckley, B., and Lioy, P.J. 1998. Bioaccessibility of metals in soils for different liquid to solid ratios in synthetic gastric fluid. Environ. Sci. Technol. 32, 358-362. 
James, B.J, and Bartlett, R.J. 1983. Behavior of chromium in soils. VII. Adsorption and reduction of hexavalent forms. J. Environ. Qual. 12, 177-181.

Jardine, P.M., Fendorf, S.E., Mayes, M.A., Brooks, S.C., and Bailey, W.B. 1999. Fate and transport of hexavalent chromium in undisturbed heterogeneous soil. Environ. Sci. Technol. 33, 29392944.

Jardine, P.M., Weber, N.L., and McCarthy, J.F. 1989. Mechanisms of dissolved organic carbon adsorption on soil. Soil. Sci. Soc. Am. J. 53, 1378-1385.

Kooner, Z.S., Jardine, P.M., and Feldman, S. 1995. Competitive surface complexation reactions of sulfate and natural organic carbon on soil. J. Environ. Qual. 24, 656-662.

Leckie, J.O., Benjamin, M.M., Hayes, K., Kaufman, G., and Altman, S. 1980. Adsorption/ coprecipitation of trace elements from water with iron oxyhydroxide. Electric Power Res. Inst. Rept. Palo Alto, Ca., EPRI-RP-910.

Levis, A.G. and V. Bianchi. 1982. Mutagenic and cytogenic effects of chromium compounds. In: Biological and Environmental Aspects of Chromium. pp. 171-208 (Sverre Langjard, Ed.) New York, Elsevier Biomedical Press.

Losi, M.E., Amrhein, C., and Frankenberger, W.T. Jr. 1994. Bioremediation of chromate-contaminated groundwater by reduction and precipitation in surface soils. J. Environ. Qual. 23, 11411150.

Mayer, L.M., and Schick, L.L. 1981. Removal of hexavalent chromium from estuarine waters by model substrates and natural sediments. Environ. Sci. Technol. 15, 1482-1484.

Nriagu, J. O. and Nieboer, E. 1988. Chromium in the Natural and Human Environments. New York, John Wiley \& Sons.

Patterson, R.R., Fendorf, S., and Fendorf, M. 1997. Reduction of hexavalent chromium by amorphous iron sulfide. Environ. Sci. Technol. 31, 2039-2044.

Paustenbach, D. J. 1989. The Risk Assessment of Environmental and Human Health Hazards: A Textbook of Case Studies. New York, John Wiley \& Sons.

Peterson, M.L., Brown, G.E. Jr., Parks, G.A., and Stein, C.L. 1997. Differential redox and sorption of $\mathrm{Cr}(\mathrm{III} / \mathrm{VI})$ on natural silicate and oxide minerals: EXAFS and XANES results. Geochim. Cosmochim. Acta. 61, 3399-3412.

Proctor, D.M., Shay, E.C., and Scott, P.K. 1997. Health-based soil action levels for trivalent and hexavalent chromium: a comparison with state and federal standards. J. Soil Contamin. 6, 595648.

Ruby, M.V., Davis, A., Schoof, R., Eberle, S., Sellstone, S.M. 1996. Estimation of lead and arsenic bioavailability using a physiologically based extraction test. Environ. Sci. Technol. 30, 422430.

Ruby, M.V., Schoof, R., Brattin, W., Goldade, M., Post, G., Harnois, M., Mosby, D.E., Casteel, S.W., Berti, W., Carpenter, M., Edwards, D., Cragin, D., and Chappell, W. 1999. Advances in evaluating the oral bioavailability of inorganics in soil for use in human health risk assessment. Environ. Sci. Technol. 33, 3697-3705.

Sheehan, P.J., Meyer, D.M., Sauer, M.M., and Paustenbach. D.J. 1991. Assessment of the human health risks posed by exposure to chromium contaminated soils. J. Toxicol. Environ. Health 32, 161-201.

Skowronski, G.A., Seide, M., and Abdel-Rahman, M.S. 2001. Oral bioaccessibility of trivalent and hexavalent chromium in soil by simulated gastric fluid. J. Toxicol. Environ. Health, Part A. 63, 351-362.

Sparks, D.L. 1995. Environmental Soil Chemistry. New York, Academic Press.

Stewart, M.A., Jardine, P.M., Barnett, M.O., Mehlhorn, T.L., Hyder, K., and McKay, L.D. 2003. Influence of soil geochemical and physical properties on the sorption and bioaccessibility of Cr(III). J. Environ. Qual. 32, 129-137 
Zachara, J.M., Girvin, D.C., Schmidt, R.L., and Resch, C.T. 1987. Chromate adsorption on amorphous iron oxyhydroxide in the presence of major groundwater ions. Environ. Sci. Technol. 21, 589-594.

Zachara, J.M., Cowan, C.E., Schmidt, R.L., and Ainsworth, C.C. 1988. Chromate adsorption by kaolinite. Clays Clay Miner. 36, 317-326.

Zachara, J.M., Ainsworth, C.C., Cowan, C.E., Resch, C.T. 1989. Adsorption of chromate by subsurface soil horizons. Soil Sci. Soc. Am. J. 53, 418-428. 


\section{APPENDIX E}

YANG, J-K., M.O. BARNETT, P.M. JARDINE, AND S.C. BROOKS. 2003. FACTORS CONTROLLING THE BIOACCESSIBILITY OF ARSENIC(V) AND LEAD(II) IN SOIL. SOIL AND SEDIMENT CONTAMINATION. 12:165-179. 


\section{Factors Controlling the Bioaccessibility of Arsenic(V) and Lead(II) in Soil}

\author{
Jae-Kyu Yang, ${ }^{1}$ Mark O. Barnett, ${ }^{1 *}$ \\ Philip M. Jardine, ${ }^{2}$ and Scott $C$. \\ Brooks $^{2}$ \\ ${ }^{1}$ Department of Civil Engineering, 238 Harbert \\ Engineering Center, Auburn University, \\ Auburn, AL 36849; '2Environmental Sciences \\ Division, Oak Ridge National Laboratory, \\ P. O. Box 2008, Oak Ridge, TN 37831
}

The relative oral bioaccessibility of labile $\mathrm{Pb}$ (II) and $A s(V)$ added to soils was investigated in a well-characterized soil using a physiologically based extraction test (PBET) to simulate metal solubility in a child's digestive sys-

\begin{abstract}
tem. The effect of soil and PBET (i.e., simulated stomach and small intestine) $\mathrm{pH}$, soil metal concentration, soil to solution ratio, and soil-metal aging time were investigated. Arsenic bioaccessibility was relatively unaffected by a variation in simulated stomach and small intestine $\mathrm{pH}$ over the range 2 to 7 and soil $\mathrm{pH}$ over the range 4.5 to 9.4. In contrast, $\mathrm{Pb}$ (II) bioaccessibility was strongly dependent on both the simulated stomach, small intestine, and soil $\mathrm{pH}$, showing enhanced sequestration and decreased bioaccessibility at higher $\mathrm{pH}$ values in all cases. Although the bioaccessibility of $\mathrm{Pb}$ (II) was constant over the concentration range of approximately 10 to $10,000 \mathrm{mg} / \mathrm{kg}$, the $A s(\mathrm{~V})$ bioaccessibility significantly increased over this concentration range. The bioaccessibility of both arsenic and lead increased as the soil-to-solution ratio decreased from 1:40 to 1:100. Additional lead sequestration was not observed during 6 months of soil aging, but As (V) bioaccessibility decreased significantly during this period.
\end{abstract}

\footnotetext{
Corresponding author phone: (334) 844-6291; fax: (334)844-6290; email: barnettm@eng.auburn.edu
}

Key Words: bioaccessibility, bioavailability, extraction, arsenic, lead, soil.

$1532-0383 / 03 / \$ .50$

(C) 2003 by AEHS 


\section{INTRODUCTION}

$S$

oil ingestion is typically the primary human health exposure pathway at metal-contaminated sites. For residential or recreational land use scenarios, for example, the ingestion of soil by children is almost always the critical exposure pathway. The calculated health risk due to the incidental ingestion of a metalcontaminated soil is a function of several variables: the soil-metal concentration, soil ingestion rate, body weight, exposure frequency and duration, and the oral toxicity (cancer slope factor for carcinogens or the reference dose for non-carcinogens). However, the oral toxicity of metals is often based on toxicological studies where the metal is potentially more bioavailable than metals in soils (e.g., from animal feeding studies with soluble metal salts). Thus, with the exception of $\mathrm{Pb}$, risk assessments implicitly assume a default value of $100 \%$ relative bioavailability. In other words, the bioavailability of the metal in the soil is implicitly assumed to be the same as in the dosing medium (e.g., water or food) in the critical toxicity study. The risk assessment methodology for $\mathrm{Pb}$ in soils is unique; $\mathrm{Pb}$ is the only metal that has an explicit soil bioavailability adjustment.

Metals in soils, however, are often relatively insoluble, requiring aggressive digestion procedures for complete analytical metal recovery. As a result, an oral toxicity value developed from studies using soluble metal species may overstate the risk posed by less-soluble metals in soils. The generally low bioavailability of $\mathrm{Pb}$ and As in soils in mining areas has been well documented, and risk assessments based on data from studies using soluble metal salts overestimate the risk posed by these soils (Davis et al., 1992). Numerous studies, for example, have shown that $\mathrm{Pb}$ in soil (Freeman et al., 1994; Casteel et al., 1997), mining waste (Dieter et al., 1993; Polak et al., 1996) and aggregate (Cheng et al., 1991; Preslan et al., 1996), is much less bioavailable than more soluble $\mathrm{Pb}$ species, such as $\mathrm{Pb}$ oxide, nitrate, or acetate used in toxicological studies. Relatively low $\mathrm{Pb}$ bioavailability is a consequence of $\mathrm{Pb}$ speciation and the corresponding solubility constraints (Davis et al., 1993) and kinetic limitations to dissolution in the limited residence time of the GI tract (Ruby et al., 1992). Similarly, the oral toxicity for As is based on a human epidemiological study of As in drinking water. However, soluble As in drinking water is much more bioavailable than insoluble As in soils, the latter of which is primarily excreted through the feces without being absorbed through the GI tract (Freeman et al., 1995). Estimates of risk due to As ingestion in soils in mining areas would overstate the risk unless the lower bioavailability of As in these soils is considered (Davis et al., 1996; Davis et al., 2001).

In mining-impacted areas, low soil-metal bioavailability might be due to the presence of residual low solubility metal sulfides from the ore body. However, even in non-mining areas, soil metal bioavailability may be lower than for soluble metal species because soils typically bind metals due to sorption to the solid phase and the formation of other secondary solid phases with lower solubility, including authigenic metal sulfides (Barnett et al., 1997). For example, the presence of the 
soil matrix significantly reduced the absorption of soluble $\mathrm{CdCl}_{2}$ from the GI tract in rat studies (Schilderman et al., 1997). In fact, animals are believed to instinctively consume soils when exposed to contaminants in their diets as a way of decreasing the bioavailability and the effect of these contaminants (Sheppard et al., 1995).

The purpose of this article is to describe the results of an investigation into the bioaccessibility of $\mathrm{Pb}(\mathrm{II})$ and $\mathrm{As}(\mathrm{V})$ added to soils using a physiologically based extraction test (PBET) to simulate soil ingestion. $\mathrm{As}(\mathrm{V})$ and $\mathrm{Pb}(\mathrm{II})$-spiked soils were used because (1) the initial metal concentration and speciation could be controlled, (2) changes in bioaccessibility from the initial labile metal could be followed with time, and (3) beginning with labile metals provided insight into the ability of soils themselves to limit metal bioaccessibility, without regard to any unique site-specific speciation. The effects of soil and PBET $\mathrm{pH}$, soil-to-solution ratio, soil-metal concentration, and soil-metal aging time were investigated.

\section{EXPERIMENTAL METHODS}

\section{A. Materials}

All chemicals employed in this research were analytical grade or above, and solutions were prepared with deionized water $(18 \mathrm{M} \Omega-\mathrm{cm})$ from a reverse osmosis/ ion exchange apparatus (Milli-Q ${ }^{\mathrm{TM}}$ Water System). Soil samples were collected from the B- and C-horizon of a weakly developed Inceptisol on the Department of Energy Oak Ridge (Tenn.) Reservation. The soils were air dried and passed through a $250-\mu \mathrm{m}$ (B-horizon) or $2-\mathrm{mm}$ (C-horizon) sieve. The $<250-\mu \mathrm{m}$ fraction represents the soil fraction most likely ingested as a result of children's hand-tomouth activities and was adopted after the initial experiments with the $\mathrm{C}$-horizon material were begun. These soils are acidic ( $\mathrm{pH} \sim 4.2$ in a 1:2 $\mathrm{g} / \mathrm{mL}$ suspension) and heavily coated with Fe-oxides. Some physical and chemical properties of the two soil samples are shown in Table 1.

\section{B. Soil Spiking}

Arsenic(V) and $\mathrm{Pb}(\mathrm{II})$ were added to the soil from a small volume of concentrated metal stock solution to a $1: 10 \mathrm{~g} / \mathrm{mL}$ suspension in $10^{-3} \mathrm{M} \mathrm{CaCl}_{2}$ solution. In most experiments, the soil slurry was maintained at the natural soil $\mathrm{pH}(\sim 4.5$ in a 1:10 $\mathrm{g} / \mathrm{mL}$ suspension) by immediately neutralizing the acidity from the metal stock solution with dilute $\mathrm{NaOH}$. The $\mathrm{pH}$ of some slurries was changed by adding additional dilute $\mathrm{NaOH}$ to study the effect of soil $\mathrm{pH}$ on the bioaccessibility of $\mathrm{As}(\mathrm{V})$ and $\mathrm{Pb}(\mathrm{II})$. After mixing for $48 \mathrm{~h}$, the soil suspension was centrifuged and

the supernatant was decanted. The remaining soil was washed twice with distilled 
TABLE 1

Some Physical and Chemical Properties of Inceptisol Soils Used in Study

\begin{tabular}{|c|c|c|}
\hline Property & B-horizon & C-horizon \\
\hline \hline Sand (\%) & 31 & 31 \\
Silt (\%) & 50 & 50 \\
Clay (\%) & 19 & 19 \\
pH* & 4.2 & 4.1 \\
Mn (g/kg)** & 0.17 & 0.36 \\
Fe (g/kg)** & 22.1 & 25.8 \\
Organic Matter (\%) & 0.42 & 0.55 \\
Inorganic Carbon (\%) & 0.26 & not measured \\
CEC (cmol $/ \mathrm{kg})$ & 14 & not measured \\
Mineralogy (\%)*** & $\mathrm{I}(45) \mathrm{IS}(20) \mathrm{V}(10) \mathrm{K}(9)$ & $\mathrm{I}(30) \mathrm{IS}(25) \mathrm{K}(20) \mathrm{S}(10)$ \\
& $\mathrm{VC}(6) \mathrm{M}(5) \mathrm{Q}(3) \mathrm{F}(1)$ & $\mathrm{V}(10) \mathrm{Q}(5)$ \\
\hline
\end{tabular}

* The $\mathrm{pH}$ of the soil solution was measured in $5 \mathrm{mM} \mathrm{CaCl}_{2}$ in a $1: 2 \mathrm{~g} / \mathrm{mL}$ suspension.

** Dithionite/citrate/bicarbonate extractable.

*** $\mathrm{K}=$ kaolinite, $\mathrm{V}=$ vermiculite, $\mathrm{VC}=$ chloritized vermiculite, $\mathrm{I}=$ illite, $\mathrm{IS}=$ =interstratified $2: 1, Q=$ quartz, $\mathrm{G}=$ gibbsite, $\mathrm{M}=$ montmorillinite, $\mathrm{F}=$ feldspar, $\mathrm{S}=$ smectite.

water to remove any traces of the original soluble $\mathrm{As}(\mathrm{V})$ or $\mathrm{Pb}(\mathrm{II})$ spike. The decanted supernatant and rinse water were filtered through $0.45-\mu \mathrm{m}$ membrane filter, and the concentration of $\mathrm{As}(\mathrm{V})$ and $\mathrm{Pb}(\mathrm{II})$ in the filtrate was analyzed using an atomic absorption spectrophotometer equipped with an electrodeless discharge lamp (EDL) for As and a hollow cathode lamp for $\mathrm{Pb}$. The difference between the amount of $\mathrm{As}(\mathrm{V})$ or $\mathrm{Pb}(\mathrm{II})$ added and that remaining in the supernatant was used to calculate the initial soil concentration. The soil residues from the PBET extraction (below) were also analyzed for $\mathrm{Pb}$ and As using EPA Method 3050B to verify a mass balance of $\pm 10 \%$.

The soils were then air-dried and homogenized by mixing. Initial subsamples were taken representing the conditions at the beginning of the aging experiment (i.e., $\mathrm{t}=0$ ). The remaining soil was placed in a weighing dish, and deionized water was added to bring the soil to field capacity ( $30 \%$ moisture). The open containers were then aged in a larger container through which a steady flow of $100 \%$ relative humidity air was passed. The moisture content of the soils was monitored periodically by weight, with deionized water added as necessary to maintain a constant moisture content of $30 \%$. Periodically, subsamples were removed and analyzed as described below.

\section{Adsorption}

The degree of adsorption $\mathrm{As}(\mathrm{V})$ and $\mathrm{Pb}(\mathrm{II})$ to the soil was measured by adding 5 $\mathrm{g} / \mathrm{L}$ B-horizon soil and $1 \mathrm{mg} / \mathrm{L} \mathrm{Pb}(\mathrm{II})$ or $\mathrm{As}(\mathrm{V})$ concentrations in $10^{-2} M \mathrm{NaNO}_{3}$ 
solution. After adjusting the $\mathrm{pH}$ of the initial suspension to between 2 and 12 using dilute $\mathrm{HNO}_{3}$ or $\mathrm{NaOH}$ solutions, the samples were shaken for $48 \mathrm{~h}$ at normal room temperature $\left(22\right.$ to $\left.25^{\circ} \mathrm{C}\right)$. After $48 \mathrm{~h}$, the suspension $\mathrm{pH}$ of each sample was measured, and the suspensions were filtered using $0.45-\mu \mathrm{m}$ filters (Gelman). The concentration of $\mathrm{As}(\mathrm{V})$ or $\mathrm{Pb}(\mathrm{II})$ in the filtrate was measured using an atomic absorption spectrophotometer as described above.

\section{Extractions}

The physiologically based extraction test (PBET) used here was adopted from a modification to the original PBET described by Ruby et al. (1996). This extraction test has been shown to be predictive of $\mathrm{Pb}$ bioavailability in two animal models and is currently being validated for As (Ruby et al., 1999). The extraction device consisted of a sample holder that held 16 wide-mouth, high-density polyethylene bottles $(125 \mathrm{~mL})$ and a motor that rotated the sample holder at variable speed. The sample holder was located in a temperature-controlled water bath. During the extraction, the water temperature in the bath was maintained at body temperature $\left(37 \pm 2{ }^{\circ} \mathrm{C}\right)$. The extraction solution consisted of $30 \mathrm{~g} / \mathrm{L}$ glycine $(0.4 M)$ with the $\mathrm{pH}$ adjusted to $1.5,2,3$, or 4 with $\mathrm{HCl}$. These conditions simulated the stomach, because recent research has suggested that $\mathrm{Pb}$ and As dissolution in the simulated stomach environment is predictive of $\mathrm{Pb}$ and As bioavailability in animals (Ruby et al., 1999).

One gram of each air-dried soil was placed in a 125-mL HDPE bottle. Then 40 or $100 \mathrm{~mL}$ of $37^{\circ} \mathrm{C}$ simulated gastric solution was poured in each bottle. After capping, each bottle was placed in the sample holder and rotated end over end at $30 \pm 2 \mathrm{rpm}$ for $1 \mathrm{~h}$. After $1 \mathrm{~h}$, the bottles were immediately removed and stood up right for approximately 5 min before taking a portion of the supernatant, which was then filtered with 0.45 - $\mu \mathrm{m}$ filter. For all experiments, duplicate or triplicate samples were run and the results were reported as \pm one standard deviation unless otherwise noted. The dissolved metal concentration in the filtrate was measured with an atomic absorption spectrophotometer, with the fraction of metal dissolved representing the bioaccessibility (see below). Although the stomach may be important in solubilizing soil-bound metals, systemic absorption occurs in the small intestine, where chemical conditions (especially $\mathrm{pH}$ ) are significantly different. To examine these effects, the $\mathrm{pH}$ of the remaining PBET solution was adjusted to 7 by adding $4 \mathrm{~mL}$ of $0.5 \mathrm{M} \mathrm{NaHCO}_{3}$, maintaining a constant soil-solution ratio. The bottles were returned to the extractor and rotated end over end at $30 \pm 2 \mathrm{rpm}$ for $3 \mathrm{~h}$, when they were sampled and analyzed as described previously. The remaining soil sample was analyzed for $\mathrm{As}$ or $\mathrm{Pb}$ using acid digestion (see below) to verify mass balance within $\pm 10 \%$.

To measure the $\mathrm{pH}$ and the readily soluble and exchangeable concentrations of As and $\mathrm{Pb}, 1 \mathrm{~g}$ of each soil was mixed with $2 \mathrm{~mL}$ of $5 \times 10^{-3} \mathrm{M} \mathrm{CaCl}_{2}$ solution for 
$2 \mathrm{~h}$. After centrifugation (10 min at $2000 \mathrm{rpm})$, the supernatant was filtered with $0.45-\mu \mathrm{m}$ filter. Then the $\mathrm{pH}$ and metal content of the supernatant were measured. For all soils, blanks (no metal added) were used to correct all data obtained from $\mathrm{CaCl}_{2}$ and PBET extractions.

The absolute oral bioavailability is the fraction of an administered metal dose that reaches systemic circulation from the gastrointestinal tract (Ruby et al., 1999). The relative bioavailability is the bioavailability of a metal in one form or media compared with another (e.g., the bioavailability of a metal in soil relative to the bioavailability of the metal in water). In in vitro extraction tests, the fraction of metal solubilized and available for absorption is termed the bioaccessibility and is an indicator of the bioavailability of soil-bound metals relative to the soluble metal species on which the oral toxicity is based (Ruby et al., 1996). The bioaccessibility of soluble $\mathrm{As}_{2} \mathrm{O}_{5}$ and $\mathrm{Pb}\left(\mathrm{NO}_{3}\right)_{2} \bullet 6 \mathrm{H}_{2} \mathrm{O}$ at the same concentration as in the soils was $96.1 \pm 0.1 \%$ and $99.8 \pm 1.1 \%$, respectively. In vitro extraction procedures are a more useful tool than expensive and time-consuming animal feeding studies for investigating the effect a number of variables on bioaccessibility/bioavailability.

\section{E. Soil Analysis}

In order to verify the mass balance, the residual soil $\mathrm{Pb}$ or As was determined using a strong acid extraction method (EPA 3050B; $10 \mathrm{~mL}$ of $50 \% \mathrm{HNO}_{3}, 5 \mathrm{~mL}$ of concentrated $\mathrm{HNO}_{3}, 2 \mathrm{~mL}$ of water $+3 \mathrm{~mL}$ of $30 \% \mathrm{H}_{2} \mathrm{O}_{2}$ at $95 \pm 5^{\circ} \mathrm{C}$ ) after each PBET extraction. After digestion, the samples were filtered using a Whatman filter paper, and the filtrate was measured with AAS to obtain the total metal amounts remaining on the soil. An analysis of the soil residues from the procedure yielded a mass recovery of $100 \pm 10 \%$.

\section{RESULTS AND DiSCUSSION}

\section{A. Effect of Aging Time}

Figure 1 shows the water-soluble/exchangeable and bioaccessible concentrations of $\mathrm{Pb}(\mathrm{II})$ and $\mathrm{As}(\mathrm{V})$ in contact with soils from the $\mathrm{C}$-horizon as a function of aging time. The soil rapidly and strongly sequestered both $\mathrm{Pb}(\mathrm{II})$ and $\mathrm{As}(\mathrm{V})$. The $\mathrm{CaCl}_{2}-$ extractable $\mathrm{Pb}(\mathrm{II})$ and $\mathrm{As}(\mathrm{V})$ was less than $3 \%$ of the total soil concentration over all time periods. The bioaccessibility of arsenic was rapidly and dramatically reduced, decreasing from $11.3 \pm 0.7 \%$ initially to $5.8 \pm 0.2 \%$ after 6 months, a significant decrease $(\mathrm{p}<0.001)$. The $\mathrm{Pb}(\mathrm{II})$ bioaccessibility was greater than that arsenic, $62.6 \pm 3.2 \%$ initially with no further significant sequestration over 6 months. The reductions in bioaccessibility are due to metal-soil interactions rather than preexisting solid phase speciation, as soluble metals were added to the soil 


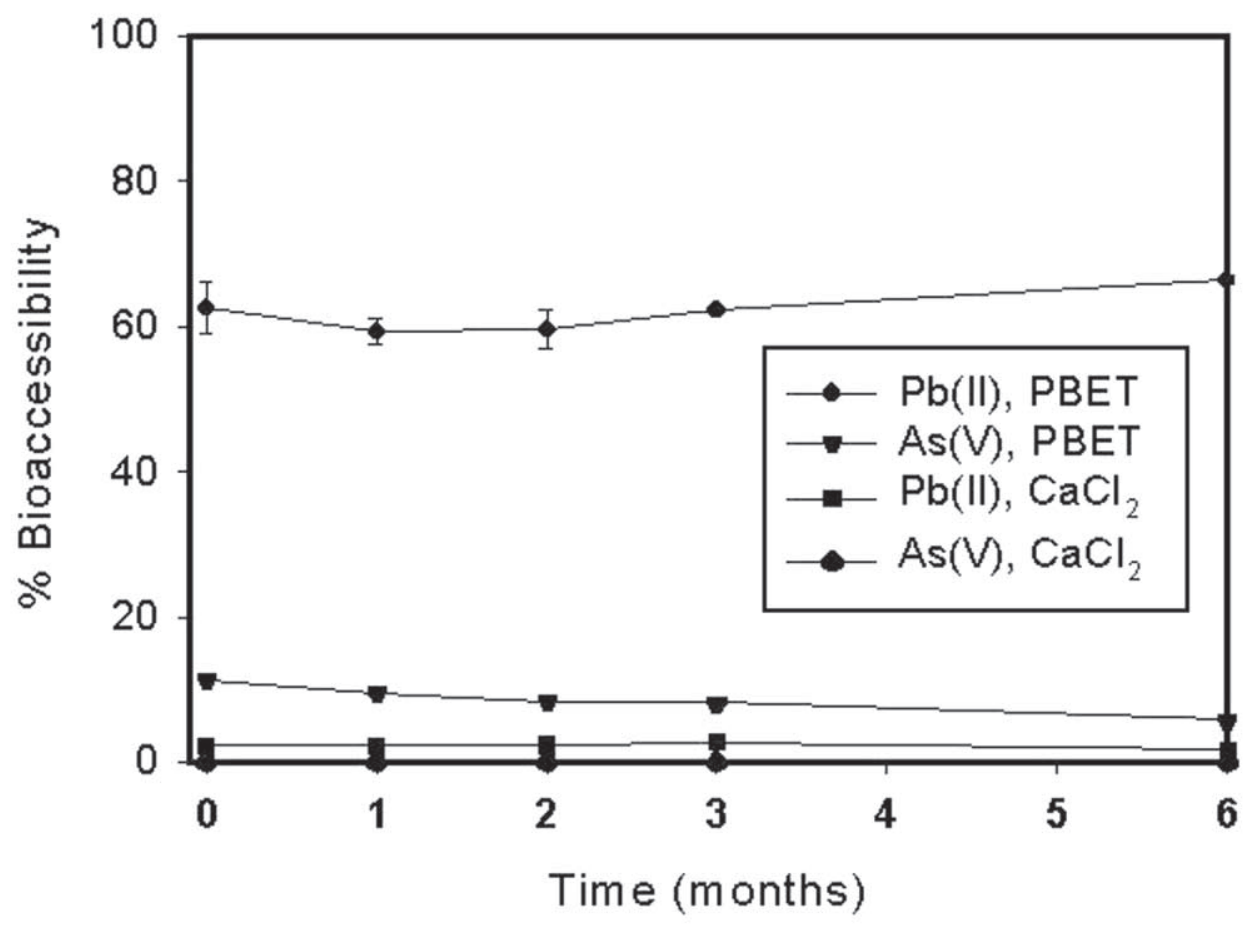

FIGURE 1

Simulated stomach bioaccessibility of $A s(V)$ and $\mathrm{Pb}(\mathrm{II})$ with aging times (C-horizon soil, $\mathrm{pH} 2,1: 40$ soil/solution ratio). Error bars are \pm one standard deviation $(n=2-4)$.

initially. This is important because it implies a long-term reduction in bioaccessibility as long as the soil properties governing metal sequestration do not change. This is in contrast to long-term changes in metal speciation (e.g., metal sulfide oxidation) that may be a concern in situations where metal speciation, as opposed to soilmetal interactions, is controlling bioaccessibility.

\section{B. Effect of Simulated Gastrointestinal pH}

The $\mathrm{pH}$ of the stomach is variable, ranging from approximately 2 (fasting) to 4 to 5 after eating (Ruby et al. 1996). To examine the potential effects of different $\mathrm{pH}$ conditions in a simulated stomach, the bioaccessibility of $\mathrm{As}(\mathrm{V})$ and $\mathrm{Pb}(\mathrm{II})$ were measured at four different $\mathrm{pH}$ values. Figure $2 \mathrm{a}$ shows a comparison of the bioaccessibility of $\mathrm{As}(\mathrm{V})$ and $\mathrm{Pb}(\mathrm{II})$ in freshly spiked B-horizon soil at four different simulated stomach $\mathrm{pH}$ values. The bioaccessibility of arsenic was constant at $25.9 \pm 6.8 \%$ with $\mathrm{pH}$ over the range 1.5 to 4 . The differences between the bioaccessibility in the B-horizon (Figure 2a) and C-horizon (Figure 1) may be due 


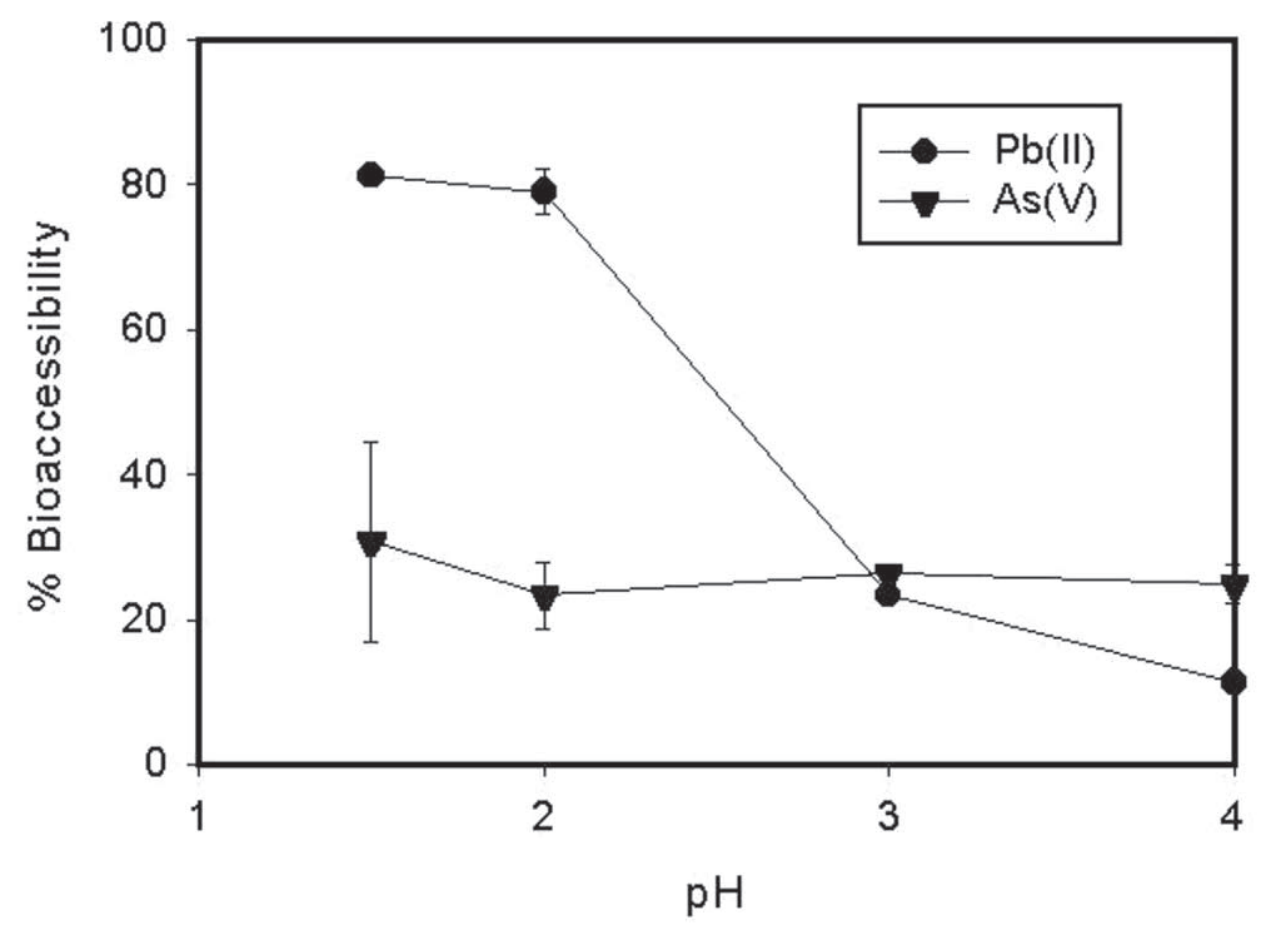

FIGURE 2A

Simulated stomach bioaccessibility of $A s(V)$ and $\mathrm{Pb}(\mathrm{II})$ from fresh soil with variation of $\mathrm{pH}$ of PBET solution (B-horizon soil, 1:40 soil/solution ratio). Error bars are \pm one standard deviation $(n=2-3)$.

to differences in particle size used $(<250 \mu \mathrm{m}$ vs. $<2000 \mu \mathrm{m})$ or small changes in the amount and reactivity of Fe or other metal-sequestering solid phases. The $\mathrm{Pb}$ (II) bioaccessibility, in contrast to $\mathrm{As}(\mathrm{V})$, exhibited a greater $\mathrm{pH}$ dependence. At $\mathrm{pH} 1.5,81.1 \pm 1.3 \%$ of lead was bioaccessible, while only $11.1 \pm 0.7 \%$ was bioaccessible at $\mathrm{pH}$ 4. This result suggests that the bioaccessibility of lead is strongly affected by the stomach $\mathrm{pH}$. Thus, an eightfold variation in bioaccessibility is possible due to a daily variation in stomach $\mathrm{pH}$. This phenomenon illustrates another source of uncertainty that must be considered in conducting a risk assessment. From studies of the bioavailability of soil-borne lead in adults, Maddaloni et al. (1998) reported a great difference in lead absorption between fasting (26.1\%) and after eating $(2.5 \%)$.

After approximately $2 \mathrm{~h}$ of residence time in the stomach, food enters the small intestine where the $\mathrm{pH}$ increases to approximately 7 (Ruby et al., 1996). Although the overall dissolution of $\mathrm{Pb}(\mathrm{II})$ and $\mathrm{As}(\mathrm{V})$ may be controlled by the stomach, it is not clear that all the metals dissolved in the stomach may be absorbed, because the proximal area of the small intestine is known as the primary region of heavy metal 


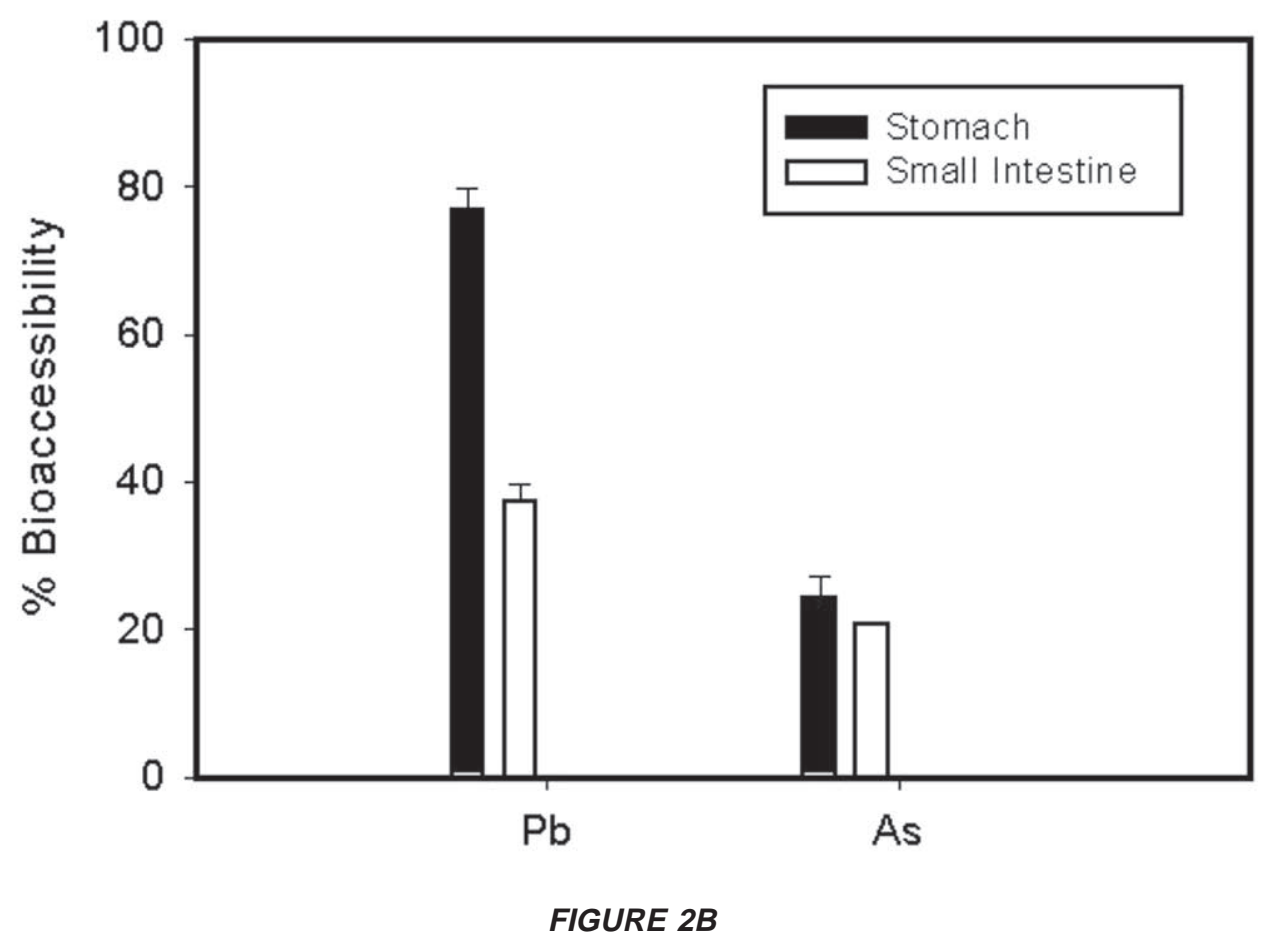

Simulated stomach ( $p H$ 2) and small intestine $(\mathrm{pH}$ 7) bioaccessibility of $A s(\mathrm{~V})$ and $\mathrm{Pb}(\mathrm{II})$ from fresh $B$-horizon soil (1:40 soil/solution ratio). Error bars are \pm one standard

deviation $(n=2-3)$.

absorption (Ashmead et al., 1985). To simulate the small intestine, the $\mathrm{pH}$ of the extraction solution was increased to 7 by the addition of $\mathrm{NaHCO}_{3}$. Metal bioaccessibility in the simulated small intestine following digestion is shown in Figure $2 \mathrm{~b}$. The bioaccessible As was not significantly affected as the $\mathrm{pH}$ of the extraction solution was changed from 2 to 7 , suggesting that the $\mathrm{pH}$ is not a major controlling parameter for the dissolution of $\mathrm{As}(\mathrm{V})$ from this soil at this $\mathrm{pH}$ range. However, lead bioaccessibility decreased significantly $(\mathrm{p}<0.01)$ from $76.7 \pm 3.1 \%$ to $37.4 \pm 2.3 \%$. As the small intestine is the major region of heavy metal absorption, the bioaccessibility of $\mathrm{Pb}$ in the stomach may be greater than the actual bioavailability.

The $\mathrm{pH}$-dependent bioaccessibility of $\mathrm{As}(\mathrm{V})$ and $\mathrm{Pb}(\mathrm{II})$ can be understood in terms of standard geochemical phenomena. For example, cationic metals (e.g., $\mathrm{Pb}(\mathrm{II})$ ) typically partition to solids to a greater degree at higher $\mathrm{pH}$, while anionic metals (e.g., As(V)) exhibit the opposite behavior, as shown in Figure 2c. Therefore, the lower bioaccessibility of $\mathrm{Pb}$ (II) at higher $\mathrm{pH}$ may be due to the same factors (e.g., pH-dependent sorption) that favor $\mathrm{Pb}$ (II) adsorption at higher $\mathrm{pH}$. In contrast, $\mathrm{As}(\mathrm{V})$ bioaccessibility was relatively independent of simulated stomach 


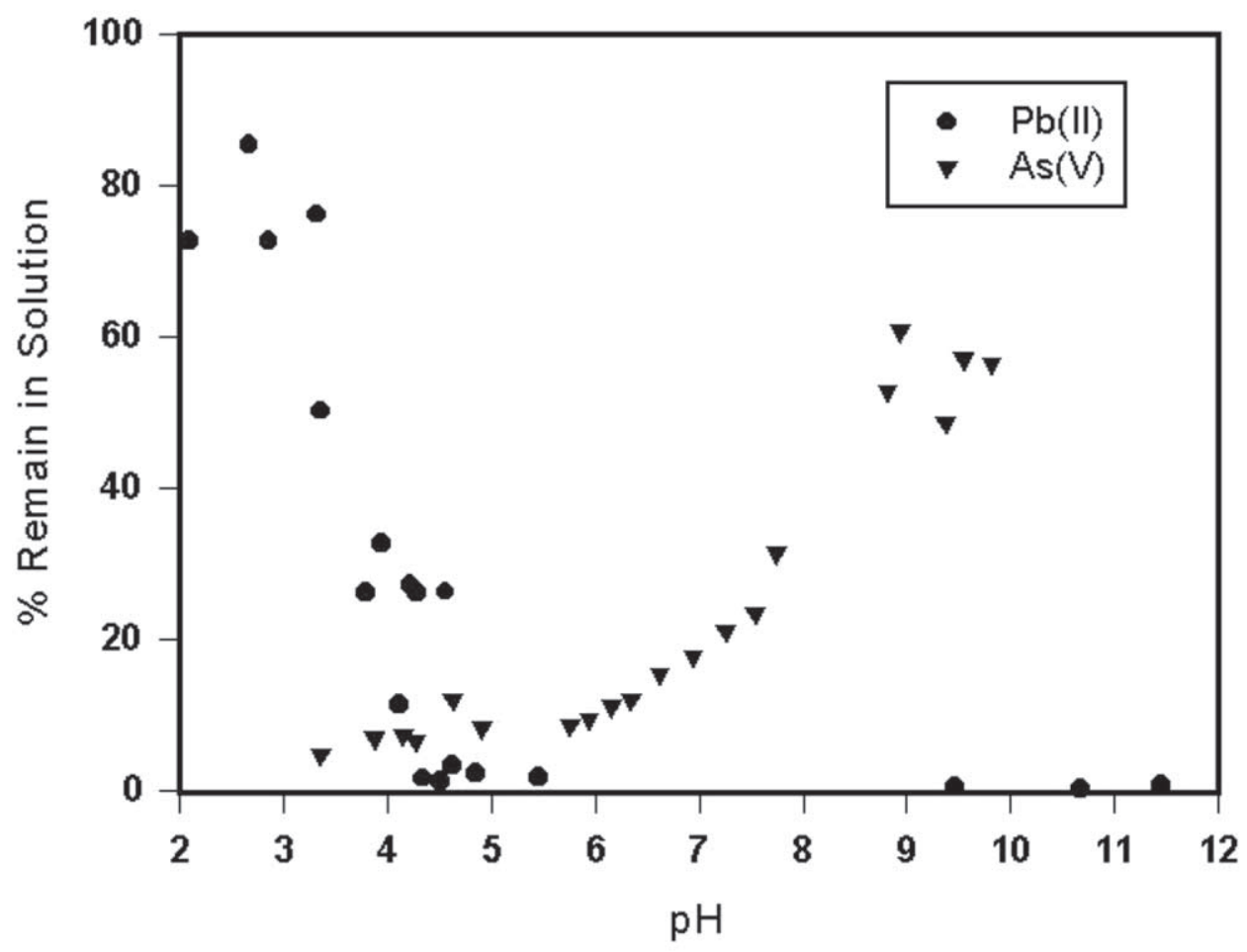

FIGURE $2 C$

$\mathrm{Pb}(\mathrm{II})$ and $\mathrm{As}(\mathrm{V})$ adsorption onto B-horizon soil as a function of $\mathrm{pH}(5 \mathrm{~g} / \mathrm{L}$ soil; $1 \mathrm{mg} / \mathrm{L}$ $\mathrm{Pb}(\mathrm{II})$ and $\left.\mathrm{As}(\mathrm{V}) ; \mathrm{I}=0.01 \mathrm{M} \mathrm{NaNO}_{3}\right)$.

and small intestine $\mathrm{pH}$, which is consistent with a relatively little variation in adsorption from $\mathrm{pH} 2$ to 7 (Figure 2c).

\section{Effect of Soil pH}

B-horizon soil was used to study initial soil $\mathrm{pH}$ effects on metal bioaccessibility. As shown in Figure 3, the effect of soil $\mathrm{pH}$ on $\mathrm{As}(\mathrm{V})$ and $\mathbf{P b}(\mathrm{II})$ bioaccessibility was different. Although $\mathrm{As}(\mathrm{V})$ sorption increased sharply from $\mathrm{pH} 7$ to 9 (Figure $2 \mathrm{c})$, the variation of $\mathrm{As}(\mathrm{V})$ bioaccessibility was relatively small over the $\mathrm{pH}$ range 4.5 to 9 . These results indicate that the $\mathrm{As}(\mathrm{V})$ bioaccessibility in this soil is controlled by the simulated stomach and small intestine $\mathrm{pH}$ rather than the initial soil $\mathrm{pH}$, possibly reflecting relatively rapid $\mathrm{pH}$-dependent partitioning in the solution phase (i.e., $\mathrm{As}(\mathrm{V})$ partitioning responds relatively rapidly to solution $\mathrm{pH}$ independent of initial soil $\mathrm{pH}$ ). In contrast, $\mathrm{Pb}$ (II) bioaccessibility significantly $(\mathrm{p}<0.02)$ decreased from $76.7 \pm 3.1 \%$ to $47.2 \pm 3.2 \%$ at higher soil $\mathrm{pH}$, reflecting 


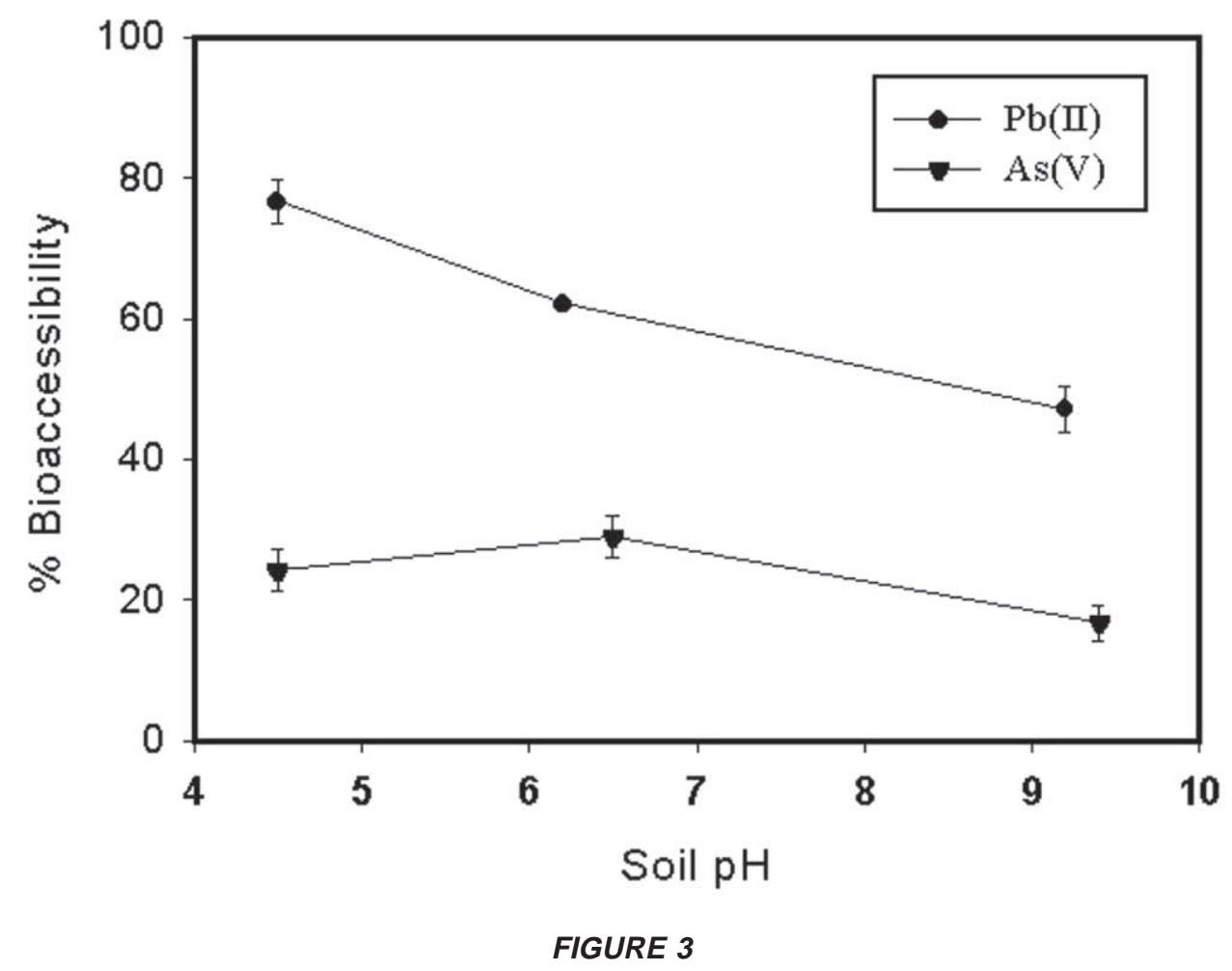

Simulated stomach bioaccessibility of $A s(V)$ and $\mathrm{Pb}(\mathrm{II})$ with variation of soil $\mathrm{pH}$ (fresh $B$-horizon soil, $\mathrm{pH}$ 2, $1: 40$ soil/solution ratio). Error bars are \pm one standard deviation $(n=2-3)$.

the same pattern as typical cationic-type adsorption (Figure 2c). These results indicate that the binding of $\mathrm{Pb}(\mathrm{II})$ in the soil is influenced by the initial soil $\mathrm{pH}$, and that the $\mathrm{Pb}$ (II) bioaccessibility depended on both the simulated stomach (Figure 2a) and soil (Figure 3) $\mathrm{pH}$. In contrast, the $\mathrm{As}(\mathrm{V})$ bioaccessibility was relatively independent of both the simulated stomach (Figure 2a) and soil (Figure 3) pH.

\section{Effect of Concentration}

Figure 4 shows the bioaccessibility of $\mathrm{Pb}(\mathrm{II})$ and $\mathrm{As}(\mathrm{V})$ as a function of soil metal concentration. The current risk assessment methodology implicitly assumes that the bioavailability is independent of the concentration by using a constant relative bioavailability adjustment factor. However, metals often partition to the solid phase in a nonlinear manner (i.e., the fraction of metal sorbed decreases with increasing concentration). In order to investigate the accuracy of using a constant bioaccessibility, $\mathrm{Pb}(\mathrm{II})$ and $\mathrm{As}(\mathrm{V})$ bioaccessibility were measured over almost three orders of magnitude of concentration (10 to $10,000 \mathrm{mg} / \mathrm{kg}$ ). $\mathrm{Pb}$ (II) 


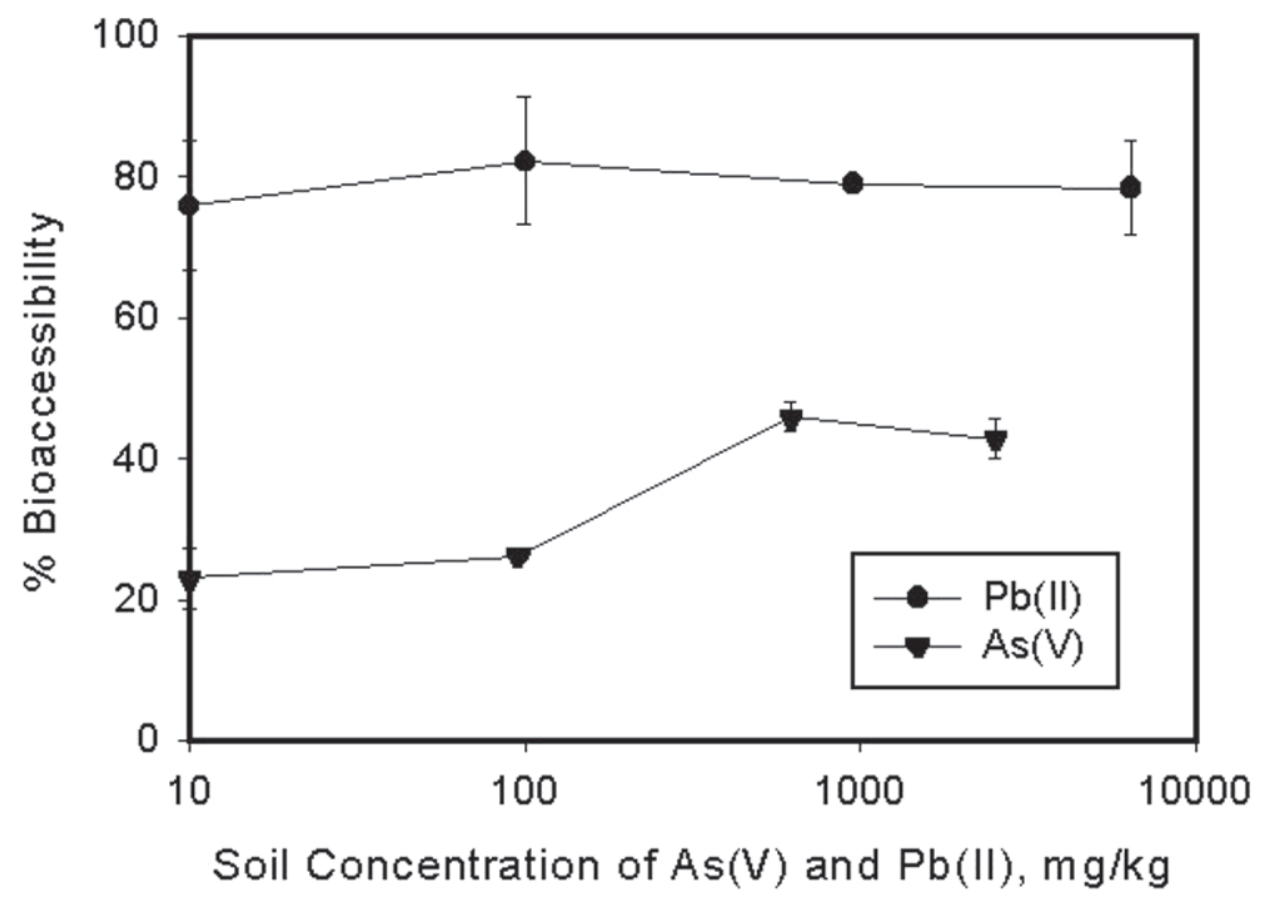

FIGURE 4

Simulated stomach bioaccessibility of $A s(V)$ and $\mathrm{Pb}(\mathrm{II})$ with variation of initial concentration (fresh B-horizon soil, $\mathrm{pH}$ 2, 1:40 soil/solution ratio). Error bars are \pm one standard deviation $(n=2-3)$.

bioaccessibility was relatively insensitive to the concentration of lead, yielding $78.7 \pm 6.8 \%$ bioaccessibility over all concentration ranges. However, As(V) bioaccessibility significantly $(\mathrm{p}<0.05)$ increased from $23.0 \pm 4.2 \%$ to approximately $42.8 \pm 2.7 \%$ as the concentration of $\mathrm{As}(\mathrm{V})$ increased from approximately 10 to $1000 \mathrm{mg} / \mathrm{kg}$, illustrating another potential source of uncertainty introduced in risk assessments by using a constant bioavailability adjustment.

\section{E. Effect of Soil to Solution Ratio}

The soil to solution ratio in the stomach will not be constant over time due to the ingestion of different amounts of soil on varying occasions and because the volume of fluid in the stomach depends on the fasting condition of the child. As a result, the bioaccessibility of $\mathrm{As}(\mathrm{V})$ and $\mathrm{Pb}(\mathrm{II})$ was investigated as a function of soil to solution ratio (Figure 5). The bioaccessibility increased from $30.8 \pm 13.8$ to 53.2 \pm 0.9 for $\mathrm{As}(\mathrm{V})$ and from $81.8 \pm 1.8$ to $91.0 \pm 2.1$ for $\mathrm{Pb}(\mathrm{II})$ with decreasing soil 


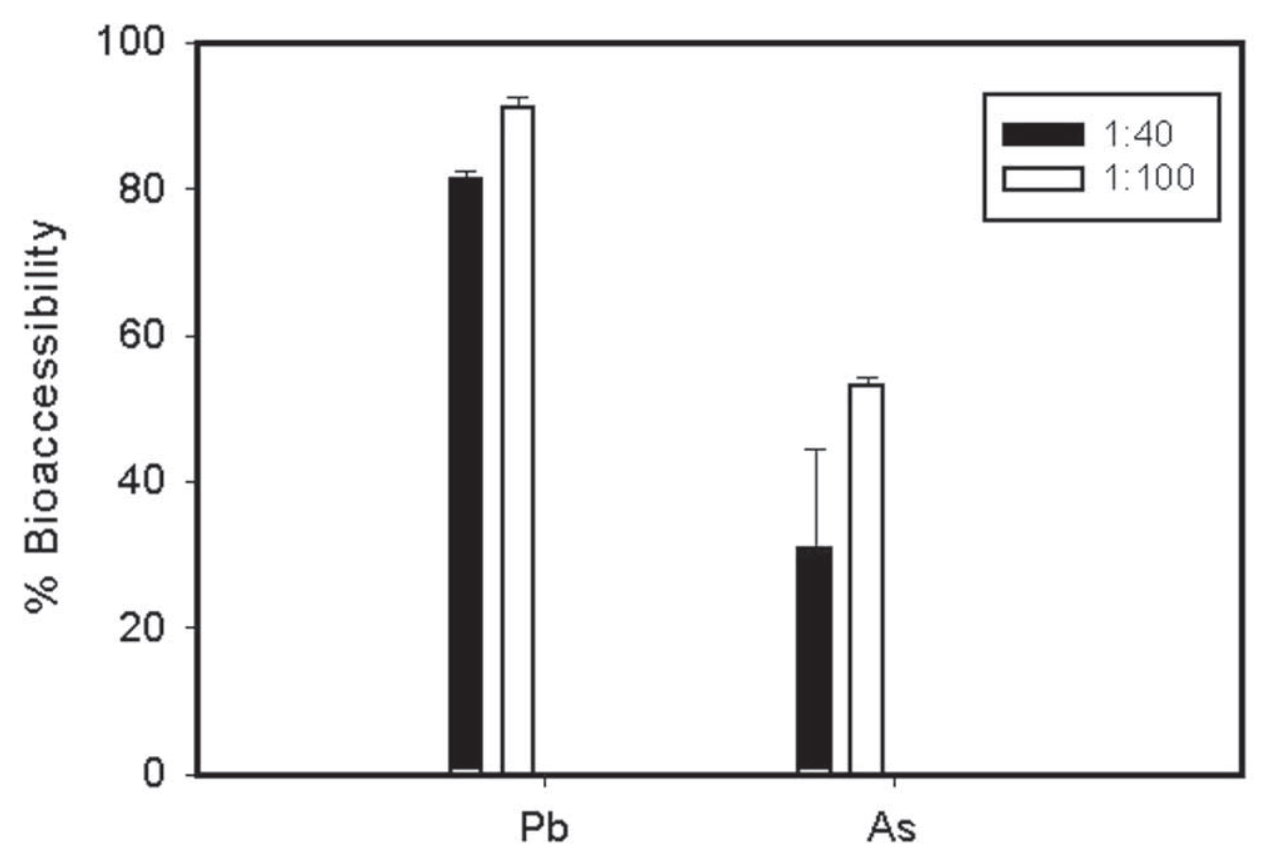

FIGURE 5

Simulated stomach bioaccessibility of $A s(\mathrm{~V})$ and $\mathrm{Pb}(\mathrm{II})$ from fresh $B$-horizon soil $(\mathrm{pH} 1.5$, $1: 40$ and 1:100 soil/solution ratio). Error bars are \pm one standard deviation $(n=2)$.

to solution ratio. The same trend was observed in soluble and exchangeable $\mathrm{Pb}$ (II) in the $\mathrm{CaCl}_{2}$ solution, especially for aged soil samples. Hamel et al. (1998) reported that the effect of the soil to solution ratio on lead and arsenic bioaccessibility depended on the soil sample. Although a higher bioaccessibility of $\mathrm{Pb}$ and As from Jersey City soil was observed as the soil to solution ratio decreased from 1:100 to 1:5000, a relatively constant bioaccessibility of $\mathrm{Pb}(\mathrm{II})$ and $\mathrm{As}(\mathrm{V})$ was observed with Montana soils over all soil to solution ratios tested.

\section{SUMmARY AND CONCLUSIONS}

These results have illustrated several salient aspects of $\mathrm{Pb}(\mathrm{II})$ and $\mathrm{As}(\mathrm{V})$ bioaccessibility. First, the soils decreased both $\mathrm{Pb}(\mathrm{II})$ and especially $\mathrm{As}(\mathrm{V})$ bioaccessibility solely as a result of soil-metal interactions and not as a result of any specific preexisting metal speciation. Reduced $\mathrm{Pb}(\mathrm{II})$ and $\mathrm{As}(\mathrm{V})$ bioaccessibility then can be a result of the fundamental nature of soil-metal interactions rather than site-specific speciation (e.g., metal sulfides from ore bodies). These results also promote greater confidence in the long-term ability of soil to lower $\mathrm{Pb}$ (II) and 
$\mathrm{As}(\mathrm{V})$ bioaccessibility as long as the soil properties governing metal sequestration remain constant. This might not be the case if the reduced $\mathrm{Pb}(\mathrm{II})$ or $\mathrm{As}(\mathrm{V})$ bioaccessibility was due to unique metal speciation that was subject to change over time (e.g., oxidation of metal sulfides in surface soils). In fact, the As(V) bioaccessibility significantly decreased over a 6-month aging period. Second, $\mathrm{Pb}$ (II) bioaccessibility significantly depended on the $\mathrm{pH}$ of both the simulated GI fluid and the soil, showing enhanced sequestration and reduced bioaccessibility at higher $\mathrm{pH}$ values. In contrast, neither soil nor GI $\mathrm{pH}$ significantly affected As(V) bioaccessibility over the range of GI $\mathrm{pH}$ from 2 to 7 and soil $\mathrm{pH}$ from 4.5 to 9.4. Third, although $\mathrm{Pb}(\mathrm{II})$ bioaccessibility was not significantly influenced by soilmetal concentration over the range 10 to $10,000 \mathrm{mg} / \mathrm{kg}$, the $\mathrm{As}(\mathrm{V})$ bioaccessibility significantly increased over this same concentration range. Thus, the use of a concentration-independent bioaccessibility/bioavailability factor in a risk assessment for $\mathrm{As}(\mathrm{V})$ may not be warranted. Finally, both $\mathrm{Pb}(\mathrm{II})$ and $\mathrm{As}(\mathrm{V})$ bioaccessibility increased with decreasing soil to solution ratio, illustrating another degree of uncertainty in estimating the risk of soil ingestion at metal-contaminated sites.

\section{ACKNOWLEDGMENTS}

The authors acknowledge the comments of two anonymous reviewers that greatly improved the paper. This research was sponsored by the Strategic Environmental Research and Development Program (SERDP) under the direction of Ms. Cathy Vogel and Dr. Andrea Leeson. We appreciate the assistance of Beth DerrickWilliams in measuring soil-metal partitioning.

\section{REFERENCES}

Ashmead, H. D., Graff, D. J., and Ashmead, H. H. 1985. Intestinal Absorption of Metal Ions and Chelates, pp. 76-77. (Ed.) Charles C Thomas, Springfield, IL.

Barnett, M. O., Harris, L. A., Turner, R. R., Stevenson R. J., Henson, T. J., Melton, R. C., and Hoffman, D. P. 1997. Formation of mercuric sulfide in soil. Environ. Sci. Technol. 31, 30373043.

Casteel, S. W., Cowart, R. P., Weis, C. P., Henningsen, G. M., Hoffman, E., Brattin, W. J., Guzman, R. E.,Starost, M. F., Payne, J. T., Stockham, S. L., Becker, S. V., Drexler, J. W., and Turk, J. R. 1997. Bioavailability of lead to juvenile swine dosed with soil from the smuggler mountain NPL site of Aspen, Colorado. Fundam. Appl. Toxicol. 36, 177-187.

Cheng, Y. L., Preslan, J. E., Anderson, M. B., and George, W. J. 1991. Solubility and bioavailability of lead following oral ingestion of vitrified slagged aggregate. J. Hazard. Mater. 27, 137-147.

Davis, A., Drexler, J. W., Ruby, M. V., and Nicholson, A. 1993. Micromineralogy of mine wastes in relation to lead bioavailability, Butte, Montana. Environ. Sci. Technol. 27, 1415-1425.

Davis, A., Ruby, M. V., and Bergstrom, P. D. 1992. Bioavailability of arsenic and lead in soils from the Butte, Montana, mining district. Environ. Sci. Technol. 26, 461-468. 
Davis, A., Ruby, M. V., Bloom, M., Schoof, R., Freeman, G., and Bergstrom, P. D. 1996. Mineralogic constraints on the bioavailability of arsenic in smelter-impacted soils. Environ. Sci. Technol. 30, 392-399.

Davis, A., Sherwin, D., Ditmars, R., and Hoenke, K. A. 2001. An analysis of soil arsenic records of decision. Environ. Sci. Technol. 35, 2401-2406.

Dieter, M. P., Matthews, H. B., Jeffcont, R. A., and Mosemers, R. F. J. 1993. Comparison of lead bioavailability in F344 rats fed lead acetate, lead-oxide, lead sulfide, or lead ore concentrate from Skagway, Alaska. J. Toxicol. Environ. Health 39, 79-93.

Freeman, G. B., Johnson, J. D., Liao, S. C., Feder, P. I., Davis, A. O., Ruby, M. V., Schoof, R. A., Chaney, R. L., and Bergstrom, P. D. 1994. Absolute bioavailability of lead acetate and mining waste lead in rats. Toxicology 91, 151-163.

Freeman, G. B., Schoof, R. A., Ruby, M. V., Davis, A. O., Dill, J. A., Liao, S. C., Lapin, C. A., and Bergstrom, P. D. 1995. Bioavailability of arsenic in soil and house dust impacted by smelter activities following oral administration in cynomolgus monkeys. Fundam. Appl. Toxicol. 28, 215-222.

Hamel, S. C., Buckley, B., and Lioy, P. J. 1998. Bioaccessibility of metals in soils for different liquid to soild ratios in synthetic gastric fluid. Environ. Sci. Technol. 32, 358-362.

Maddaloni, M., Lolacono, N., Manton, W., Blum, C., Drexler, J., and Graziano, J. 1998. Bioavailability of soilborne lead in adults, by stable isotope dilution. Environ. Health Perspect. 106, 15891594.

Polak, J. E., Oflaherty, E. J., Freeman, G. B., Johnson, J. D., Liao, S. C., and Bergstrom,

P. D. 1996. Evaluating lead bioavailability data by means of a physiologically based lead kinetic model. Fundam. Appl. Toxicol. 29, 63-70.

Preslan, J. E., Chang, C. Y., Schiller, N. K., and George, W. J. 1996. Bioavailability of lead from vitrified slagged aggregate. J. Hazard. Mater. 48, 207-218.

Ruby, M. V., Davis, A., Kempton, J. H., Drexler, J. W., and Bergstrom, P. D. 1992. Lead bioavailabilitydissolution kinetics under simulated gastric conditions. Environ. Sci. Technol. 26, 1242-1248.

Ruby, M. V., Davis, A., Schoof, R., Eberle, S., and Sellstone, C. M. 1996. Estimation of lead and arsenic bioavailability using a physiologically based extraction test. Environ. Sci. Technol. 30, 422-430.

Ruby, M. V., Schoof, R., Brattin, W., Goldade, M., Post, G., Harnois, M., Mosby, D. E., Casteel, S. W., Berti, W., Carpenter, M., Edwards, D., Cragin, D., and Chappell, W. 1999. Advances in evaluating the oral bioavailability of inorganics in soil for use in human health risk assessment. Environ. Sci. Technol. 33, 3697-3705.

Schilderman, P. E., Moonen, J. C., Kempkers, P., and Kleinjans, J. C. S. 1997. Bioavailability of soiladsorbed cadmium in orally exposed male rats. Environ. Health Perspect. 105, 234-238.

Sheppard, S. C., Evenden, W. G., and Schwatz, W. J. 1995. Ingested soil bioavailability of sorbed lead, cadmium, cesium, iodine, and mercury. J. Environ. Qual. 24, 498-505. 
ORNL/TM-2004/49

\section{INTERNAL DISTRIBUTION}

1. G. K. Jacobs, 1505, MS-6037

2. D. E. Fowler, 1505, MS-6037
3. - 4. ESD Library

5. ORNL Central Research Library

6. ORNL Laboratory Records-RC

7. P. M. Jardine, 1505 , MS- 6038

8. C. C. Brandt, 1505 , MS- 6038

9. S. A. Heuscher, 1505, MS-6036

\section{ELECTRONIC NOTIFICATION}

10. Scott Dockum (sdockum@hgl.com)

11. Andrea Leeson (andrea.leeson@osd.mil)

12. Richard Mach (MachRG@navfac.navy.mil)

13. Alicia Shepard (aanderson@hgl.com)

14. Annette Gatchett (gatchett.annette@epa.gov)

15. Beth Moore (beth.moore@em.doe.gov)

16. Chuck Coyle (charles.g.coyle@nwd02.usace.army.mil)

17. Don Ficklen (Holmes.Ficklen@brooks.af.mil)

18. Erica Becvar (Erica.Becvar@brooks.af.mil)

19. Erik Hangeland (erik.hangeland@aec.apgea.army.mil)

20. Grover Chamberlain (grover.chamberlain@em.doe.gov)

21. Hans Stroo (hstroo@retec.com)

22. Ivette O'Brien (ivette.obrien@brooks.af.mil)

23. Jeff Breckenridge (jeff.l.breckenridge@usace.army.mil)

24. Jeff Cornell (Jeffrey.Cornell@pentagon.af.mil)

25. John Cullinane (cullinm@wes.army.mil)

26. Linda Chrisey (chrisel@onr.navy.mil)

27. Mark Hampton (mark.hampton@aec.apgea.army.mil)

28. Martin Nguyen (mnguyen@comdt.uscg.mil)

29. Marvin Unger (MUnger@retec.com)

30. Michelle Simon (Simon.Michelle@epamail.epa.gov)

31. Rajat Ghosh (rghosh@retec.com)

32. Rebecca Biggers (rbigger@nfesc.navy.mil)

33. Katie Houff (khouff@hgl.com)

34. Katherine Perdue (KPerdue@hgl.com)

35. Mark Barnett (barnettm@eng.auburn.edu)

36. Rebecca Bigger (biggersr@nfesc.navy.mil)

37. Nick Basta (basta.4@osu.edu)

38. Amy Hawkins (amy.hawkins@navy.mil)

39. Roman Lanno (lanno.1@osu.edu)

40. Stan Casteel (CasteelS@missouri.edu)

41. Jeff Marqusee (jeffery.marqusee@osd.mil)

42. Valerie Eisenstein (vke@hgl.com) 